FHWA/IN/JTRP-2000/27

Final Report

EVALUATION OF THE IMPLEMENTATION OF HOT POUR SEALANTS AND EQUIPMENT FOR CRACK SEALING IN INDIANA (AN IMPLEMENTATION OF RESARCH RESULTS FOR SPR-2076)

David R. Ward

April 2001 
Final Report

FHWA/IN/JTRP-2000/27

\title{
EVALUATION OF THE IMPLEMENTATION OF HOT POUR SEALANTS AND EQUIPMENT FOR CRACK SEALING IN INDIANA (AN IMPLEMENTATION OF RESEARCH RESULTS FOR SPR-2076)
}

\author{
By \\ David R. Ward \\ Section Manager \\ Indiana Department of Transportation \\ Division of Research \\ 1205 Montgomery Street - P.O. Box 2279 \\ West Lafayette, Indiana 47906 \\ (765) 463-1521 (Phone) \\ (765) 497-1665 (Fax)
}

April, 2001 


\begin{tabular}{|c|c|c|c|}
\hline $\begin{array}{l}\text { 1. Report No. } \\
\text { NA }\end{array}$ & $\begin{array}{l}\text { 2. Government Accession No. } \\
\text { NA }\end{array}$ & \multicolumn{2}{|c|}{$\begin{array}{l}\text { 3. Recipient's Catalog No. } \\
\text { NA }\end{array}$} \\
\hline \multirow{2}{*}{\multicolumn{2}{|c|}{$\begin{array}{l}\text { 4. Title and Subtitle: } \\
\text { Evaluation of the Implementation of Hot Pour Sealants and } \\
\text { Equipment For Crack Sealing in Indiana }\end{array}$}} & \multicolumn{2}{|c|}{$\begin{array}{l}\text { 5. Report Date: } \\
\text { April } 2001\end{array}$} \\
\hline & & \multicolumn{2}{|c|}{$\begin{array}{l}\text { 6. Performing Organization Code } \\
\text { NA }\end{array}$} \\
\hline \multicolumn{2}{|l|}{$\begin{array}{l}\text { 7. Author(s) } \\
\text { Ward, D.R. }\end{array}$} & \multicolumn{2}{|c|}{$\begin{array}{l}\text { 8. Performing Organization Report } \\
\text { No. HPR-2076 }\end{array}$} \\
\hline \multirow{2}{*}{\multicolumn{2}{|c|}{$\begin{array}{l}\text { 9. Performing Organization Name and Address } \\
\text { Indiana Department of Transportation } \\
\text { Division of Research } \\
\text { 1205 Montgomery St. P.O. Box } 2279 \\
\text { West Lafayette, IN 47906 (765) 463-1521 }\end{array}$}} & \multicolumn{2}{|c|}{$\begin{array}{l}\text { 10. Work Unit No. } \\
\text { NA }\end{array}$} \\
\hline & & \multicolumn{2}{|c|}{$\begin{array}{l}\text { 11. Contract or Grant No } \\
\text { NA }\end{array}$} \\
\hline \multirow{2}{*}{\multicolumn{2}{|c|}{$\begin{array}{l}\text { 12. Sponsoring Agency Name and Address } \\
\text { FHWA }\end{array}$}} & \multicolumn{2}{|c|}{$\begin{array}{l}\text { 13. Type of Report and Period } \\
\text { Covered } \\
\text { IMPLEMENTATION / FINAL } \\
\text { REPORT }\end{array}$} \\
\hline & & \multicolumn{2}{|c|}{$\begin{array}{l}\text { 14. Sponsoring Agency Code } \\
\text { NA }\end{array}$} \\
\hline \multicolumn{4}{|c|}{$\begin{array}{l}\text { 15. Supplementary Notes } \\
\text { Conducted in cooperation with U.S. Department of Transportation Federal Highway Administration }\end{array}$} \\
\hline \multicolumn{4}{|c|}{$\begin{array}{l}\text { 16. Abstract: } \\
\text { This study was initiated as an implementation effort that would monitor, assist with and report on a new } \\
\text { maintenance activity involving the trial use of hot pour crack sealant. Work associated with this new activity } \\
\text { was qualitatively assessed over a period of several years. INDOT began by purchasing six oil-jacketed melters } \\
\text { that were distributed to various sub-districts. Previous INDOT research indicated using hot pour sealant might } \\
\text { save on labor expense because it lasted significantly longer than the current emulsion. Random observations } \\
\text { were made of various sub-district crews using hot pour sealant and the results were reported to appropriate } \\
\text { personnel. Inspections were made on field operations and equipment performance. The study resulted in the } \\
\text { preparation of a written work activity, development of general guidelines for sealing, creation of a training } \\
\text { video, the exchange of information and reporting of findings. As a result of this study and other efforts INDOT } \\
\text { has purchased several more melters with improved features. The total volume of hot pour sealing being } \\
\text { conducted is relatively small compared to emulsion sealing. Currently INDOT spends over two million dollars } \\
\text { on crack sealing efforts. This study has prompted the need to conduct research that will examine the cost } \\
\text { effectiveness of crack sealing. }\end{array}$} \\
\hline $\begin{array}{l}\text { 17. Key Words } \\
\text { crack, sealant, melter, router }\end{array}$ & \begin{tabular}{l|l} 
18. Distribution Statemen \\
No Restrictions
\end{tabular} & & \\
\hline $\begin{array}{l}\text { 19. Security Classif. (of this } \\
\text { report) } \quad \text { None }\end{array}$ & $\begin{array}{l}\text { 20. Security Classif. (of this page) } \\
\text { None }\end{array}$ & $\begin{array}{c}\text { 21. No. of pages } \\
186\end{array}$ & 22. Price \\
\hline
\end{tabular}




\section{TECHNICAL Summary}

INDOT Research

Technology Transfer and Project Implementation Information

TRB Subject Code: 24-4 Pavement Evaluation and Testing

April 2001

Publication No.: FHWA/IN/JTRP-2000/27, SPR-2076

Final Report

\section{Evaluation of the Implementation of Hot Pour Sealant and Equipment for Crack Sealing in Indiana}

\section{Introduction}

This study was initiated as an implementation effort that would monitor, assist with and report on a new maintenance activity involving the trial use of hot pour crack sealant. Work associated with this new activity was qualitatively assessed over a period of several years. INDOT began by purchasing six oiljacketed melters that were distributed to various sub-districts. Previous INDOT research indicated using hot pour sealant might save on labor expense because it lasted significantly longer than the current emulsion. Random observations were made of various sub-district crews using hot pour sealant and the results were reported to appropriate personnel. Inspections were made on field operations and equipment performance. The study resulted in the preparation of a written work activity, development of general guidelines for sealing, creation of a training video, the exchange of information and reporting of findings. As a result of this study and other efforts INDOT has purchased several more melters with improved features. The total volume of hot pour sealing being conducted is relatively small compared to emulsion sealing. Currently INDOT spends over two million dollars on crack sealing efforts. This study has prompted the need to conduct research that will examine the cost effectiveness of crack sealing.

\section{Findings}

After several years of monitoring various aspects of the trial implementation the study has revealed the following:

- Oil jacketed melters purchased for the trial implementation have had considerable maintenance problems. This is believed to be a significant factor affecting the rate of implementation and production.

- Many of the crews observed during field inspections appear to lack sufficient training.

- Overall hot pour crack sealing implementation has proceeded at a relatively slow rate relative to the author's expectation. Oil jacketed melters purchased to apply hot pour crack sealant are used only about six percent of the time they are available and hot pour crack sealing accounts for only a few percent of total sealing.

- Obtaining meaningful hot pour crack sealant production cost data has been difficult and as a result cost analysis that were performed by the study should be considered speculative. Comparisons between in-house and contract work yield similar results of about 40 to 50 cents per foot for hot pour crack sealing. Emulsions cost for INDOT crews is about 26 cents per foot. A limited statistical analysis of some data did not provide additional insight regarding cost issues.

- There is considerable variability among crews regarding production and quality. Crews with higher production and quality tend to have well informed supervisors that have referenced material provided by the study.

- Field inspections have revealed that some crews have been conducting hot pour crack sealing operations outside manufacturers recommended guidelines and using sealant 
in an ineffective manner (e.g. filling large voids and mixing dissimilar sealant).

- Field inspections revealed frequent instances when routing operations have not been conducting in an effective manner. Among the problems noted were improper width to depth ratios, missed cracks, safety concerns and unnecessary routing.

- Maintenance employees seem to have a good attitude regarding hot pour crack sealing.

- Recent information reviewed with regard to sealant specifications indicates several

\section{Implementation}

Because this was an implementation effort the results were made available as the study

progressed. Among the milestones were:

preparation of a work activity, distribution of

\section{Contact}

For more information:

Indiana Department of Transportation

Division of Research

Attention: Dave Ward

1205 Montgomery Street

P.O. Box 2279

West Lafayette, IN 47906

Phone: (765) 463-1521

Fax : (765) 497-1665

Email: dward@indot.state.in.us
DOT's with established hot pour sealing programs are upgrading to sealant that must meet more demanding testing requirements.

- The preliminary feedback received on new oil jacketed melters the department purchased late in the study has been fairly positive.

- INDOT is currently not in a position to quantitatively determine when and where crack sealing is cost effective. training materials purchase of better oil jacketed melters and suggested changes in the method used to post data. Efforts will continue to provide feedback to the districts to promote quality control.

\author{
Purdue University \\ Joint Transportation Research Program \\ School of Civil Engineering \\ West Lafayette, IN 47907-1284 \\ Phone: (765) 494-9310 \\ Fax: (765) 496-1105
}




\section{TABLE OF CONTENTS}

Page

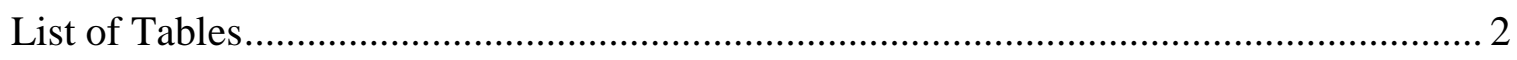

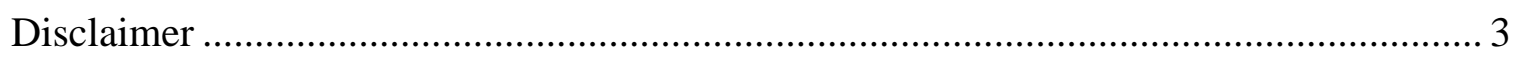

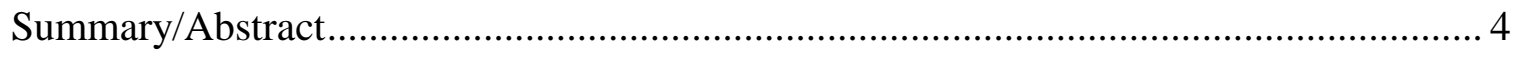

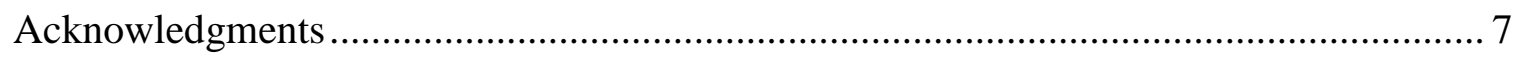

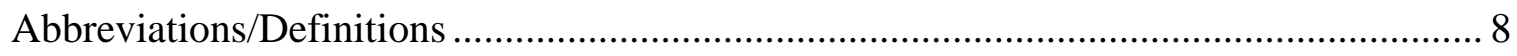

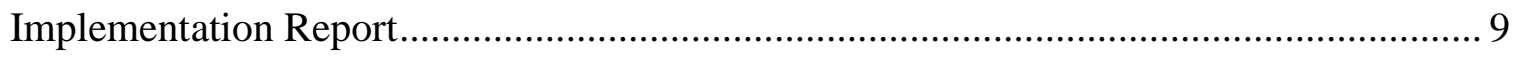

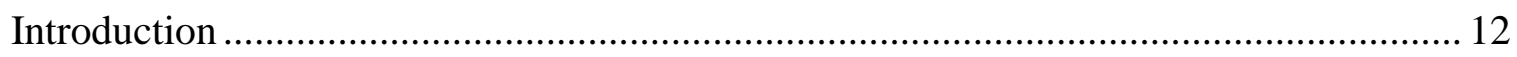

Purpose, Scope and Budget .................................................................. 12

Literature Review/Background Information ........................................... 14

INDOT Crack Sealing Program/Research Efforts ........................................ 18

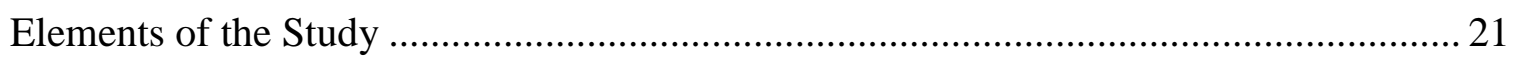

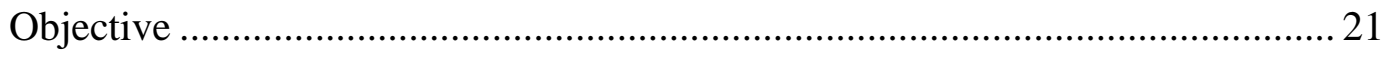

Work Tasks ........................................................................................ 21

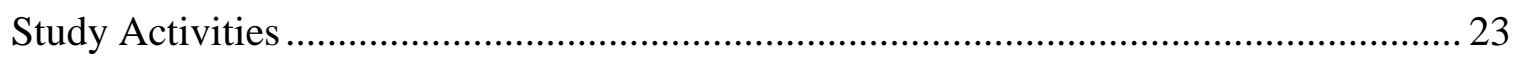

Purchase of Oil Jacketed Melters ................................................................. 23

Evaluation of Router and Related Issues................................................... 25

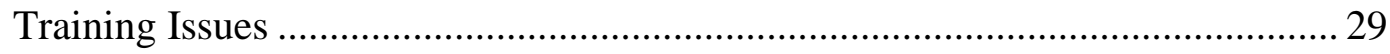

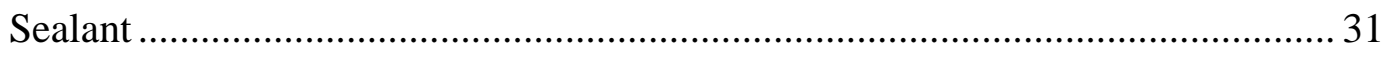

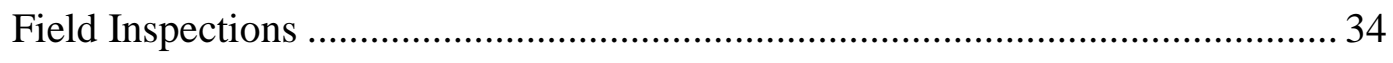

Summary of Field Inspections............................................................. 41 


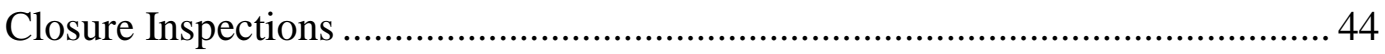

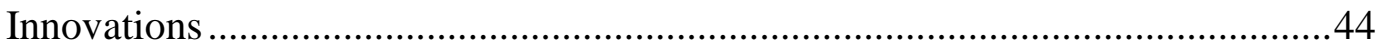

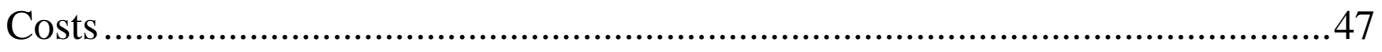

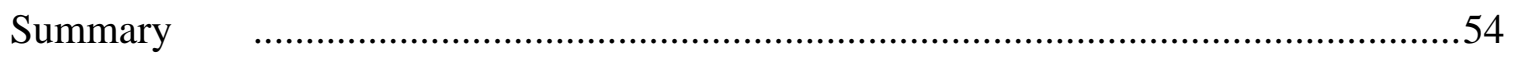

Summary of Implementation Accomplishments .................................................59

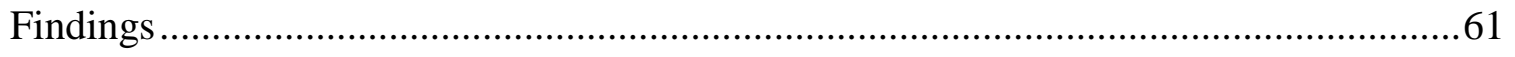

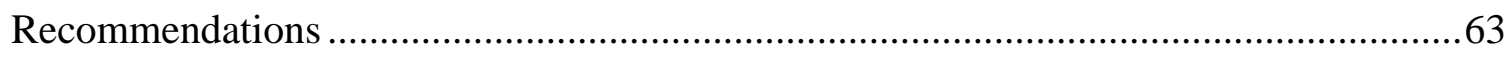

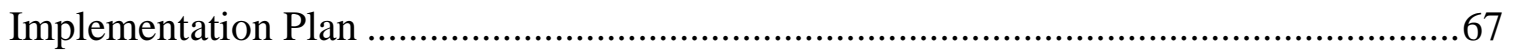

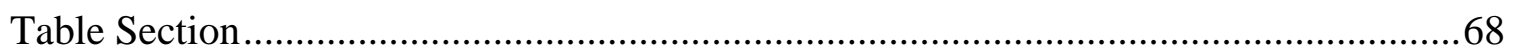

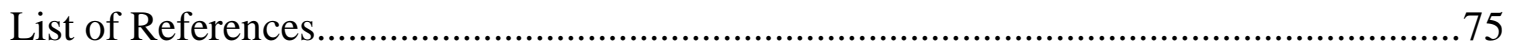

A Oil Jacketed Melter Maintenance Costs..................................................78

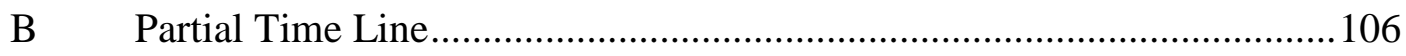

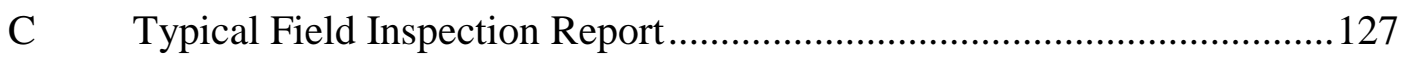

D SHRP Manual (Editorial Summary, Training Handout) .............................129

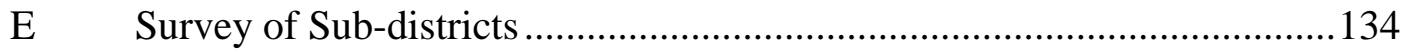

F Operational and Maintenance Procedures for OJMs..................................149

G Guidelines for the Field Evaluations of Sealant Installations ....................154

H Typical Written Report to Districts.........................................................160

I Summary of DOT Hot Pour Sealant Practices ……………......................175

J Projected Cracks Per Lane Mile.............................................................180

K Hot Pour Crack Sealing Check List ........................................................... 184 


\section{LIST OF TABLES}

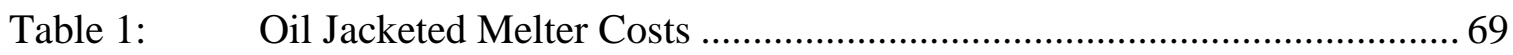

Table 2: $\quad$ Hot Pour Crack Sealing - Interstate _....................................................... 70

Table 3: $\quad$ Hot Pour Crack Sealing - Non-Interstate ................................................ 71

Table 4: $\quad$ Emulsion Crack Sealing - Interstate …………………………............ 72

Table 5: $\quad$ Emulsion Crack Sealing - Non-Interstate.................................................. 73

Table 6: $\quad$ Sub-district Crack Sealing Cost Estimates.................................................. 74 


\section{DISCLAIMER}

This implementation effort was a limited ongoing subjective assessment of a new maintenance activity conducted co-operatively with various INDOT divisions and districts. The final report's primary focus was to disseminate study results to maintenance supervisors and managers who may not be aware of the status of hot pour crack sealing. Distribution of the report beyond INDOT was not a consideration. This study did not and was not intended to make comparisons between types or grades of sealant.

The contents of this report reflect the views of the author who is responsible for the information presented herein. The report does not necessarily reflect the views or policies of the Indiana Department of Transportation or the Federal Highway Administration. The report does not constitute a standard, specification or regulation. The Indiana Department of Transportation does not endorse products, equipment or manufactures. Trademarks or manufacturers and

locations or personnel identities were not considered essential to the object of this report and therefore do not appear. Those who desire such information may contact the author. 


\begin{abstract}
In a previous Indiana Department of Transportation (INDOT) Study [22] twelve crack sealants, two cleaning techniques and three application methods were evaluated over a fortymonth period on a typical road section. It was concluded from the results that hot pour crack sealant (HPCS) if applied in a specific manner remained effective for at least three years. This was considerably longer than the six-month durability associated with the standard emulsion used by INDOT. Therefore, it was anticipated implementing HPCS might reduce application frequency for sealing and thereby reduce labor expense. Additionally, the more effective seal provided by HPCS might extend pavement life. Based on these possibilities INDOT decided to initiate a trial implementation of HPCS.
\end{abstract}

The purpose of this study was to qualitatively monitor the trial implementation, provide feedback to help make operations more effective, promote quality assurance, examine costs and help determine if the use of HPCS should be expanded. It was intended these activities be accomplished as ongoing efforts so that deliverables would not be delayed until the time of the final report. The final reports only function was to chronicle activities and summarize recommendations regarding hot pour crack sealing. The study did not evaluate types or grades of sealant.

Specific concerns at the onset of the study included justifying the cost of new equipment and determining if the typical maintenance crew could adapt to a more demanding sealing operation. 
After several years of monitoring various aspects of the trial implementation the study has revealed the following:

- OJMs purchased for the trial implementation have had considerable maintenance problems. This is believed to be a significant negative factor affecting the rate of implementation and production.

- Many of the crews observed during field inspections appear to lack sufficient training.

- Overall HPCS implementation has proceeded at a relatively slow rate relative to the authors expectations. OJMs purchased to apply HPCS are used only about six percent of the time they are available and HPCS accounts for only a few percent of total sealing.

- Obtaining meaningful HPCS production cost data has been difficult and as a result the cost analysis that were performed by the study should be considered speculative. Comparisons between INDOT crews and contract work yield similar results of about 40 to 50 cents per foot (transverse across the pavement) for HPCS. Emulsion costs for INDOT crews is about 25 cents per foot. A limited statistical analysis of data did not provide additional insight regarding cost issues.

- There is considerable variability among crews regarding production and quality. Crews with higher production and quality tend to have well informed supervisors that have made the effort to reference and apply the training material provided by the study.

- Field inspections have revealed that some crews have been conducting HCPS operations outside manufactures recommended guidelines and using HPCS in an ineffective manner (e.g. filling large voids and mixing dissimilar sealant). 
- Field inspections revealed frequent instances when routing operations have not been conducted in an effective manner. Among the problems noted were improper width to depth ratios, missed cracks, safety concerns and unnecessary routing.

- Maintenance employees seem to have a good attitude regarding HPCS.

- Recent information reviewed with regard to sealant specifications indicates several DOT's with established HPCS programs are upgrading to sealant that must meet more demanding testing requirements (e.g. MNDOT).

- The preliminary feedback received on new OJM's purchased by the department late in the study has been fairly positive.

- INDOT is not in a position at this time to quantitatively determine when and where crack sealing is cost effective.

Each of these findings and their impact is discussed within the body of the report along with supporting comments, remediation attempts or recommendations. 


\section{ACKNOWLEDGMENTS}

The author gratefully acknowledges the help of several individuals, including:

Mr. Steve Miller and Mr. Gordon Hooker with INDOT's Division of Research for assisting in field operations, obtaining data, analyzing costs and preparing reports;

Study Advisory Committee Members who provided guidance, including Mr. Larry Goode, Mr. Marvin Motuliak and Mr. Rick Smutzer all with INDOT;

Mr. Dan Norris, Ms. Ramona Williams, Ms. Debbie Hommel, Ms. Jessica Williams, Mr. Rusty Fowler, Ms. Mary Ann Michna with INDOT for operational support, resolving training issues, making distribution of materials or supplying cost data and also members of the Training Committee and District maintenance forces for their cooperation.

Scott Newbolds with INDOT's Division of Research for editing the text for grammar and content.

The Operations Support Division for supplying cost data from the Maintenance Cost Management System. 


\section{ABBREVIATIONS/DEFINITIONS}

ASTM

Crumb Rubber-

Hot Lance

HPCS

INDOT

MCMS

Melter

Overbanding

OJM

PSR

Rout

Router

Squeegee
-American Society for Testing Materials

-small grains of rubber made by grinding used tires

-crack cleaning device producing hot blast of air

-hot pour crack sealing/sealant

-Indiana Department of Transportation

-Maintenance Cost Management System

-equipment that uniformly heats sealant to high temperatures indirectly by using a double walled boiler filled with heat transfer oil (same as OJM \&.

rubberized asphalt melter, etc)

-crack sealing method which leaves a thin band of sealant on top of the

crack

-oil jacketed melter (used to provide uniform indirect heating required for hot pour melters)

-Pavement Serviceability Rating

-rectangular groove cut in pavement to create a sealant reservoir

-equipment which cuts variable width/depth groove in a pavement crack

-crack sealing tool used to spread and form the shape 


\section{IMPLEMENTATION REPORT}

Several implementation recommendations can be made based on the results obtained from HPR-2076, "Evaluation of the Implementation of Hot Pour Sealants and Equipment for Crack sealing in Indiana". Implementation recommendations in descending order of importance include:

- purchasing better quality OJMs and retiring the current ones through attrition (at the time of report printing this had been underway for some locations)

- recording all crack sealing production by the lineal foot (transverse across the pavement)

- developing expert personnel to perform or guide HPCS operations

- requiring more thorough training for crewmembers

- continue quality assurance measures and concentrate on specifics

- contracting a portion of HPCS and using warranty specifications

- limit the expansion of HPCS operations the until results of a new study are available

Of the implementation recommendations stated in the previous paragraph the first three have the greatest potential to improve operations. Brief supporting comments for these recommendations are described in the follow paragraphs. For a more thorough presentation of these and additional recommendations please refer to the report. The primary method for carrying out the implementation recommendations will be lobbying efforts by the author. 
The "original" OJMS purchased for HPCS have been difficult for crews to use and have required extensive maintenance. This has impeded implementation and likely increased HPCS production costs. Appendix A provides details of OJM costs relative to maintenance histories for the period 1993 to 1998 and also contains usage and production information. Table 1 (page 72) is an excerpt from Appendix A that compares the purchase price of OJMs to their maintenance costs. Note that the maintenance on one OJM exceeded the original purchase price.

Study personnel recognized problems associated with the OJMs fairly early in the implementation process and efforts were initiated through district and operations support personnel to encourage the purchase of better units. By copy of this report and supportive correspondence the administrative function responsible for preparing specifications will be updated regarding study findings and recommendations.

Accurately tracking HPCS costs has proven difficult. Knowing the true cost of emulsion and HPCS is essential for making reliable comparisons and for supporting future studies that will investigate crack and joint sealing cost effectiveness. Currently INDOT maintenance functions use the lane mile as the basis for posting production. This method is problematic when accessing costs because there is no allowance for crack frequency per lane mile (varies considerably between road sections). Therefore, INDOT (Operations Support Division) should consider requiring crews to record the actual lineal feet of crack sealed when performing this work activity. If this can't be accomplished an alternative procedure would be to have crews estimate a crack density or use a sampling procedure to calculate cracks per mile. By copy of this report 
and correspondence, the author will lobby to change the reporting process for emulsion and HPCS.

Many of the problems occurring in the current HPCS program could be resolved by requiring each crew to have at least one supervisor or technical person on site that thoroughly understands how to properly conduct HPCS operations. The districts need to select such an individual and study personnel can assist with the training as necessary. 


\section{INTRODUCTION}

Purpose, Scope and Budget

This implementation study was initiated to examine a new maintenance activity that uses hot pour sealant to seal transverse pavement cracks. This new activity arose primarily from the results of previous research [22] that indicated there could be advantages to using hot pour sealant over emulsions. The study focused on qualitative efforts to evaluate operations, collect information, provide feedback and cooperate with personnel involved in implementation. The scope of operations included, but was not limited to the following activities: (Note: This study did not evaluate types or grades of sealant)

- conducting a limited literature search

- $\quad$ acting as a resource for districts'

- facilitating the purchase of equipment and materials

- assisting in equipment and sealant specification preparation

- evaluating equipment and crew performance

- conducting interviews

- reviewing cost data

- developing sealant application guidelines

- $\quad$ assisting in training efforts

- making recommendations to improve operations

To accomplish these activities hundreds of contacts were made to collect or exchange information and more than forty on site inspections were conducted during the course of the 
study. Appendix B represents a time line that lists some efforts made during the course of study. Samples of the various types of information that was collected appear in the Appendices, including a typical field inspection report (Appendix C).

Of the original $\$ 20,000$ budget which was set aside mainly for purchasing minor equipment and parts, $\$ 8,922$ remains unspent at the time of this report.

The study did not conduct basic or applied research because the main focus was implementation. Most of the study activities were carried out as ongoing efforts that were intended to transfer existing information and technology to INDOT's crack sealing program.

While it is difficult to estimate a benefit to cost ratio for this study, especially since it was subjective in nature, the following comments can be made. The total cost of the project was about $\$ 11,000$ dollars or about $\$ 2000$ per year. The feedback provided during the study in the author's opinion improved field operations by at least ten per cent. During that period of time approximately more than a million dollars was spent on HPCS. Ten percent applied to this amount translates to a savings of $\$ 200,000$ which without other considerations (e.g. training etc) yields a most favorable benefit to cost ratio. 
Literature Review/Background Information

Crack sealing is one of the most common maintenance activities performed. As a result there are a good number of research reports available on the topic. A limited literature review conducted early in this implementation effort revealed that a significant number of reports focus on sealant properties and methodology. Typical subtopics of study include sealant composition, application techniques, bonding, durability, and test method development. Findings associated with these studies provide a good basis for making decisions regarding how to properly conduct crack sealing. The number of studies which address crack sealing cost effectiveness in terms of extending pavement life seem to be fewer in number, fairly limited in scope and present conclusions that may not apply to INDOT operations.

The literature review did reveal some research efforts that attempted to quantify the cost effectiveness of crack sealing.

One of these was a study conducted by the Ontario Ministry of Transportation, Canada [6]. It concluded crack sealing could extend pavement life by more than two years. A follow up effort that reviewed this study's data [7] analyzed life-cycle costs associated with sealing and concluded "that rout and seal treatment is a cost-effective pavement treatment". This and other similar study conclusions would not necessarily have direct application to INDOT operations because of several factors including, experimental design, scope of the study, and differences in climate and geography. 
INDOT conducted one study [1] that investigated pavement surface maintenance activities including crack sealing. While the study concluded crack sealing was significant with regard to Pavement Serviceability Rating (PSR) no quantification of this in terms of cost effectiveness was stated. The study did recommend INDOT initiate ongoing investigations to collect and summarized various pavement maintenance data so that the cost effectiveness of work activities could be accurately quantified. To date no other formal studies on the cost effectiveness of crack sealing have been conducted by INDOT.

One of the more useful and practical publications examined during the course of the literature review was the Strategic Highway Research Program (SHRP) manual published on crack sealing [4]. It recommends common sense procedures for developing and monitoring crack sealing programs and suggests highway agencies conduct follow-up investigations to determine the effectiveness of sealing. It could be presumed that such long term monitoring would lead to the development of guidelines that would help promote a more effective determination of when and where crack sealing is cost effective. A brief editorial summary of topics covered by the SHRP Manual appears in Appendix D as a suggested training handout.

The literature review also revealed research that challenges the accepted practice of sealing pavement cracks and joints. The Wisconsin DOT [18] conducted a long-term study on concrete pavements which presented evidence that joint sealing may not substantially effect serviceability. The results mainly impact primary roads that would be expected to have adequate engineered drainage. Based on this research that spanned over twenty years, the Wisconsin DOT has elected not to seal joints on new concrete pavements. Subsequent 
reports from WDOT indicate that millions of dollars have been saved from dropping joint sealing from construction contracts. Additionally, WDOT has elected not to reseal existing concrete pavement joints.

DOT's studies were initiated by field observations that seem to indicate sealed and unsealed concrete behaved similarly with regard to long term performance. During a statewide field study conducted in 1997 at the request of INDOT's Pavement Design Committee in which the condition of concrete joints were examined, the author observed many older concrete pavements sections in Indiana that have remained in excellent condition despite failed joint seals.

WDOT has also conducted limited research [16] on crack sealing asphalt pavements. The research was conducted on three distinct pavement sections that included overlays and full depth asphalt. The study indicated there are benefits from crack sealing, but they may be marginal and conditional. The study was not comprehensive in scope and the evidence was not compelling as to the cost effectiveness of crack sealing relative to INDOT's own program. The study does conclude that within the scope of the investigation that the results of sealing are positive and significant, but independent of the sealing method used. 
As part of the limited literature search conducted by the implementation effort approximately 26 publications were referenced and numerous others were reviewed. While many touched on important issues regarding crack sealing, the author is unaware of information in the referenced material or other sources that can accurately use quantitative methodology to predict if sealing a specific pavement section will be cost effective.

This is understandable as the cost effectiveness of crack sealing is likely linked to many factors, including pavement structure, drainage condition, current serviceability, rehabilitation options and maintenance activities. It is unlikely that every road section could be characterized adequately and subsequently linked to an accurate model to predict the cost effectiveness of crack sealing. Contacts with INDOT's Roadway Management Division regarding the feasibility of linking their database to a quantitative approach to guide crack sealing operations revealed that there are no immediate plans to under take such an effort. However, the data base is available to assist managers if they believe the information would provide insight for selecting roads for crack sealing.

In the absence of an effective quantitative approach for selecting road sections for crack sealing there is continued dependence on subjective judgement with the presumption the overall net effect will be cost effective.

The literature search and contacts made with other DOTs seem to indicate there are significant differences in crack sealing programs nationally. A survey of INDOT's own subdistricts revealed considerable variability in their HPCS practices and knowledge (Appendix E). However, there does appear to be a national consensus on general practices that should 
be followed when hot pour crack sealing is conducted. This is evidenced by information compiled and set out in SHRP Manual H-348 and other similar publications.

At the time this report was being prepared several years had transpired since the initial literature search was conducted. It is expected that major advances in this topic area have not occurred. However, it would be advisable for INDOT to review available literature periodically to remain current on HPCS developments. A new study to examine the cost effectiveness of HPCS that was approved for phase one funding beginning in August of 1999 will conduct an updated literature search.

INDOT Crack Sealing Program/Research Efforts

The Indiana Department of Transportation (INDOT), along with the majority of highway agencies, continues to accept the merit of sealing cracks to prevent harmful moisture penetration, reject debris, retard stripping and reduce ejection of fines. The total budget for INDOT's crack sealing program is approximately two million dollars. Candidate roads for this program are typically selected after a review is made of upcoming major construction and rehabilitation activities. The process is initiated at the sub-district level with the resultant recommendations passed along for review as part of the effort to develop the annual Road Improvement Program. Final selections for crack sealing locations are made using a multitude of criteria primarily driven by the subjective judgement of experienced personnel. 
INDOT has routinely sealed longitudinal and transverse pavement cracks for decades. Initially cutbacks were used, but they were replaced with emulsions that were easier to apply. The simple application procedure associated with emulsions is compromised by their apparent limited durability that usually results in re-cracking within six months. Therefore, frequent application would be necessary to keep cracks sealed. This assumes that cracking observed at the sealant surface equates to functional failure.

In the middle 1980's INDOT became aware of flexible sealant which remained durable for several years without cracking. To investigate these more durable materials a study [22] was conducted to evaluate promising sealants and application techniques for sealing transverse pavement cracks. In this study twelve crack sealants, two cleaning techniques and three application methods were evaluated under field conditions over forty months to determine if any combination would produce an effective long term seal.

The test sections were located along a typical asphalt surfaced pavement and in most instances sealant application was made by INDOT maintenance crews. The results obtained were encouraging as they indicated several name brands and grades of HPCS when applied in a specific manner could produce a seal that lasted three or more years. Concurrent testing with the emulsion routinely used by INDOT demonstrated it had an apparent functional life of about six months and typically failed in cohesion cracking at the surface. This type of failure was not particularly surprising because to the best of the author's knowledge emulsion formulations do not pass either the ASTM D-1190 or D-3405 test used to qualify many HPCS. 
Based on study findings INDOT's Operations Support Division, in co-operation with the Districts, began a HPCS trial implementation to seal transverse cracks. It was anticipated that the initial higher costs of using longer lasting HPCS would be offset by labor savings accrued from having to reseal less frequently. Labor accounts for approximately two thirds of crack sealing cost. Potential savings would be dependent upon a crew's ability to adapt to a new activity and still maintain adequate production and quality. Since districts try to seal on a five-year rotation, the use of emulsions may leave pavements vulnerable for more than four years because cracking occurs within six months. Therefore, using HPCS should provide a more effective seal with the potential to extend pavement life. 


\section{ELEMENTS OF THE STUDY}

Objective:

To assist the Operations Support Division and Districts with the trial implementation of hot pour sealant and help determine if this new activity should be expanded.

\section{Work Tasks:}

The study proposal was divided into five tasks, some of which were conducted concurrently. A summary of each task is listed below:

- Task one involved making limited random observations of maintenance crews as they received and adapted to using new equipment and sealant.

- Task two involved evaluations of equipment or procedures and noted innovations developed at the sub-district level. It coordinated efforts to address both unique and shared technical difficulties and initiated an exchange of information. It included presentations to maintenance personnel to update them regarding HPCS. This effort was conducted during most of the study.

- Task three addressed the development of training materials to help crews adapt to HPCS. Additionally, information obtained from other DOTs, SHRP and vendors was complied, edited and condensed as appropriate and distributed to the districts.

- Task four prepared suggested qualitative "operational" guidelines for using hot pour sealant.

- Task five examined various costs relative to HPCS including application cost of hot pour versus emulsion and maintenance costs associated with the OJMs. 
Deliverables associated with these tasks included, interim and final reports, training materials and guidelines for sealant application, and minor equipment and parts. 


\section{STUDY ACTIVITIES}

Purchase of Oil Jacketed Melters

Study activities began in late 1992 with communications regarding preparation of bid specifications to acquire oil-jacketed melters (OJM). The manufactures of HPCS indicated their sealant required controlled uniform indirect heating via transfer oil to prevent material degradation. At that point in time INDOT had direct fired mobile kettles for the application of emulsions and they were not suitable for HPCS. Therefore, an effort was initiated to acquire OJMs.

As part of the effort to acquire OJMs contacts were made with one INDOT district that had purchased a melter in the early 1980's as part of a limited experiment to try HPCS. At that time OJM manufacturing was very limited and INDOT had no experience in procuring this type of equipment. The unit that was acquired was fabricated as a custom made prototype and this lead to retrofits by the manufacture plus work by INDOT forces to make the unit functionally useful. In an effort to benefit from this experience in purchasing new OJMs, input was obtained from INDOT maintenance personnel, several vendors and other DOTs. Much of the information collected from these sources was compiled into the final bid specifications, but there was lingering concern that the specifications might not produce a viable unit. This resulted from considerable disparity in information received from various sources and the impact this had on preparing bid specifications.

When the contract to purchase the OJMs was let and the bids were received, one bid was significantly lower than the others. This bid was from an unexpected vendor whose 
equipment departed marginally from the generic specifications. Because the contract required the low bidder to provide a demonstration of their OJM prior to approving the purchase, arrangements were made to examine the vendor's melter. A contingent of INDOT personnel attended this demonstration to comment on the suitability of the OJM and discuss various administrative issues. Some concern was expressed about the large size of the OJM, the weight of the heated distribution hose and the limited maneuverability associated with overall design. The OJM did provide a support harness to lessen the load from the distribution hose in an attempt to reducing operator fatigue. There was debate about these and other items and several discussions took place to contemplate whether the bid should be rejected or canceled in order to modify the specification for a re-bid.

The target concept for the OJM was a small to medium sized unit with a lightweight distribution hose produced by an established company. The low bid unit was a larger newly designed OJM marketed by fairly small company. Because of these departures this author agreed to check on the performance of the low bid unit by contacting the few city and county DOTs who had purchased them. This revealed that while the OJMs had not been used extensively they had not exhibited problems.

Based on all the input received by those involved in the purchasing process the consensus decision was to support the low bid and make arrangements to have OJMs delivered. Some of the primary factors that impacted this decision were annual purchasing deadlines, funding availability and the desire implement HPCS. 
It was originally anticipated the OJMs would be received at nearly the same time and immediately put into service by five of INDOT's six districts. One district decided to delay purchasing OJMs to observe implementation efforts by the others. The manufacture's schedule for the delivery of the OJMs and subsequent delays in putting the OJMs into service spanned a period of about six months. This coupled with generally poor fall and spring weather conditions delayed the start of implementation by more than one year. Additional time transpired (6-8 months) before HPCS production reached a stage that warranted meaningful field inspections. Some districts delayed HPCS further to procure equipment so that routing could be conducted in conjunction with HPCS. The districts that elected to begin HPCS used overbanding. Essentially almost two years transpired before HPCS began in earnest.

Evaluation of Router and Related Issues

During the period before HPCS field operations began, study activities focused on a number of concerns revealed by a previous study [22]. Maintenance crews who had participated in the previous study expressed concern that the router should have a more effective guide and additional safety features. To investigate these concerns a router was purchased and study personnel experimented with possible retrofit solutions over a period of several months.

The first problem examined was how to improve the router to provide better cutting accuracy. Because the cutting head was obscured by shielding, an operator could not directly view the area that was being routed and therefore, had to estimate where to place the unit. On straight sections the operator could "hit" the crack and achieve good production. 
However, where the crack meandered (typically $20 \%$ of the length) the operator frequently missed areas and additional time was spent re-routing or areas were left unrouted. It was anticipated that improving the view of the cutting head would diminish this problem. However, exposing the head directly would enable debris to have a more direct path to the operator. Contacts with the manufacture indicated they had no plans to change the design because they were satisfied operators could learn to compensate for this deficiency. Field observations made in a previous study indicated operators could improve their accuracy with practice, but still missed cracks. Therefore, it was the decided to try simple inexpensive router modifications because they might have the potential to significantly improve accuracy and increase production.

Among the retrofits that were attempted were various sets of reflective mirrors, guide devices and selective cutouts of the shielding. It was also contemplated that a solid state camera with infrared capabilities may help improve the view of the cutting head.

As each of these options was pursued it became obvious that the over riding problem in each case was dust. While mirrors were very effective in providing a good view, they quickly became coated with dust. Attempts to redirect dust away from mirrors using airflow from the engine's cooling fan were ineffective. Each option that improved the operator's view of the cutting head was eventually compromised due to dust or safety concerns. It was concluded that a quick fix of the problem was not apparent and that sub-districts would need to monitor operators for satisfactory performance. 
Another concern expressed by maintenance workers was the tendency of routers to "kickback". In this situation the router would unexpectedly push the operator back out of control if the cutter head went to deep. This usually occurred in the early stages of operator training before workers mastered proper countermeasures. A push type kill switch mounted by the manufacture for emergency stops was not deemed as being very effective.

To address kickback a number of commercially available devices were obtained. Among these were a motor cycle type kill switch and a handgrip. The motor cycle switch was composed of a key device linked to the operator by a cord. As the router kicked back, the cord would pull the key out and shut the router off. Even though this was an improvement over the original push button kill switch, the router still had sufficient momentum after being turned off to pose a problem. The handgrip was not installed because shutting the engine down did not address the momentum problem. For this reason the approach changed to controlling kickback through prevention by mechanical means.

This was accomplished in a rather simple fashion by installing a depth control bar on the front of the router. Essentially, this was a vertical pipe welded to the front of the router through which a rod was inserted. The rod height could be adjusted using a wing bolt. The desired depth of cut was set using the router control then the rod was set approximately a quarter inch higher. The rod would contact the pavement if the router kicked back preventing the router from digging in too deeply. It was concluded that if districts had a concern about kickback they could manage the problem by adding the depth control device. Districts were advised in a summary memorandum on how kickback could be managed. Additionally, they were told operators should direct routing away from active traffic lanes or 
other hazards to diminish danger associated with an operator being pushed into an unsafe area.

A recent check with vendors indicates there are now routers available that have a more visible cutting head and a more effective kill switch.

After "retro-fit" evaluations were completed the router was released to the districts for implementation. It was tracked for several months to determine if there were operational problems and as a result additional concerns were raised. Among these were the use of inappropriate width to depth ratios, installing blades in the reverse direction, not checking machine wear (blades, roller pins, etc) lack of knowledge regarding router operation and maintenance, selecting appropriate cutter blades (e.g. carbide) and using qualified operators. To address these problems the study distributed information on proper routing, purchased and distributed replacement parts (roller pins, carbide blades) and made efforts to call district locations to advise them regarding routing operations.

Later in the study during field inspection it was noted that some crews were not aware of routine maintenance schedules and various operational issues associated with routing. Among the recommendations made to these crews was to wear appropriate safety gear (goggles, dust masks, gloves, etc.), perform routine maintenance checks (change air cleaner, check oil, check cutters for wear), and use proper operating procedures (don't lower cutting head quickly etc., reference owners manual). During the inspections several crews inquired if routers had drive wheels that would reduce the effort needed to push them up steep hills. Checks made with vendors indicated routers with power drive wheels were not available. 
To determine the extent routers are used in HPCS operations nationally, other DOT's were contacted. This revealed that routing appeared to be conditional and no consensus for use was obvious. However, routing did seem to be favored on primary roads with higher traffic volumes that were in the early stages of cracking. It appeared that routing these narrow cracks to create a reservoir for sealant was preferable to overbanding because the resulting seal would be more effective. Since significant investments were made in these roads the added cost to rout them seemed justified. Checks on routing costs vary considerably, however, the average cost per lineal foot for routing was estimated by a regional sealant contractor to be about ten cents per foot.

A limited scope value engineering study [25] published in May of 1990 recommended routing only for roads where underbody plows or graders are used for snow removal. In these instances the hard contact of the plow blades strips overbanding from the pavement.

Training Issues

Concurrently with the purchasing of the OJMs, the study addressed training aspects associated with HPCS. Cognizant of the importance of equipment training the contract for purchasing OJMs included provisions requiring the vendor to provide initial setup and operational training. As a follow up to this requirement, study personnel contacted the OJM manufacture and sub-districts to determine if the training was adequate. Indications were that training was typically provided to personnel that were available the day the OJM was delivered. However, some sub-districts stated the training was not as thorough as they had 
expected. Additionally, personnel trained that day were not always available to transfer information to other users. To help resolve this problem study personnel contacted the vendor to request additional training and inquire if a videotape or manual was available on OJM operation. The company indicated that a tape and manual covering some aspects of OJM operation and maintenance was under development and would be made available in the near future. Eventually this information was received and reviewed by study personnel. The written material supplied by the vendor was not particularly user friendly, therefore, the study prepared a condensed and re-organized version that was distributed to the districts (Appendix F) along with reproductions of the videotape.

Contacts made in a previous study indicated several DOTs had developed HPCS training programs that included videotapes and written material and that they were willing to make these available. Among these were videotapes from the Illinois Department of Transportation and Canada. Permission was obtained to distribute a limited number of these videotapes to the districts for review. Within this same time period INDOT's Training Committee was approached regarding the need to develop HPCS training materials. They reviewed materials provided via this study and endorsed the use of the IDOT/Canadian videotape as an interim measure. It was decided, however, that INDOT should create an inhouse training tape as a priority effort. The SHRP crack sealing manual that was presented to Training Committee via the study (also distributed to districts) was subsequently endorsed as the basis for a script. This effort began in November 1994 and the tape was made available in early 1998. This study provided script editing and video equipment to assist in this effort. 
In addition to assisting with the videotape the study determined that supervisors and maintenance personnel would likely benefit form having a reference manual similar to those developed by other DOTs. It was decide that it could be prepared by the study and distributed in conjunction with the videotape (supplemental attachment) to aid in training. The first release was made in early 1998 via a limited distribution made by INDOT's Research Division (supplemental attachment). A second more wide spread circulation was accomplished by the Operations Support Division in the summer of 1998. It was determined that further distributions and updates should be the responsibility of the Operations Support Division who was subsequently provide with the original document on diskette.

Sealant

When it became known INDOT would purchase OJMs some districts attempted to anticipate the volume of sealant they would require in order to meet purchasing deadlines. In some instances this lead to over stocking of sealant for several seasons because projected production levels were not achieved. Several sub-districts contacted study personnel to express concern regarding long-term storage because the containers had degraded and the sealant had discolored. These concerns were addressed via contacts with sealant vendors and the distribution of appropriate handling and storage guidelines to sub-districts. In essence districts were informed that HPCS does not degrade readily with time and packaging protection is the only concern. Reports by some sub-districts that the overstocked material had become "stringy" when heated were traced to overheating, excessive re-heating, mixing of dissimilar sealants and clogging of the OJM pump from packing liners that had not melted. 
The clogging problem is usually remedied by reversing the pump and allowing the liners to melt or by retrieving suspect materials from the tank.

Most of the initial sealant purchases were made based on the results from a previous study that indicated a high success rate could be achieved with a specific brand of "crumb rubber" sealant. This sealant was purportedly a good choice for inexperienced crews because it was "forgiving" in nature and would perform satisfactorily even if application guidelines were not strictly followed. However, because generic specifications usually are the accepted procurement method districts eventually had to adopt broader based specifications for sealant. To assist the districts in this effort the study recommended specifying an "equivalent" ASTM grade (D-1190 or D-3405) in lieu of using a name brand. While current ASTM tests tend to be good indicators of field performance they are not as effective as evaluating sealant under actual field conditions over long periods of time. Therefore, procurement by specifying ASTM grades can lead to purchasing sealant with unequal and occasionally poor field performance. Additionally, low bid procurement can result in sealant stockpiles that contain a variety of formulations from different vendors. Crews may then inadvertently mix dissimilar formulations which sealant manufactures generally agree diminishes field performance

Nationally, there are efforts underway to develop better laboratory test methods that can predict field performance (some DOTs currently specify supplemental tests). In the interim, the best way to judge a sealant is to track field performance over time, select the best brands via an approved list and use competitive bidding to control cost. However, it is apparent that procurement procedures within regional state governments do not support the 
"approved list concept" and instead "encourage" generic specifications. This essentially means that under current purchasing guidelines districts may buy sealant with varying levels of field performance when utilizing various ASTM designations. Contacts with other DOT's indicate many face the same dilemma. Some DOTs have been able through persistent efforts to maintain an approved list approach. Recent INDOT sealant purchases have been accomplished by specifying an ASTM D-3405 designation coupled with a percentage of "crumb rubber". This was an attempt to replicate the formula of the sealant recommended by a previous study. While this approach may solicit an acceptable material, it is important that developments with regard to sealant formulas and testing be tracked so that specifications can be appropriately updated. For those districts that may want to evaluate sealant performance via field trials a suggested methodology appears in Appendix G (reprint from reference \# 5). This is a thorough approach and a less rigorous evaluation may provide the necessary information.

Even if sealant is certified as a particular ASTM grade and generally exhibits good performance, it is desirable to obtain field samples and conduct quality assurance testing. Several samples of certified sealant obtained during the course of this study did not pass the corresponding ASTM laboratory analysis. Additionally, there are other concerns regarding sealants that need to be monitored. Recently a problem with mineral fillers developed. Some sealants use fillers that have a tendency to settle out if material remains in OJMs for extended periods of time. The fillers accumulate as deposits at the bottom of the OJMs and prevent effective heat transfer. This problem can be lessened if crews would monitor sealant usage so that only a minimum amount is left in the OJMs at the end of the day. For a number of reasons leaving excess sealant in the OJMs is not recommended. 
Field Inspections and Related Issues

Summaries of field inspection results appear at the end of this section. The following paragraphs chronicle events and present significant findings revealed by field inspections.

Beginning in the spring of 1993 districts began to conduct some HPCS and a few field inspections were made. It was originally anticipated there would be substantial HPCS activity with the arrival of OJMs and frequent inspections would be possible. Some districts had anticipated high OJM use and had purchased significant sealant for that reason. However, HPCS activity was minimal. In fact, some districts restricted or delayed initial implementation to observe and benefit from the startup experiences of other locations.

There were several underlying causes for the slow start including problems with the OJMs, generally poor seasonal weather conditions, uncertainty as to the necessity for routing, inadequate training, no specific work activity designation, lack of guidelines for selecting roads, concern about IOSHA regulations and other lessor issues.

Eventually HPCS activity increased by late 1994 as did the number of inspections and contacts with districts. The perception formed by study personnel as a result of these preliminary interactions was that HPCS operations would benefit by clarifying various issues. Initial efforts to accomplish this involved providing on the spot information during field inspections to emphasize accepted methods for conducting HPCS. Additionally, equipment and parts, such as, squeegees, carbide cutting blades, roller pins, sample cans, and temperature gauges were purchased and distributed by the study to crews to promote more 
effective operations. During these visits it was determined that crews occasionally received information that seemed to conflict with research findings and accepted HPCS practices. In these instances an effort was made to inform "the chain of command" that they should consider revising verbal/written crack sealing directives. This usually took the form of a phone call to the appropriate sub-district superintendent or operations engineer to discuss various aspects of HPCS. Interim updates of general findings were also provided to districts along with various training materials and the phone numbers of key personnel in other DOTs who had considerable experience with HPCS operations.

As monitoring of field operations continued it was decided that HPCS operations might benefit by reporting the results of crew field inspections directly to their district operations engineer in lieu of distributing general memorandums. This method of feedback began in late 1996 and continued until early 1997 until most districts received two reports. An example of a typical report appears in Appendix H. Most inspections conducted subsequent to this effort and late in the study focused on making an assessment of the status of HPCS with an emphasis on determining production costs. The results of those efforts appear in the cost section.

As the HPCS field inspections continued it became apparent that there were significant quality and production differences among crews. Some crews seem to be very adept in performing HPCS while others appeared disorganized and less knowledgeable. The main difference appeared to be a function of the initiative/leadership of the crew chief. It was obvious that when the crew chief had referenced to information provide via this study, 
conveyed detailed instruction to crewmembers and conducted preliminary hands on training, field operations were performed in an acceptable manner.

Field trips made to districts early in the implementation focused on several issues including the performance of equipment. Of particular interest was the performance of the OJMs acquired to apply HPCS. Interviews conducted with crewmembers and maintenance repair personnel familiar with the OJMs revealed there were a number of recurring problems. Among these were burner dysfunction, inconsistent material flow rate, clogging of the pump, ineffective over-night heaters, broken valves, apparent degradation of heat transfer oil, inaccurate temperature gauges and a multitude of leaks. These problems were traced to various causes including mechanical failure, design flaws, no preventative maintenance and insufficient training on the use of the OJMs. Many of the mechanical problems did not appear until the OJMs had been in service for several months or longer. In many instances some districts tried to remedy many of the mechanical problems themselves rather than take advantage of warrantee coverage. When warrantee coverage had been pursued there appeared to be a sense of frustration in dealing with the equipment manufacture. After contacting several sub-districts to determine the extent of the warrantee problem the author offered to mediate possible solutions. Eventually, a meeting was arranged with the manufacturer who agreed to review sub-district concerns and send a technical representative to visit each location to provide appropriate service or additional training. A review of OJM problems several months after this juncture indicated the situation improved, but many subdistrict crews continued to express concern about the OJMs. 
One of the chronic problems noted during field inspections involved OJM distributor hoses. These hoses are heavy and bulky because they contain three separate lines two of which supply hot oil (feed and return line) and one that carries sealant. Field observations indicate the hose assemblies must be pulled across the pavement frequently so that crews can work over a sufficient range to reach cracks and be efficient. Eventually, the protective cover over the lines wears out. When the cover wears through, the under lying heating and sealant lines can be damaged. Exposing these lines is unsafe as they carry extremely hot fluids that can cause severe burns. The coupling between the distributor hose and OJMs has also been a maintenance concern. It is difficult for crews to maneuver the hose with out over stressing this joint. Repeated bending weakens this coupling and results in damage to the hose assembly. One district tried to manage this problem by adding a second distribution hose to reduce the distance needed to reach cracks. It has been necessary to replace the hoses or covers on a fairly routine basis. A review of maintenance logs indicates the cost to resolve hose problems has been significant. Replacing the hose can costs of over $\$ 1000.00$ and take more than one day to complete. Failure to complete the installation in a specific sequence has resulted in loss of transfer oil and damage to the new cover.

During the first series of field inspections some crewmembers expressed concern regarding the large size of the OJMs and the heavy distributor hose. They were advised the original concept for the OJM was a smaller more maneuverable unit, however, procurement issues and administrative constraints resulted in the purchase of a larger unit. Comments made regarding the distributor hose by crewmembers were fairly frequent during field inspections. The advice given by study personnel was to adjust the support arm and harness to reduce the load and help keep the hose from dragging. Most operators responded they had 
tried this and found it restricted the range of motion and slowed production. Some crewmembers expressed concern that wearing the harness may restrict an operator's ability to escape the path of errant vehicles. Many operators had suggested or tried various retrofits to support the hose including elastic bands and springs. However, no effective solution was found, therefore, the prevailing practice was to adjust the support arm for maximum reach, try to keep the hose from dragging on the pavement and rotate operators to avoid fatigue. As a follow up to this issue the author contacted the manufacture to see what could be done to reduce the impact of the heavy hose. One suggestion was to replace the steel wand with an aluminum retrofit that would reduce the weight by about one half. The study arranged for the purchase of aluminum wands and had them delivered to the districts. In follow-up inspections operators were asked if the aluminum wand helped reduce fatigue. Most felt the aluminum wand made a difference, but commented the weight was still significant and the bulky hose made it difficult to distribute sealant to cracks.

The OJMs used by state crews in a previous research project had a lightweight flexible distributor hose and wand that operators felt comfortable using. The strategy used by this manufacturer was to store the distributor hose and wand in an oven compartment attached to the burner assembly. Before beginning operations the oven was heated sufficiently to melt residual sealant in the hose. The sealant was then dispensed at a rate that kept it from solidifying in the hose. If production slowed or was interrupted the wand was immediately placed in a re-circulation slot in the tank or returned to the heating compartment to prevent sealant from solidifying. 
During field inspections it was observed that several crews were unaware of important differences between emulsion sealing and HPCS. Therefore, many aspects important to successful HPCS sealing were not receiving proper attention. Among the observations made on a recurring basis were: sealing when moisture was present, improper crack cleaning, inappropriate sealant temperature, wasting sealant and selecting inappropriate roads. When these problems were encountered crews were encouraged to adopt proper procedures and asked to discuss these "suggestions" with their sub-districts. Because sealant temperature became a major concern and the gauges on the OJMs were known to be unreliable, the study eventually purchased and distributed laboratory thermometers. Unfortunately the use of these was not widespread because they required access to a hot smoky tank and frequent cleaning. Later in the study a limited number of easy to use infrared thermometers were purchased and distributed (May 1997) in the hopes crews would be more likely to monitor sealant temperature (some DOTs require crews to maintain a temperature log). Follow up investigations disclosed that some sub-districts were using the infrared guns to monitor HPCS, but a few of these devices had been diverted to alternate uses. It appears that some districts are now purchasing and using these relatively inexpensive devices to monitor asphalt production and check pavement temperatures for anti-icing purposes.

As part of the field inspection work task, two trips were made to Illinois DOT locations to observe HPCS operations. The Illinois DOT has been using HPCS for approximately a decade. One of these inspections was made on the morning of July 21 , 1994. The location was in district number five just east of Danville on I-64. The road was a resurfacing over concrete that was estimated to be about six years old. 
A discussion with the supervisor indicated procedures for conducting HPCS were well established. Approximately two hours were spent at the site interviewing workers, observing the procedures, recording the operation on videotape and checking the equipment. Overall the operation was well organized and efficient. Each crewmember seemed to know their responsibility and understand how it contributed to the overall operation. The crew, in general, seemed very motivated and this was reflected in what appeared to be good production. The OJM being used was from an established company and the supervisor indicated it had been reliable. It appeared to be in good condition and very well maintained. The OJM was relatively small and the wand was fairly lightweight making it easy to distribute sealant to the cracks. The wand had a spring actuated valve that appeared to be superior to the twist type used by some INDOT crews. Some routing may have been done the previous day. The crew was cleaning the cracks with compressed air ahead of the sealing operation and sealant was being placed in a wide overband using a squeegee bent to a shallow "u". The cracks appeared to be dry and no bubbling was noticed when sealant was placed.

The supervisor explained the wide overband was selected to cover areas where secondary cracking was present or expected to develop. They sometimes seal longitudinal and transverse cracks at the same time. The sealant being used was an ASTM D-3405 grade manufactured by a major sealant company. The overband was immediately covered with rolled tissue paper dispensed from a paint roller fitted with an extended handle. Most HPCS conducted by IDOT mandates that sealant be covered with tissue paper to eliminate tracking. The paper soon wears off or is washed away by rain. The tissue appears very effective in controlling tracking and adds only marginally to the cost of HPCS. Later contacts with 
IDOT revealed they planned to test an anti-tracking spray and replace the tissue paper if the results were comparable. The inspection report for the IDOT crew appears in the Appendix

C. Illinois keeps records of all crack sealing and attempts to go back and check performance. All guidelines for properly conducting HPCS were being observed by the IDOT crew.

The sealing operations being conducted by the IDOT crew were likely an indication of what could be expected from INDOT crews after the HPCS program becomes more fully developed. Several atypical INDOT crews observed by this study were nearly as well organized as the IDOT crew and approached their level of quality and quantity. Most of the DOTs that have been contacted during the course of this study including IDOT, indicate it takes from eight to ten years to fully implement HPCS operations.

\section{Summary of Field Inspections}

The summary beginning on the next page denotes recurring departures from accepted HPCS practices that were observed during field inspections of INDOT crews. While this summary focuses on the problems, it should be noted that much of the feedback obtained from field inspections was positive. The entries also include equipment problems that were observed. The results are presented in approximate descending order of importance. Part 1 deals with operational and personnel issues and Part 2 deals with inherit equipment problems. 
Summary of Field Inspection Reports

Part 1

\begin{tabular}{|c|c|}
\hline Operational observation & Comment \\
\hline -incorrect application temperature & This was one of the most widespread problems noted \\
\hline $\begin{array}{l}\text {-sealing when moisture or dust was } \\
\text { present }\end{array}$ & This was a bigger problem earlier in the study \\
\hline -poor choice of road location & Same as above \\
\hline $\begin{array}{l}\text {-inefficient operations such (e.g. waiting } \\
\text { for kettle to come up to temperature versus } \\
\text { having someone come in to start the } \\
\text { melter) }\end{array}$ & $\begin{array}{l}\text { INDOT crews need to combine equipment operations and } \\
\text { adopt innovations to reduce crew size }\end{array}$ \\
\hline -wasting sealant & $\begin{array}{l}\text { This appeared to be less of a problem towards the end of } \\
\text { the study }\end{array}$ \\
\hline -mixing of dissimilar materials & This continues to be a problem \\
\hline -improper flame adjustments & Same as above \\
\hline -not verifying depth with depth gauge & Same as above \\
\hline -improper width to depth ratios on router & Same as above \\
\hline $\begin{array}{l}\text {-concern regarding the melting of the } \\
\text { Teflon liner in the oil delivery lines and } \\
\text { resultant low sealant temperature }\end{array}$ & $\begin{array}{l}\text { Crews became concerned with transfer oil temperature } \\
\text { (melting of teflon liners) and failed to maintain adequate } \\
\text { sealant temperature. Also it appeared that in some } \\
\text { instances the OLMs could not maintain sufficient BTUs to } \\
\text { attain desired temperature. It was believed this occurred } \\
\text { due to degraded transfer oil or deposits on the tank walls }\end{array}$ \\
\hline $\begin{array}{l}\text {-handouts and video tapes distributed by } \\
\text { this study and equipment vendors had not } \\
\text { been used by district personnel }\end{array}$ & $\begin{array}{l}\text { This appears to be a continuing problem. The resolution of } \\
\text { this issue might eliminate other problems. The long } \\
\text { awaited video tape released for training purposes had only } \\
\text { been viewed by a small number of employees }\end{array}$ \\
\hline -broken or faulty temperature gages & $\begin{array}{l}\text { Broken and inaccurate gages on the OJMs continue to be a } \\
\text { problem }\end{array}$ \\
\hline $\begin{array}{l}\text {-crews unaware traps are needed on } \\
\text { compressors or need to drain them }\end{array}$ & This continues to be a problem \\
\hline $\begin{array}{l}\text {-lack of knowledge regarding the } \\
\text { operation and maintenance of equipment }\end{array}$ & $\begin{array}{l}\text { Crewmember's knowledge of equipment appears to be only } \\
\text { minimal }\end{array}$ \\
\hline $\begin{array}{l}\text {-not making independent temperature } \\
\text { checks }\end{array}$ & $\begin{array}{l}\text { This continues to be a problem even though crews seem } \\
\text { more aware that temperature is critical. Additionally, no } \\
\text { crews were keeping temperature logs }\end{array}$ \\
\hline $\begin{array}{l}\text {-leaving the boiler substantially full of } \\
\text { sealant at the end of the day and re-heating } \\
\text { the same load }\end{array}$ & This problem is not as severe as it was early in the study \\
\hline
\end{tabular}




\section{Part I (continued)}

\begin{tabular}{|c|c|}
\hline -no secondary testing of sealant & $\begin{array}{l}\text { This was a problem early in the study that appears to have } \\
\text { been addressed }\end{array}$ \\
\hline -worn hose covers & $\begin{array}{l}\text { This is a safety problem that most crews are aware of that } \\
\text { can not be easily resolved }\end{array}$ \\
\hline -lack of spare parts & $\begin{array}{l}\text { On several occasions if crews would have had basic spare } \\
\text { parts on hand the downtime lost could have been } \\
\text { significantly reduced. Also having a few tools available } \\
\text { would have helped }\end{array}$ \\
\hline -not adjusting packing nuts & $\begin{array}{l}\text { Crews seem totally oblivious to the need to adjust packing } \\
\text { nuts and replace the packing on a routine basis. The } \\
\text { sealant that leaks is wasted and becomes a fire hazard }\end{array}$ \\
\hline -not replacing roller pins on the router & $\begin{array}{l}\text { These pins wear out causing the blades to wobble. This } \\
\text { results in broken blades and a poor quality rout }\end{array}$ \\
\hline -worn bumper bar on router & Crews do not seem realize bumper bars need to be replaced \\
\hline -lack of PM schedules & $\begin{array}{l}\text { PM schedules seem to be inadequate relative to the } \\
\text { manufactures recommendations }\end{array}$ \\
\hline -no lock on spout dispenser & Safety issue observed on a few occasions \\
\hline -brake disconnect problems & Same as above \\
\hline -degradation of heat transfer oil & $\begin{array}{l}\text { Continues to be a problem, even though some crews were } \\
\text { aware of the need to change this fluid or at least check it. } \\
\text { In order to check this fluid the mechanics need to install a } \\
\text { convenient petcock }\end{array}$ \\
\hline $\begin{array}{l}\text {-not changing air filters and oil filters on } \\
\text { router }\end{array}$ & $\begin{array}{l}\text { It appears crews and mechanics are becoming more aware } \\
\text { of this problem }\end{array}$ \\
\hline -over filling or under filling cracks & This was more of a problem early in the study \\
\hline $\begin{array}{l}\text {-not removing the wand tip and storing it } \\
\text { in the flue box }\end{array}$ & $\begin{array}{l}\text { Most crews are aware this will help with startup operations } \\
\text { early in the day }\end{array}$ \\
\hline -improper installation of router blades & $\begin{array}{l}\text { This was mainly a problem early in the study or occurs } \\
\text { with new operators }\end{array}$ \\
\hline -poor house keeping & $\begin{array}{l}\text { This continues to be a problem. Much of the problem is } \\
\text { inherent with the OJM }\end{array}$ \\
\hline $\begin{array}{l}\text {-debris sticking to sealant blocks as they } \\
\text { are loaded into boiler }\end{array}$ & $\begin{array}{l}\text { This is a new problem that can lead to break downs in the } \\
\text { sealant pump or clogging. Some sealant blocks with } \\
\text { exposed faces when loaded on the transport vehicle pick up } \\
\text { rocks and debris that subsequently ends up in the OJM }\end{array}$ \\
\hline -routing then sealing at a later date & Doubles traffic control costs \\
\hline
\end{tabular}




\begin{tabular}{|l|l|}
\hline \multicolumn{1}{|c|}{ Equipment observations } & \multicolumn{1}{c|}{ Comment } \\
\hline $\begin{array}{l}\text {-primary burner control module problems } \\
\text { (OJM) }\end{array}$ & $\begin{array}{l}\text { Continues to be a problem, but occurs less frequently. It } \\
\text { appears to be a design flaw. }\end{array}$ \\
\hline -burned out warning/indicator lights(OJM) & Same as above \\
\hline -material pump problems (OJM) & Same as above \\
\hline -nozzle shutoff valve breaking (OJM) & Same as above \\
\hline -tank leaks at various locations (OJM) & Same as above \\
\hline $\begin{array}{l}\text {-melter fails to maintain heat output in cold } \\
\text { weather (OJM) }\end{array}$ & Same as above \\
\hline -ineffective kill switch (router) & $\begin{array}{l}\text { This has been addressed by a new router design by some } \\
\text { vendors }\end{array}$ \\
\hline
\end{tabular}

Closure inspections

For closure and to reflect upon previous crew observations six additional field inspections were conducted in five of the six districts in the final months of the study. A primary goal of these inspections was to obtain production information in order to analyze HPCS costs. However, these inspections also revealed that the level of knowledge and performance of crews regarding hot pour crack sealing appears to have improved significantly compared to several years ago. Nevertheless there are still discrepancies between what some crews are doing and recommended guidelines for conducting HPCS.

Innovations

During the course of making field inspections the study made an attempt to record innovations that may be of interest to all sub-district crews that perform HPCS. Listed below are some simple ideas that sub-districts have come up with or borrowed to improve operations. 
- In order to reduce fatigue and speed HPCS applications one district added a second application hose installed on their OJM.

- During the course of the study the Division of Research supplied voice activated two way headsets to several crews in order to improve communications with the truck driver pulling the OJM and the applicator. Most who used the radios felt it improved production by co-ordinating their efforts. Some vendors use these radios

- One district installed a lift hoist on the OJM to haul the router to the job site.

- One crew performing longitudinal sealing affixed an air hose to the side of the truck towing the OJM in such a way that as operations moved along the shoulder cracks were blown clean thereby eliminating the laborer who would normally perform the cleaning operation

- Some crews not having access to propane torches for heating wand tips to remove clogs have used safety flares to heat the tips

- A few districts have tried using either the shoe attachment or disc thereby eliminating the need for a squeegee operator

- Some districts have on occasion used tissue paper as an anti tracking measure

- Occasionally there are fairly long distances between cracks. One district uses the snow plow mount to transport the router for these circumstances

- Some locations keep the melters in heated buildings in cold weather to reduce heat-up time in the morning, especially if the onboard heaters have proved ineffective

- One district has mount a flashing light on their router to increase visibility 
- The use of a drip can in the pump housing to catch leaking sealant to reduce clean up time and the risk of fire

- Prior to conducting sealing operations many sub-districts unload sealant from in the boxes and place the blocks in the trucks to eliminate cardboard from blowing out at job sites (care must be taken not to contaminate blocks with dirt/rocks etc.)

- A few districts have substituted a more durable hose covering for the one supplied by the original vendor.

- To better control sealant flow from the wand, the Division of Research investigated the use of a user-friendly sealant valve that works similarly to a gas pump nozzle.

- The use of a lift gate on pickup trucks to load sealant 
Costs

It was originally anticipated that INDOT's HPCS production costs could be bench marked against long standing programs by other DOTs. However, a review of other HPCS programs revealed that operational and production differences made meaningful cost comparisons unlikely. There are no practical methods for converting various DOTs' HPCS cost data to a common base. There are considerable differences in the way DOTs operate their HPCS programs. Each summarizes production using various units (e.g. lane mile, meter, gallon, ton, lineal foot), uses multiple sealant types, operates with different equipment, has varying labor rates, dissimilar cost of living factors and operates across separate climatic and geographical zones. Additionally, some DOT's have operational differences between their own districts. Because of these issues only cursory comparisons with other DOTs were pursued. A summary of the information that was obtained appears in the Appendix I.

As part of the study proposal a life cycle cost comparison was to be made between HPCS and emulsion crack sealing. However, production information, especially that obtained early in the study varied over a wide range making meaningful comparisons difficult. When sub-districts first began HPCS no new work activity had been established and subsequent production entries into the Maintenance Cost Management System (MCMS) were frequently in error despite the issuing of preliminary guidelines. This prompted development of a separate work activity (\# 209 ) that recommended equipment and crew resources, and established corresponding MCMS entries. It was anticipated this action coupled with more HPCS activity over a period of several years would promote a relatively uniform output among crews. However, a review of MCMS HPCS data from 1995 to 1998 
indicates there is a significant range in production costs among sub-districts. Independent field observations of sub-district crews tend to confirm an unexpected lack of consistency.

Because crews did not achieve a fairly uniform sustainable output and because HPCS lacks a historical database a representative unit cost could not be identified. This precluded conducting a reliable lifecycle cost comparison. However, a review of statewide average lane mile costs by district for 1995 through 1998 was made that did provide some insight into HPCS costs. Table 2 through 5 (Table Section-page 71) depicts average yearly HPCS and emulsion costs by interstate and non-interstate lane mile. Districts are listed across the top of the table (10 to 60$)$ with the year listed down the side. Zeros entries indicate no crack sealing was performed that year. The average lane mile costs for each category appears at the bottom of the tables.

By examining the tables there are general statements that can be made.

- A review of the cost data in all tables shows considerable variation by district and year.

- The range and dispersion of values for emulsion sealing seems to be less than for HPCS. This is probably a reflection of the greater experience crews have in conducting emulsion sealing.

- Some lane mile costs for HPCS were very high. An attempt was made validate such entries. In one instance a low volume of sealing coupled with excessive down time for one sub-district skewed the results. 
- A possible explanation for variation, aside from crew performance, is the difference in the number of cracks that occur in any given lane mile (crack density). The impact of crack density is discussed later in the report

An overall cost comparison between interstate and non-interstate crack sealing (emulsion versus HPCS) shows that non-interstate costs less, although the difference in the case of emulsion sealing is relatively small at $\$ 82.62 /$ lane mile $(\$ 487.52-\$ 404.90)$. The difference for HPCS is more significant at \$144.98/lane mile (\$820.74 - \$675.76) representing a $21.45 \%$ increase $(\$ 144.98 / \$ 675.76)$ for sealing interstate roads. While an analysis of traffic control costs was not made, it is offered as a possible explanation for some of this difference.

If interstate and non-interstate averages are combined to make a general comparison between HPCS and emulsion sealing (\$748.25/lane mile versus $\$ 446.21 /$ lane mile) then the additional cost to perform HPCS is $\$ 302.04$ per lane mile or a $67.69 \%$ increase $(\$ 302.04 / \$ 446.21)$.

To assess various HPCS costs it was necessary to select a common base for making comparisons. Because the cost per lineal foot of crack sealed frequently appears in contract work, this method was chosen. Currently INDOT's HPCS costs are posted by the lane mile, therefore, a conversion to linear feet was required. This was accomplished by estimating the number of lineal feet of transverse cracks contained in an average lane mile of pavement. INDOT’s Roadway Management Division database was reviewed for this purpose and information from two of the six districts was used to represent all six districts. 
The subsequent analysis of this data (Appendix $\mathbf{J}$ ) revealed a significant difference between the number of average cracks per lane mile between the two districts selected (230 versus125). After making inquiries as to what might explain this, it was concluded that one district may have significantly more overlaid concrete pavement. The original joint spacing of this pavement was believed to be 40 foot on center with a likelihood of mid-slab cracking. This would result in cracks being reflected through an overlay at a spacing of about twenty feet. An analysis of the crack data from this district yielded an overall crack spacing of about 23 feet. The other district had significantly more full depth asphalt pavement and the data revealed an average spacing of about 42 feet. By averaging the two district's data [(5280) / $(\underline{23+42}) / 2]$ the number of cracks per lane mile for INDOT pavements was estimated to be 162.5 .

Assuming cracks average about 11 feet in length (average width of lane mile) the projected value of transverse lineal feet per lane mile is 1787 (11 x 162.5). This value was used along with a statewide weighted average for HPCS crew cost posted by lane mile to generate a cost per lineal foot of 44 cents $[(\$ 675.76 \times 453.3)+(\$ 820.74 \times 1434.5)] /(453.3+$ 1434.5) x 100) / (1787)]. The cost per lineal foot to seal transverse cracks using emulsion sealing is about 26 cents $[(\$ 404.90 \times 3586.5)+(\$ 487.52 \times 16177.7) /(3586.5+16177.7) \times$ 100) / (1787)]. The validity of these values is subject to several assumptions including that crews do only transverse sealing/routing and that the entire road network can be represented by data from two districts. Additionally, even though lane mile production was weighted appropriately the study did not validate the MCMS entries or crack data from districts. 
To determine how the 44 cents would compare to actual HPCS production costs, field trips were made to five districts in the fall of 1998 to collect data. A total of six crews were observed and production was recorded in terms of lineal feet measured on site instead of by the lane mile. This information was then linked to the actual costs posted to MCMS database for the corresponding crew, day and location. This data is summarized in Table 6 and 7 (Table Section-page 71). As can be seen from Table 7 (bottom of the page) the cost per lineal foot varies from a low of 24 cents to a high of $\$ 1.33$. The average for all five of the inspection locations is 49 cents which compares favorably with the 44 cents calculated by using statewide values.

A few districts have used a limited amount of contract work to accomplish HPCS. The costs from these contracts provide some insight regarding the productivity of INDOT HPCS crews. The cost per lineal feet for these contracts has ranged from 30 to 49 cents. Contacts made with regional crack sealing contractors regarding the bid pricing of sealing operations indicate those costs typically average about 50 cents per foot for operations that require traffic control, routing, cleaning and sealing. In essence the overall averages for state and contract HPCS work fall within the same range.

If statewide HPCS costs are coupled with data obtained from the field trips to estimate a cost per lineal foot, an indirect simplistic "life-cycle" cost comparison can be made between HPCS and emulsion sealing. The cost to seal a lineal foot of transverse cracking using HPCS is projected by study results to be about 46cents (approximate average of 44 and 49). This application is expected to last three years (or longer) assuming the material has been placed according to manufacturer's recommendations. This same foot of 
pavement would require six applications of emulsion over three years to sustain an equivalent sealed appearance. The cost to accomplish this would be $\$ 1.56$ (6 applications at about 26 cents foot). From this result it would appear that the HPCS "life cycle" cost is far cheaper (46 $\varnothing$ verses $\$ 1.56$ over three years). However this type of simplistic analysis ignores operational considerations and other factors.

For example, it is assumed that when the emulsion cracks it provides less benefit than the HPCS. While this is suspected to be the case, there currently are no conclusive studies applicable to Indiana that provide quantitative evidence that when the emulsion cracks (typically with six months) it is less effective than HPCS. Additionally, the full depth filling of cracks with emulsions might provide ancillary benefits, such as, retarding stripping or preventing the ejection of fines that might extend pavement life. The current study was not initiated to examine the quantitative impact of sealing on pavement life, therefore, the data collected can not address the cost effectiveness issue. A valid cost effectiveness study would likely require a large scope effort that would need to examine many factors (pavement thickness, traffic, deflection, moisture, freeze/thaw etc) that effect pavement performance relative to maintenance options.

Another problem with the simplistic analysis is the assumption that state crews would or could seal on a six-month rotation. Currently districts are challenged to seal on a five-year rotation and this was a primary factor that initiated the investigation to find longer lasting sealant. 
In the absence of conclusive evidence regarding the effectiveness of emulsions, a reasonable assumption would be that two applications spaced equally over a three-year period would provide the same protection as a properly applied single application of HPCS. Additionally, districts might considerable sealing on a three-year rotation. Given those circumstances, and considering the assumptions that were made, the HPCS option is cheaper by about ten percent ( $46 \phi$ versus $52 \phi)$.

There are secondary factors that could impact the selection of sealant. Among these would be that using HPCS reduces the frequency of resealing which keeps crews out of traffic and makes them available for alternate work. Also using HPCS eliminates environmental storage problems associated with liquid asphalt. While it is not easy to identify costs associated with these benefits, the overall impact would lend support to using HPCS.

When the current grade of hot pour sealant specified by INDOT is applied correctly it should achieve a durability of at least three years. There are other sealant grades that have been shown to have significantly longer lives and are only marginally more expensive. However, these materials typically require more precise application and until the majority of INDOT crews become more proficient, using the current grade of sealant is probably a good choice. Some research has shown that "high-end" hot pours can last more than six years. As new improved HPCS come on the market INDOT may want to investigate their use as this may make the application cost comparison with the current emulsion significantly more favorable. As crews become more proficient HPCS costs will likely decline. 


\section{SUMMARY COMMENTS}

In late 1993 INDOT initiated efforts to begin the trial implementation of HPCS. The current study was an ongoing effort to track and report on HPCS operations and provide assistance to districts.

Early study activities included a limited literature search, the evaluation of a router and contacts with maintenance employees and vendors involved with HPCS. These initial efforts were intended to provide help with start up operations. Additionally, a field assessment was made of HPCS placed in the late 1980s (mid and northern Indiana) as part of a very limited experiment. These inspections revealed that some HPCS was still providing an adequate seal after more than six years.

The implementation progressed at a slow pace over the first few years due to operational and weather problems. As HPCS field applications began various problems became obvious including the poor performance of the OJMs and the lack of knowledge of many crews regarding proper procedures. It became apparent by the second year of the study that the anticipated schedule of the implementation was overly optimistic. HPCS production was relatively low and the associated cost data exhibited substantial variability. Some of the variability was linked to the entry of erroneous HPCS data into the MCMS. Despite proactive intervention by study and operations personal the implementation proceeded at a slow pace and multiple no cost time extensions were requested and granted. 
As early production cost data was reviewed the variability that was encountered precluded a reliable cost analysis. It was believed the time extensions would eventually span a sufficient period so that production would stabilize and a reliable cost analysis could be performed. It was anticipated that additional training efforts during this same time would assist in promoting more uniform production.

To promote training the study engaged in various activities including the distribution of written materials and videotapes, co-ordination with the Training Committee and onsite HPCS instruction during field inspections. It was also anticipated these efforts would help address HPCS quality issues raised by field inspections. After several seasons the training efforts were supplemented with field inspection reports that were sent directly to a crew's district regarding their performance. Prior to this point updates on crew performance had been summarized and reported as general memorandums. It was felt the direct reporting could lend support to identifying and resolving production issues.

Even though about five years has transpired since HPCS began, a review of recent production data indicates costs continue to vary over a wide range even when normalized for crack density. Since more uniform production was not achieved, the cost comparison made between HPCS and emulsion sealing is speculative. Also the volume of HPCS data is limited and, therefore, costs could not be examined from a historical perspective. A limited statistical analysis of the cost data conducted by the Division of Research's statistical engineer did not provide additional insight. A comparison between the production cost data and limited contract HPCS data was also made. 
Among the problems noted in tracking HPCS cost was how the data is posted. All MCMS data related to general road maintenance is summarized by lane mile. There is no allowance for crack density per lane mile and this tends to obscure actual production. In essence a crew sealing a road that has a high crack density will seem to be less productive than a crew working in lower density area. If HPCS and emulsion sealing was posted by the lineal foot of crack sealed a more equitable comparison could be achieved. Posting in this manner would require a change in MCMS entries, however, the benefit would be more specific production information that would enable INDOT to set realistic production standards and accurately evaluate various sealing options (e.g. in-house versus contract, emulsion versus HPCS).

Many of the factors necessary to adequately make detailed cost comparisons are not entered into the MCMS. If the database had accounted for crack density then individual crew production could have been more accurately determined. Crews with good efficiency could have been identified and studied to improve operations.

In general the MCMS database was only partially effective for tracking cost trends, mainly on the macro level, but it was useful in reviewing equipment maintenance histories.

In the closing months of the study the cost analysis issue was revisited and a comparison was made between HPCS and emulsion sealing using production data collected by lineal feet during field inspections. 
At the time of this report INDOT had purchased approximately twelve OJMs of which eight were original purchases made to startup the implementation. The other four were bought much later in the study using modified specifications that resulted in the purchase of a different make and model with the anticipation of more reliable performance.

In general all OJMs are typically used only a small percent of the time they are available (approximately 6\%). The total annual production for these units has averaged about 850 miles (1700 lane miles). Typical yearly production for emulsion sealing is about 2500 miles (5000 lane miles). The average cost per lane mile for HPCS is estimated to be about $\$ 748$. Cost for emulsion sealing is about $\$ 446$ per lane mile. Based on crack density data received from INDOT's Roadway Management Division the costs per lane mile for HPCS and emulsion sealing were converted to cost per lineal foot of crack sealed. The respective costs are 45 cents (HPCS) and 25 cents (emulsion). Limited HPCS contact work done by several districts has ranged from 30 to 49 cents per lineal foot. INDOT has about 13,000 miles (26,000 lane miles) in its' road network. Annual emulsion sealing is performed on about 5000 lane miles or about 19 per cent of the network. Annual HPCS is performed on about 500 lane miles and only accounts for about two per cent of the road network.

Some problems encountered with OJMs resulted from improper operation due to a lack of training. However, most problems appear to be inherent to the design of the OJM. Among these problems are: burner malfunctions, break downs of the distributor hose and wand (resulting in costly replacements), temperature gauge malfunctions, leaks in piping/tanks, occasional fires, inconsistent delivery rates, complaints about the heavy hose and lessor problems. One district has retired a five year old OJM due to maintenance 
problems. The cost of maintenance on one OJM has exceeded the original purchase price. It was originally anticipated OJMs would have a useful life of at least ten years.

There were limited OJMs shared by several units/sub-districts. As a result many crews were unable to become proficient before the OJM was reassigned to another location. Inquires of crewmembers indicated many received only minimum training prior to being instructed to perform HPCS. In order to allow crews time to gain experience on OJMs some districts elected to keep the OJM within a limited number of units. Some districts kept an experienced operator with the OJM to provide training as it moved to different locations.

While the results of field inspections have revealed problems associated with the implementation of HPCS various remediation efforts by study personnel and districts appear to be having a positive impact on crew performance. In the closing months of the study a limited number of inspections and other contacts with HPCS personnel (e.g. Purdue Road School, calls to districts) seemed to indicate crews and supervisory personnel are more aware of the problems and taking measures to improve operations.

The two primary problems associated with HPCS implementation have been the poor performance of the OJMs and lack of sufficient training for crews. In retrospect buying more reliable OJMs and developing trained "expert crews" to conduct HPCS would have substantially improved implementation.

It should be noted that the current study was not initiated to examine material or performance qualities of sealant. Nor, was it to investigate the cost effectiveness of crack 
sealing in terms of extending pavement life. Both these issues were outside the scope of the study.

Summary of Implementation Accomplishments

Listed below in approximate chronological order are some of the implementation accomplishments the study was able to achieve. The more significant accomplishments appear in bold type. Many of these were cooperative efforts with other INDOT functions.

- Assisted in purchasing OJMs and related equipment (efforts began in 1992).

- Conducted field inspections and provided instruction to crews (1993-1998).

- Provided various information and small part resources including aluminum wands (started 1993 and continued as needed).

- Purchased router (1993)

- Districts provided with updates on field problems (started 1993 and continued throughout study).

- Lobbied for and assisted with developing new work activity for HPCS (10/94).

- Implementation report issued to districts (7/94).

- Training materials distributed to districts (SHPR manual, video tapes from Ill. \& Canada, head set radios, etc-early 1994).

- Verified performance of HPCS placed in early 1980s in northern Indiana (1994).

- Began lobbing to purchase new OJMs with improved features (1994).

- Promoted field testing of sealant to assure quality (effort began on 11/19/95).

- Infrared temperature guns distributed to districts $(5 / 19 / 97)$ 
- Initial training tape footage was shot as a cooperative effort with the Crawfordsville District and Maintenance Operations (7/2/97 on SR 267 near Plainfield).

- Prepared and distributed HPCS “in house” training manual/general guidelines and distributed (9/18/97).

- Draft Training Manual distributed to districts via Central Office (9/18/97).

- Videotape was developed for HPCS in cooperation with the Training Committee (1998).

- Provided camera equipment for producing the training tape and making updates (1998).

- Assisted in road school HPCS presentation (spring 1999). 


\section{FINDINGS}

After several years of monitoring INDOT's HPCS efforts and observing maintenance crews the following statements can be made. They are in approximate order of their importance.

- OJMs purchased for the trial implementation have had considerable maintenance problems. This is believed to be a significant factor affecting the rate of implementation and production.

- Many of the crews observed during field inspections appear to lack sufficient training.

- Overall HPCS implementation has proceeded at a relatively slow rate relative to the authors expectations. OJMs purchased to apply HPCS are used only about six percent of the time they are available and HPCS accounts for only a few percent of total sealing.

- Obtaining meaningful HPCS production cost data has been difficult and as a result cost analysis that were performed by the study should be considered speculative. Comparisons between in-house and contract work yield similar results of about 40 to 50 cents per foot for HPCS. Emulsion costs for INDOT crews is about 25 cents per foot. A limited statistical analysis of some data did not provide additional insight regarding cost issues.

- There is considerable variability among crews regarding production and quality. Crews with higher production and quality tend to have well informed supervisors that have referenced material provided by the study. 
- Field inspections have revealed that some crews have been conducting HCPS operations outside manufactures recommended guidelines and using HPCS in an ineffective manner (e.g. filling large voids and mixing dissimilar sealant).

- Field inspections revealed frequent instances when routing operations have not been conducted in an effective manner. Among the problems noted were improper width to depth ratios, missed cracks, safety concerns and unnecessary routing.

- Maintenance employees seem to have a good attitude regarding HPCS.

- Recent information reviewed with regard to sealant specifications indicates several DOT's with established HPCS programs are upgrading to sealant that must meet more demanding testing requirements.

- The preliminary feedback received on new OJM's purchased by the department late in the study has been fairly positive.

- INDOT is not in a position at this time to quantitatively determine when and where crack sealing is cost effective. 


\section{RECOMMENDATIONS}

The following recommendations appear in approximate order of their potential impact for improving HPCS operations. Additionally, they are divided into two groups: immediate application and longer-term application. Individuals involved with this study are available to assist in implementing the recommendations.

Immediate application:

- Realistic production goals need to be established for HPCS preferably in lineal feet of crack sealed (not lane mile). For comparison purpose emulsion crack sealing should also be posted on the MCMS in cost per lineal feet. Other cost factors, such as, routing, brand of OJM, transverse/longitudinal sealing etc. should be posted to determine their bearing on production and cost. These additions should help provide the basis for making accurate comparisons between various types of sealing options. Additionally, it is anticipated that a more complete accounting of sealing operations is necessary to determine the impact of various road parameters and to make comparisons to contract work. Based on field interviews it is expected that crews can track the lineal feet of cracks sealed or at least specify a crack density per mile (e.g. high, medium, low). If posting is made according to the lineal foot, the database should be reviewed periodically to evaluate various cost factors. Personnel from the Division of Research are available to apply statistical methods to such an analysis. 
- Districts need to institute repetitive efforts to insure crews receive adequate training prior to performing HPCS. Information distributed via efforts of this study should be presented through timely training sessions (view videotape \& read guidelines *) conducted by supervisors at the sub-district/unit locations level. Inexperienced personnel should be required to have the training prior to performing HPCS. Refresher sessions held on a routine basis to would help remind personnel of the importance of conducting HPCS according to accepted procedures. Additionally, supervisors and managers responsible for HPCS should consult the SHRP manual on crack sealing. This publication is an excellent reference and presents many options for developing more effective crack sealing operations. An Intranet site would provide an easy access for these training materials. * Note: the videotape and manual were prepared for in house use. Both were produced as interim steps as cooperative measures to solve immediate problems. Both these items should be reviewed with regard to their current applications regarding safety and operational issues. It is recommended that Maintenance Operations produce more timely training aids or shop on the open market for suitable replacements.

- Due to continuing problems with OJMs this study recommends they be replaced through attrition. Future OJM purchasing should be guided by the experience learned from the trial implementation. INDOT should consider renting or leasing OJMs so crews can evaluate them and thereby provide input into the process that develops bid specifications. Alternatively, purchasing contracts could contain a lease option that can be canceled if OJMs do not perform as expected. Additionally, there are several provisions which should/could appear in the contract bid document to reduce the chances of obtaining undesirable OJMs. 
Example provisions might include

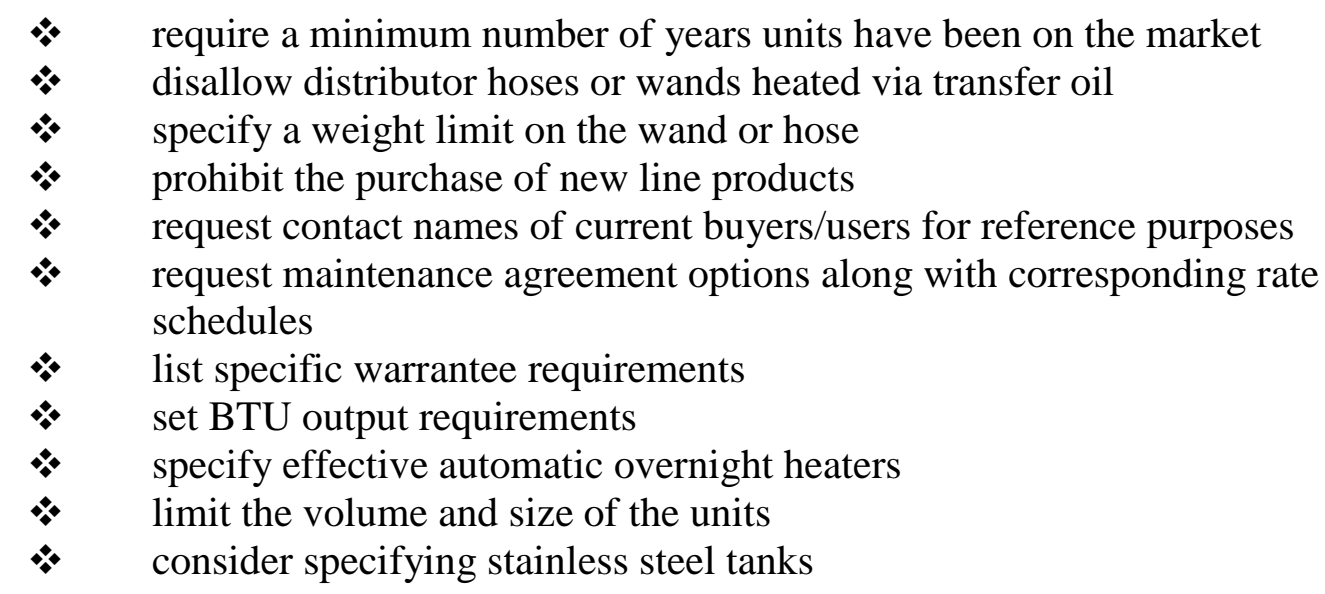

NOTE:

When OJMs were first purchased the Department had very little experience regarding hot pour sealing equipment. The units seemed adequate when first purchased as the "conditional" low bid. Based on the maintenance problems that have arisen they were not a good investment. The units are cumbersome to use and have a heavy wand that requires frequent rotation of crewmembers. They have had frequent and expensive maintenance problems. The author believes a key ingredient in promoting HPCS and gaining support for maintenance crews is the use of reliable user friendly OJMs even if initial costs for the units are higher.

- Crews conducting HPCS should be provided with infrared temperature guns and should be required to maintain a temperature $\log$.

- Crews should be required to complete a simple checklist to guide them in conducting HPCS in a cost-effective manner. A proposed checklist appears in Appendix J.

- Until the results of an ongoing study that will help decide the cost effectiveness of joint and crack sealing become available (September 2002) INDOT should refrain from committing itself to large investments in HPCS equipment. 
- Sealant should be tested according to frequency Manual Guidelines. Some sealant tested as part of this study failed the specified ASTM tests.

Longer-term Applications (These items should be addressed by Maintenance Operations and the Districts within the coming year)

- INDOT needs to consider developing a plan to utilize the existing OJMs more effectively. Among the options that could be considered is the use of "expert crews".

- Supervisors should be made aware of information in the training and SHRP manual to guide them in choosing areas that may benefit from routing. Not every road requires routing and only working cracks require HPCS. When routing is performed an experienced knowledgeable physically capable person should run the equipment

- More emphasis needs to be placed on combining HPCS equipment into a standard efficient production convoy.

- To compare in house to private sector work a limited amount of HPCS contracts should be let. This comparison would be conducted under controlled conditions. An additional option would involve the use of warrantee provisions for HPCS contracts.

- A review of the preventive maintenance schedules (PMs) associated with HPCS equipment indicates maintenance could be more thorough (especially that for routers). It is recommended that PMs be reviewed and updated to include more detail. 
- The Department should given serious thought to implementing a long term program linked to Roadway Management that would leave some road sections unsealed then compare them with adjoining areas that were sealed. Recent information indicates some DOTs in FWHA region five have begun such an effort.

- INDOT's Materials and Tests Division should review available ASTM sealant tests to determine if they should replace or supplement current bid specifications.

- Prior to implementing the widespread use of new sealant types or brands districts should conduct field trials at a conspicuous road location so that an evaluation of these materials can be made.

- An Intranet location for exchanging HPCS experiences should be developed.

\section{IMPLEMENTATION PLAN}

Because this was an implementation study many of the problems that were encountered were addressed as ongoing efforts. The previously stated recommendations will be presented to the appropriate locations via distribution of the report and follow-up correspondence and personal contacts. Continuing lobbying efforts by the author regarding the recommendations constitute the proposed implementation mechanism. 
TABLE SECTION 
TABLE 1

Purchase Versus

Maintenance Cost

\begin{tabular}{ccc}
\hline $\begin{array}{c}\text { Commission } \\
\text { Number }\end{array}$ & Total Purchase Price & $\begin{array}{c}\text { Total Maintenance } \\
\text { Cost }\end{array}$ \\
\hline 58726 & $\$ 17,595.00$ & $\$ 3,266.00$ \\
\hline 58727 & $\$ 17,595.00$ & $\$ 4,735.00$ \\
\hline 58728 & $\$ 17,595.00$ & $\$ 23,285.00$ \\
\hline 58729 & $\$ 17,595.00$ & $\$ 9,901.00$ \\
\hline 58730 & $\$ 17,595.00$ & $\$ 1,646.00$ \\
\hline 58731 & $\$ 17,595.00$ & $\$ 2,440.00$ \\
\hline 64798 & $\$ 18,279.00$ & $\$ 3,346.00$ \\
\hline 59217 & $\$ 17,165.00$ & $\$ 1,354.00$ \\
\hline
\end{tabular}

\section{Purchase Cost and Maintenance Cost of Oil Jacketed Melters}

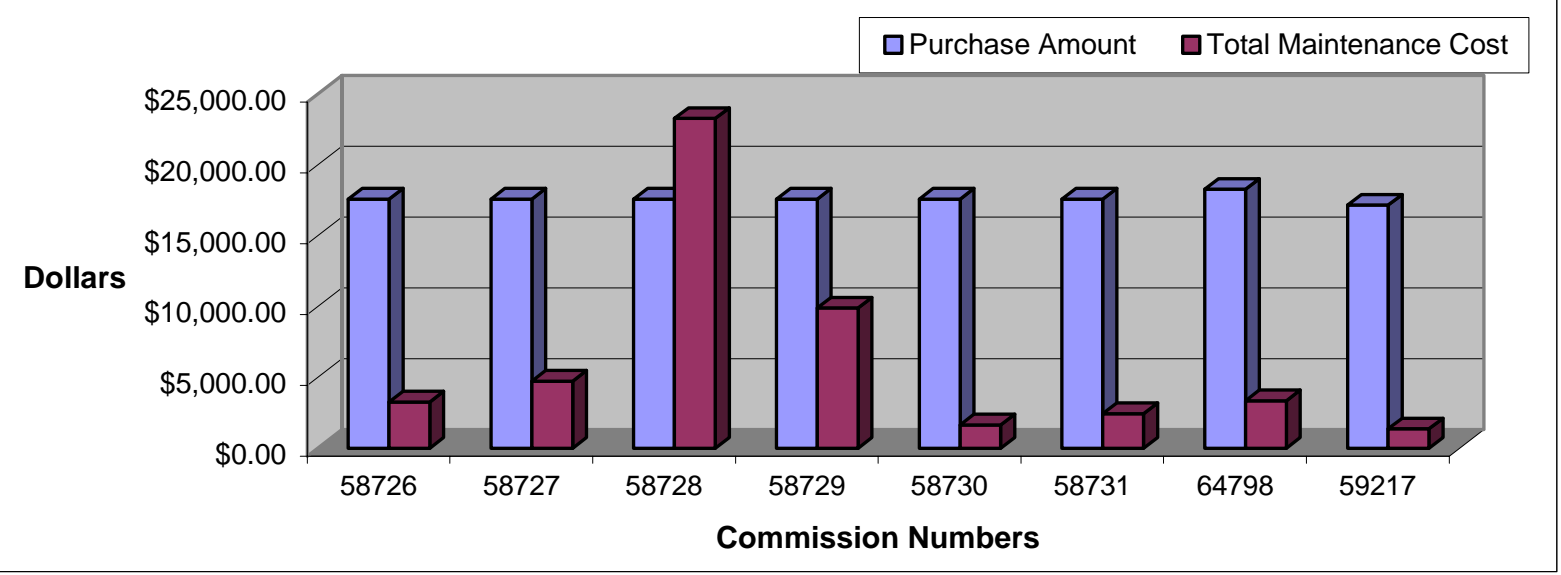


TABLE 2

Hot Pour Crack Sealing

(Interstate Lane Miles)

Lane Miles

District \#

\begin{tabular}{c|ccccccc} 
Year & 10 & 20 & 30 & 40 & 50 & 60 & Total \\
\hline 95 & 0.0 & 31.9 & 1.2 & 0.0 & 4.9 & 0.0 & 38.0 \\
96 & 11.7 & 44.9 & 84.6 & 0.0 & 21.1 & 3.2 & 165.5 \\
97 & 0.0 & 7.9 & 70.5 & 0.0 & 26.3 & 0.0 & 104.7 \\
98 & 3.2 & 0.0 & 96.4 & 0.0 & 41.0 & 4.5 & 145.1 \\
\hline Subtotals 4 & 14.9 & 84.7 & 252.7 & 0.0 & 93.3 & 7.7 & 453.3
\end{tabular}

\begin{tabular}{cccccccc} 
99(Plan) & 2.0 & 0.0 & 93.0 & 0.0 & 64.0 & 2.0 & 161.0 \\
\hline Total 5 & 16.9 & 84.7 & 345.7 & 0.0 & 157.3 & 9.7 & 614.3
\end{tabular}

98 data is thru June

Average lane mile production $=614.3 / 5=122.9$

Cost Per Lane Mile

District \#

\begin{tabular}{c|cccccc} 
Year & 10 & 20 & 30 & 40 & 50 & 60 \\
\hline 95 & $\$ 0.00$ & $\$ 819.81$ & $\$ 1,290.83$ & $\$ 0.00$ & $\$ 402.04$ & $\$ 0.00$ \\
96 & $\$ 697.32$ & $\$ 945.26$ & $\$ 907.27$ & $\$ 0.00$ & $\$ 406.11$ & $\$ 1,355.00$ \\
97 & $\$ 0.00$ & $\$ 1,041.65$ & $\$ 710.68$ & $\$ 0.00$ & $\$ 396.96$ & $\$ 0.00$ \\
98 & $\$ 2,254.38$ & $\$ 0.00$ & $\$ 507.77$ & $\$ 0.00$ & $\$ 217.80$ & $\$ 561.56$
\end{tabular}

Average Cost Per Lane Mile

District \#

\begin{tabular}{ccccccc|r} 
& 10 & 20 & 30 & 40 & 50 & 60 & \multirow{2}{*}{ Total } \\
\cline { 1 - 6 } \$ Per Lane Mile & $\$, 1031.75$ & $\$ 907.00$ & $\$ 701.84$ & N/A & $\$ 320.57$ & $\$ 891.30$ & \\
Total Miles & 14.9 & 84.7 & 252.7 & 0.0 & 93.3 & 7.7 & 453.3 \\
\hline
\end{tabular}

Total Overall Average Cost Per Lane Mile $=\$ \mathbf{6 7 5 . 7 6}$ 
TABLE 3

Hot Pour Crack Sealing

(Non-Interstate Lane Miles)

Lane Miles

District \#

\begin{tabular}{c|ccccccc} 
Year & 10 & 20 & 30 & 40 & 50 & 60 & Total \\
\hline 95 & 19.4 & 85.5 & 84.6 & 53.9 & 0.0 & 3.5 & 246.9 \\
96 & 31.5 & 40.5 & 160.8 & 148.1 & 2.2 & 9.7 & 392.8 \\
97 & 34.7 & 43.4 & 139.2 & 165.4 & 5.2 & 73.5 & 461.4 \\
98 & 27.7 & 11.0 & 88.4 & 148.7 & 0.8 & 56.8 & 333.4 \\
\hline Subtotals 4 & 113.3 & 180.4 & 473.0 & 516.1 & 8.2 & 143.5 & 1134.5
\end{tabular}

\begin{tabular}{cccccccc} 
99(Plan) & 43.0 & 24.0 & 144.0 & 159.0 & 10.0 & 90.0 & 470.0 \\
\hline Total 5 & 156.3 & 204.4 & 617.0 & 675.1 & 18.2 & 233.5 & 1604.5
\end{tabular}

98 data is thru June

Average lane mile production $=1604 / 5=320.9$

Cost Per Lane Mile

District \#

\begin{tabular}{c|cccccc} 
Year & 10 & 20 & 30 & 40 & 50 & 60 \\
\hline 95 & $\$ 1,007.11$ & $\$ 897.15$ & $\$ 770.21$ & $\$ 2,863.56$ & $\$ 0.00$ & $\$ 504.57$ \\
96 & $\$ 1,728.54$ & $\$ 719.31$ & $\$ 570.91$ & $\$ 933.25$ & $\$ 328.64$ & $\$ 2,245.57$ \\
97 & $\$ 1,418.88$ & $\$ 467.67$ & $\$ 505.83$ & $\$ 806.70$ & $\$ 470.19$ & $\$ 671.76$ \\
98 & $\$ 733.75$ & $\$ 469.91$ & $\$ 494.50$ & $\$ 651.65$ & $\$ 1,473.75$ & $\$ 550.35$
\end{tabular}

Average Cost Per Lane Mile

District \#

\begin{tabular}{|c|c|c|c|c|c|c|c|}
\hline & 10 & 20 & 30 & 40 & 50 & 60 & Total \\
\hline \$ Per Lane Mile & $\$ 1,266.96$ & $\$ 727.85$ & $\$ 573.12$ & $\$ 1,013.15$ & $\$ 530.12$ & $\$ 726.01$ & \\
\hline Total Miles & 113.3 & 180.4 & 473.0 & 516.1 & 8.2 & 143.5 & 1434.5 \\
\hline
\end{tabular}

Total Overall Average Cost Per Lane Mile $=\mathbf{\$ 8 2 0 . 7 4}$ 
TABLE 4

Emulsion Crack Sealing

(Interstate Lane Miles)

Lane Miles

District \#

\begin{tabular}{c|ccccccc} 
Year & 10 & 20 & 30 & 40 & 50 & 60 & Total \\
\cline { 1 - 6 } 95 & 336.9 & 136.3 & 426.6 & 0.0 & 210.0 & 67.1 & 1176.9 \\
96 & 377.3 & 56.3 & 174.4 & 51.9 & 186.6 & 20.8 & 867.3 \\
97 & 238.7 & 85.2 & 192.1 & 51.6 & 137.0 & 32.2 & 736.8 \\
98 & 316.7 & 32.4 & 230.2 & 0.0 & 186.0 & 40.2 & 805.5 \\
\hline Subtotals 4 & 1269.6 & 310.2 & 1023.3 & 103.2 & 719.6 & 160.3 & 3586.5
\end{tabular}

\begin{tabular}{cccccccc} 
99(Plan) & 213.0 & 810.0 & 92.0 & 0.0 & 113.0 & 40.0 & 1268.0 \\
\hline Total 5 & 1482.6 & 1120.2 & 1115.3 & 103.2 & 832.6 & 200.3 & 4854.5
\end{tabular}

98 data is thru June

Average lane mile production $=4854.5 / 5=970.9$

Cost Per Lane Mile

District \#

\begin{tabular}{c|cccccc} 
Year & 10 & 20 & 30 & 40 & 50 & 60 \\
\hline 95 & $\$ 398.47$ & $\$ 368.54$ & $\$ 483.48$ & $\$ 0.00$ & $\$ 331.56$ & $\$ 484.98$ \\
96 & $\$ 389.37$ & $\$ 408.21$ & $\$ 623.30$ & $\$ 522.68$ & $\$ 186.16$ & $\$ 537.50$ \\
97 & $\$ 351.80$ & $\$ 466.08$ & $\$ 454.13$ & $\$ 621.12$ & $\$ 289.63$ & $\$ 434.81$ \\
98 & $\$ 373.11$ & $\$ 404.66$ & $\$ 498.15$ & $\$ 0.00$ & $\$ 244.49$ & $\$ 486.64$
\end{tabular}

Average Cost Per Lane Mile

District \#

\begin{tabular}{ccccccc|c} 
& 10 & 20 & 30 & 40 & 50 & 60 & \multirow{2}{*}{ Total } \\
\cline { 1 - 6 } \$ Per Lane Mile & $\$ 380.67$ & $\$ 406.30$ & $\$ 505.10$ & $\$ 571.76$ & $\$ 263.37$ & $\$ 482.13$ & \\
Total Miles & $1,263.6$ & 310.2 & $1,023.3$ & 103.5 & 719.6 & 160.3 & $3,586.5$ \\
\hline
\end{tabular}

Total Overall Average Cost Per Lane Mile $=\$ \mathbf{6 7 5 . 7 6}$ 
TABLE 5

Emulsion Crack Sealing

(Non Interstate Lane Miles)

Lane Miles

District \#

\begin{tabular}{c|ccccccc} 
Year & 10 & 20 & 30 & 40 & 50 & 60 & Total \\
\cline { 1 - 6 } 95 & 718.0 & 817.2 & 543.7 & 505.6 & 866.5 & 786.3 & 4237.3 \\
96 & 638.1 & 790.1 & 413.2 & 503.6 & 933.3 & 839.2 & 4117.5 \\
97 & 644.4 & 8.5 .5 & 377.5 & 450.0 & 940.5 & 682.7 & 3930.6 \\
98 & 654.5 & 854.5 & 359.3 & 494.6 & 767.9 & 761.5 & 3892.3 \\
\hline Subtotals 4 & 2655.0 & 3297.3 & 1693.7 & 4035.5 & 3508.2 & 3069.7 & 16177.7
\end{tabular}

\begin{tabular}{|c|c|c|}
\hline 99(Plan) & 543.0 & 810 \\
\hline Total 5 & 3198.0 & 1107 \\
\hline
\end{tabular}

98 data is thru June

Average lane mile production $=19829.7 / 5=3965.9$

Cost Per Lane Mile

District \#

\begin{tabular}{c|cccccc} 
Year & 10 & 20 & 30 & 40 & 50 & 60 \\
\hline 95 & $\$ 530.92$ & $\$ 477.18$ & $\$ 613.93$ & $\$ 713.48$ & $\$ 271.27$ & $\$ 569.83$ \\
96 & $\$ 461.79$ & $\$ 477.20$ & $\$ 721.74$ & $\$ 630.32$ & $\$ 296.78$ & $\$ 416.15$ \\
97 & $\$ 470.17$ & $\$ 436.15$ & $\$ 882.65$ & $\$ 609.55$ & $\$ 343.45$ & $\$ 470.62$ \\
98 & $\$ 495.16$ & $\$ 498.94$ & $\$ 800.24$ & $\$ 622.30$ & $\$ 294.84$ & $\$ 469.80$
\end{tabular}

Average Cost Per Lane Mile

District \#

\begin{tabular}{ccccccc|c} 
& 10 & 20 & 30 & 40 & 50 & 60 & \multirow{2}{*}{ Total } \\
\cline { 1 - 6 } \$ Per Lane Mile & $\$ 490.75$ & $\$ 464.99$ & $\$ 739.65$ & $\$ 645.03$ & $\$ 302.57$ & $\$ 480.94$ & \\
Total Miles & $2,655.0$ & $3,297.3$ & $1,693.7$ & $1,953.8$ & $3,508.2$ & $3,069.7$ & $16,177.7$ \\
\hline
\end{tabular}

Total Overall Average Cost Per Lane Mile $=\mathbf{\$ 4 8 7 . 5 2}$ 
Table 6

SUBDISTRICT CRACK SEALING COST ESTIMATES

COST OF LABOR, EQUIPMENT AND MATERIALS

\begin{tabular}{|c|c|c|c|c|c|c|c|}
\hline \multicolumn{2}{|l|}{ Subdistricts } & A & B & C & D & $\mathrm{E}$ & $\mathbf{F}$ \\
\hline \multicolumn{2}{|l|}{ Individual } & $\$ 36.45$ & $\$ 54.67$ & $\$ 69.75$ & $\$ 64.50$ & $\$ 61.50$ & $\$ 54.75$ \\
\hline \multirow{10}{*}{\multicolumn{2}{|c|}{ Labor Cost }} & $\$ 43.00$ & $\$ 64.50$ & $\$ 73.50$ & $\$ 65.77$ & $\$ 61.50$ & $\$ 54.75$ \\
\hline & & $\$ 45.85$ & $\$ 65.77$ & $\$ 76.80$ & $\$ 68.77$ & $\$ 69.82$ & $\$ 61.50$ \\
\hline & & $\$ 50.00$ & $\$ 71.68$ & $\$ 76.80$ & $\$ 68.77$ & $\$ 69.82$ & $\$ 61.50$ \\
\hline & & $\$ 50.00$ & $\$ 76.27$ & $\$ 79.72$ & $\$ 69.82$ & $\$ 76.80$ & $\$ 61.50$ \\
\hline & & $\$ 50.85$ & $\$ 76.80$ & $\$ 79.95$ & $\$ 72.60$ & $\$ 76.87$ & $\$ 72.97$ \\
\hline & & $\$ 52.85$ & $\$ 77.77$ & $\$ 82.05$ & $\$ 73.57$ & $\$ 80.85$ & $\$ 81.67$ \\
\hline & & $\$ 54.45$ & $\$ 81.67$ & & $\$ 75.00$ & $\$ 80.85$ & $\$ 81.67$ \\
\hline & & $\$ 56.35$ & $\$ 81.67$ & & $\$ 84.52$ & & $\$ 81.67$ \\
\hline & & & $\$ 81.67$ & & $\$ 84.52$ & & \\
\hline & & & $\$ 81.67$ & & $\$ 85.95$ & & \\
\hline \multirow{2}{*}{\multicolumn{2}{|c|}{$\begin{array}{l}\text { * Labor Cost } \\
\text { With Additive }\end{array}$}} & $\$ 439.80$ & $\$ 814.14$ & $\$ 538.57$ & $\$ 813.79$ & $\$ 578.01$ & $\$ 611.98$ \\
\hline & 1.61 & $\$ 708.08$ & $\$ 1,310.77$ & $\$ 867.10$ & $\$ 1,310.20$ & $\$ 930.60$ & $\$ 985.29$ \\
\hline \multicolumn{8}{|l|}{ Avg. Hourly } \\
\hline \multirow{3}{*}{$\begin{array}{l}\text { Labor Cost } \\
\text { (with Additive) }\end{array}$} & & $\$ 15.74$ & $\$ 15.89$ & $\$ 16.52$ & $\$ 15.88$ & $\$ 15.51$ & $\$ 14.60$ \\
\hline & Equip & Hrs. worked & r Sub & & & & \\
\hline & Per Hour & 5.0 & 7.5 & 7.5 & 7.5 & 7.5 & 7.5 \\
\hline \multirow[t]{3}{*}{ Pickups } & $\$ 1.80$ & $\$ 9.00$ & $\$ 13.50$ & $\$ 13.50$ & $\$ 13.50$ & $\$ 13.50$ & $\$ 13.50$ \\
\hline & & $\$ 9.00$ & $\$ 13.50$ & $\$ 13.50$ & $\$ 13.50$ & $\$ 13.50$ & $\$ 13.50$ \\
\hline & & $\$ 9.00$ & $\$ 13.50$ & & & & \\
\hline \multirow[t]{2}{*}{ S/A Dump } & $\$ 16.63$ & $\$ 83.15$ & $\$ 124.72$ & $\$ 124.72$ & $\$ 124.72$ & $\$ 124.72$ & $\$ 124.72$ \\
\hline & & & & $\$ 124.72$ & $\$ 124.72$ & & \\
\hline T/Ä Dump & $\$ 20.02$ & & $\$ 150.15$ & & $\$ 150.15$ & & \\
\hline Doall & $\$ 19.84$ & $\$ 99.20$ & & & $\$ 148.80$ & $\$ 148.80$ & \\
\hline Trailer & & & $\$ 17.32$ & & & $\$ 17.32$ & \\
\hline Router & $\$ 9.00$ & & $\$ 67.50$ & $\$ 67.50$ & & $\$ 67.50$ & $\$ 67.50$ \\
\hline Compressor " & $\$ 7.85$ & $\$ 39.25$ & $\$ 58.87$ & $\$ 58.87$ & $\$ 58.87$ & $\$ 58.87$ & $\$ 58.87$ \\
\hline \multirow[t]{2}{*}{ Traf. Arrow Brd } & $\$ 4.00$ & & & & $\$ 30.00$ & & \\
\hline & & & & & $\$ 30.00$ & & \\
\hline Double Boiler.' & $\$ 24.41$ & $\$ 122.05$ & $\$ 183.07$ & $\$ 183.07$ & $\$ 183.07$ & $\$ 183.07$ & $\$ 183.07$ \\
\hline \multicolumn{2}{|l|}{ * Equip. Cost } & $\$ 370.65$ & $\$ 642.13$ & $\$ 585.88$ & $\$ 877.33$ & $\$ 627.28$ & $\$ 461.16$ \\
\hline \multirow{2}{*}{\multicolumn{2}{|c|}{$\begin{array}{l}\text { Lbs. Material } \\
\text { Price/LB }\end{array}$}} & 300 & 225 & 200 & 1230 & 850 & 175 \\
\hline & & $\$ 0.19$ & $\$ 0.19$ & $\$ 0.19$ & $\$ 0.19$ & $\$ 0.19$ & $\$ 0.23$ \\
\hline
\end{tabular}




\section{LIST OF REFERENCES}

1) Al-Mansour, Abdullah, Mouaket M., Ibrahim, Sinha C., Kumares, "Evaluation of Cost-Effectiveness of Pavement Surface Maintenance Activities." Joint Highway Research Project, Purdue University Department of Civil Engineering, FHWA/IN/JHRP-90/12

2) Anderson, Douglas I. and Belangie, Michael C. "Crack Sealing Methods and Materials for Flexible Pavements." Report No. FHWA/UT-85/1. Federal Highway Administration, May, 1985.

3) Annual Book of ASTM Standards. Section 4. Philadelphia: American Society for Testing and Materials, 1985.

4) “Asphalt Pavement Repair Manuals of Practice.” SHRP-H-348.

5) Chehovits, Jim, and Manning, Mark. "Materials and Methods for Sealing Cracks in Asphalt Concrete Pavements." Report No. 99. Transportation Research Record.

6) Chong, G.J., "Improved Preventive Maintenance: Sealing Cracks in Flexible Pavements in Cold Regions." Report No. PAV-87-01. Research and Development, Branck, Ontario Ministry of Transportation, December 1987.

7) Chong, G.J., "Rout and Seal Cracks in Flexible Pavement - A Cost effective Preventive maintenance Procedure." Report No. PAV-89-04. Research and Development Brach, Ontario Ministry of Transportation, August 1989.

8) Cook, John P., Minkarah, Issam A., and Weisgerber, Frank E., "Development of a Rational Approach To The Evaluation of Pavement Joint and Crack Sealing Materials.", Department of Civil and Environmental Engineering , University of Cincinnati, August 1991

9) Janish, David W. and Sexton, Jean M., "Crack Sealing Bituminous Pavement In Minnesota.” Braun Intertec Pavement Inc. Report No. 9LRR645, Sponsored By Minnesota Local Road Research Board, January 1992.

10) "Joint Sealing - A Lesson Plan." Report No. ATRA 4620 JNT SLNG. Bureau of Maintenance and Operations, Pennsylvania Department of Transportation, 1987. 
11) Knight, Norman E., "Sealing Cracks in Bituminous Overlays of Rigid Bases." Office of Research and Special Studies, Pennsylvania Department of Transportation, July 1984.

12) Morian, D.A., Epps, J.A. and Gibson, S.D., "Pavement Treatment Effectiveness, 1995 SPS-3 and SPS-4 Site Evaluations, National Report." Nichols Consulting Engineers, Chtd., Sponsored By Office of Engineering Research and Development (FHWA), May 1997.

13) Mozayen, Mozayen, Ponniah, Joseph and Svec Otto., "Laboratory Evaluation of Pavement Crack Routing And Sealing Preventive Maintenance." TRB Paper No. 950875.

14) Panniah, Joseph., "Crack Sealing In Flexible Pavements: A Life-Cycle Cost Analysis." TRB Paper No. 950763.

15) "Pavement and Shoulder Maintenance Performance Guides." Report No. FHWA-TS-84-208. Federal Highway Administration, August 1984.

16) Rutkowski, Terry S. "Evaluation of Asphaltic Concrete Crack Sealing." Report No. WI-08-96, Wisconsin Department of Transportation, Pavement Research Unit, January 1998.

17) Sampson, John M., "Transverse Crack maintenance Strategies for AC Pavements." Task Force Report. Minnesota Department of transportation, December, 1988.

18) Shober, Stephen F., P.E. "The Great Unsealing." Wisconsin Department of Transportation, April 1997

19) Spells, Sherwood., and Klosowski, Jerry M., "The Importance of Sealant Modulus to the Long-Term Performance of concrete Highway Joint Sealants." Transportation Research Record No. 1041, 1985, pp. 82-86.

20) Sudol, Joseph., “An Evaluation of Polymer Modified AE-150SC and Fiber Pave 5010 Cracks Sealers." Division of Research, Indiana Department of Transportation, February 1987.

21) Turgeon, Curtis M., "Evaluation of Materials and Methods for Bituminous Pavement Crack Sealing and Filling." Office of Materials and Research, Minnesota Department of Transportation, December 1989.

22) Ward, David R., "Evaluation Of Crack Sealant Performance On Indiana's Asphalt Concrete Surfaced Pavements.” Indiana Department, HPR-2016, October 1993 
23) Weisgerber, Frank E. and Minharah, Issam A. "Adhesion Of Crack And Joint Sealants." TRB Paper No. 890583.

24) "Value Engineering Study of Crack and Joint Sealing." Report No. FHWA-TS-84-221. Federal Highway Administration, December, 1984.

25) "Value Engineering Study of The Repair of Transverse Cracking in Asphalt Concrete Pavements.” Report No. FHWA-TS-89-010. Federal Highway Administration, May, 1990.

26) Zimmer, Thomas R., Carpenter, Samuel H. and Darter, Michael I., "Field Performance of a Low-Modulus Silicone Highway Joint Sealant." Transportation Research Record No. 990, 1984, pp 31-37. 
Appendix A 


\section{OIL JACKETED MELTER PURCHASE INFORMATION}

OIL JACKETED MELTER (INDOT LISTING)

PURCHASED ON PO\# 93023965

COMMISSION \# 64798 PURCHASED ON PO\# 95024156

COMMISSION \# 59217 PURCHASED ON PO\# 94023857
Wednesday, April 07, 1999

\begin{tabular}{|c|c|c|c|c|c|c|c|}
\hline \multirow[b]{2}{*}{ DISTRICT } & \multirow[b]{2}{*}{ COMM. \# } & \multirow[b]{2}{*}{$\mathbf{S} / \mathbf{N}$} & \multirow[b]{2}{*}{ MAINT LOCATION } & \multirow[b]{2}{*}{ PUR. DATE } & \multicolumn{3}{|c|}{ Information gathered from INDOT "MCMS" system. } \\
\hline & & & & & PUR AMOUNT & BOOK VALUE & STATUS \\
\hline DISTRICT 10 & 58726 & 9306039 & 199 & $7 / 19 / 93$ & $\$ 17,595.00$ & \$t $0,072.72$ & RETIRED \\
\hline DISTRICT 20 & 58727 & 9306041 & $2 \mathrm{MN}$ & $8 / 3 / 93$ & $\$ 17,595.00$ & $\$ 10,072.72$ & ACTIVE \\
\hline DISTRICT 30 & 58728 & 9306044 & $30 \mathrm{~S}$ & $9 / 24 / 93$ & $\$ 17,595.00$ & $\$ 10,724,00$ & $\overline{\text { ACTIVE }}$ \\
\hline DISTRICT 40 & 64798 & 9505058 & 430 & $10 / 9 / 95$ & $\$ 17,165.00$ & $\$ 13,045.32$ & ACTIVE \\
\hline DISTRICT 40 & 58730 & 9306042 & 450 & $8 / 19 / 93$ & $\$ 17,595.00$ & $\$ 10,204.69$ & ACTive \\
\hline DISTRICT 40 & $\overline{58729}$ & 9306043 & $4 \mathrm{MN}$ & $8 / 19 / 93$ & $\$ \overline{17,595.00}$ & $\$ 10,204.69$ & $\overline{\text { ACTIVE }}$ \\
\hline DISTRICT 50 & 59217 & SOKJ25063LP & & $6 / 14 / 94$ & $\$ 18,279.00$ & $\$ 11,698.68$ & ACTIVE \\
\hline DISTRICT 60 & 58731 & 9306040 & $6 \mathrm{MN}$ & $10 / 4 / 93$ & $\$ 17,595.00$ & $\$ \$ \$ 10,336.66$ & ACTIVE \\
\hline
\end{tabular}

$$
\text { COUNT } 8
$$

PURCHASE TOTAL \$141,014,00 


\section{MAINTENANCE DATA REPORT ON OIL JACKETED MELTERS PURCHASED FROM \#1 VENDOR}

Wednesday, April 07, 1999

Information gathered from INDOT "MCMS" system.

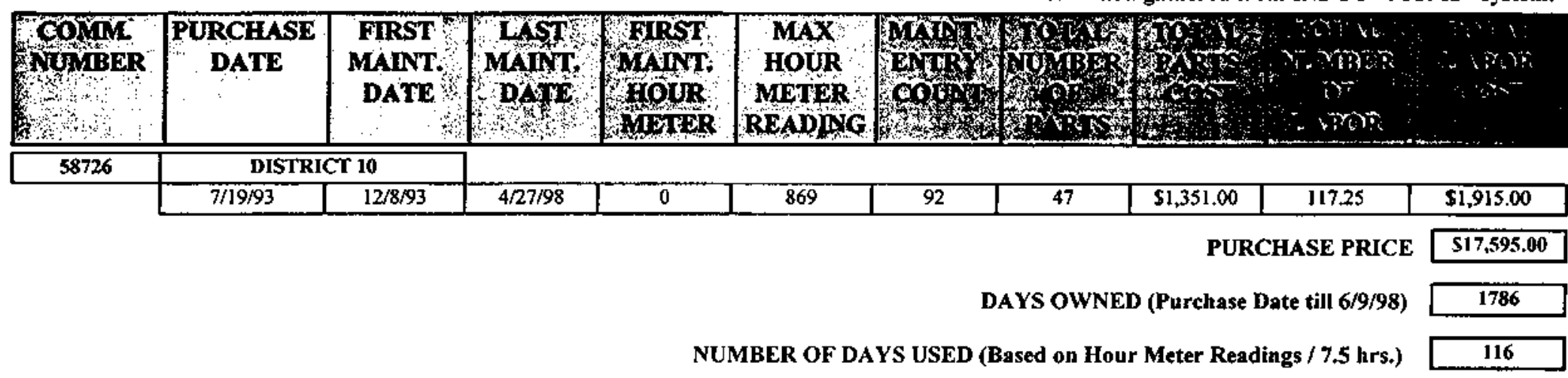

NOTE: If answer is "0", the unit did not have an hour meter from which to get the readings.

AVERAGE NUMBER OF DAYS BETWEEN MAINTENANCE CALLS

TOTAL MAINTENANCE COST (Parts and Labor)

19

LABOR COST PER HOUR

AVERAGE COST PER PART 


\section{MAINTENANCE DATA REPORT ON OIL JACKETED MELTERS PURCHASED FROM \#1 VENDOR}

Wednesday, April 07, 1999

Information gathered from INDOT "MCMS" system.

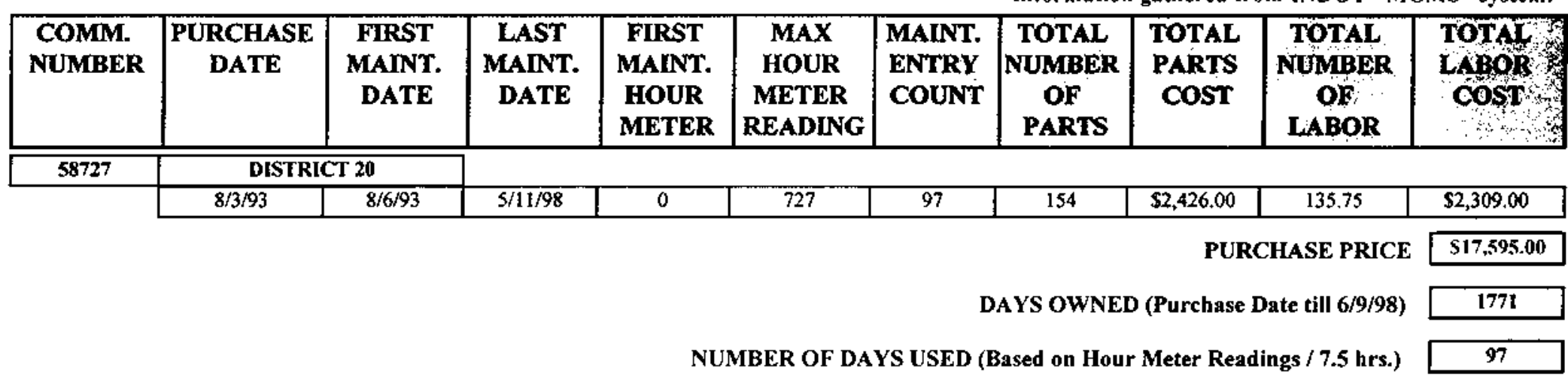

NOTE: If answer is " 0 ", the unit did not have an hour meter from which to get the readings.

AVERAGE NUMBER OF DAYS BETWEEN MAINTENANCE CALLS

TOTAL MAINTENANCE COST (Parts and Labor)

18

LABOR COST PER HOUR

AVERAGE COST PER PART

$\$ 4,735,00$

\$17.01

$\$ 15.75$

NOTES 


\section{MAINTENANCE DATA REPORT ON OIL JACKETED MELTERS PURCHASED FROM \#1 VENDOR}

Wednesday, April 07, 1999

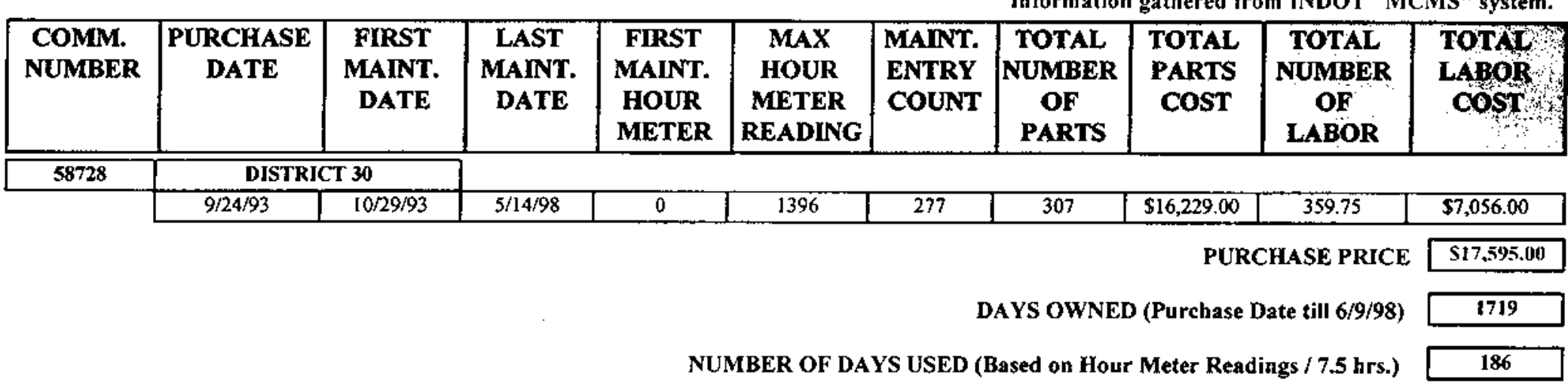

NOTE: If answer is " 0 ", the unit did not have an hour meter from which to get the readings.

AVERAGE NUMBER OF DAYS BETWEEN MAINTENANCE CALLS

TOTAL MAINTENANCE COST (Parts and Labor)

6

LABOR COST PER HOUR

$\$ 23,285.00$

AVERAGE COST PER PART

$\$ 19.61$

NOTES Based on overall maintenance cost, number of parts purchased, and number of labor hours;

this unit had the worst maintenance history. 


\section{MAINTENANCE DATA REPORT ON OIL JACKETED MELTERS PURCHASED FROM \#1 VENDOR}

Wednesday, April 07, 1999

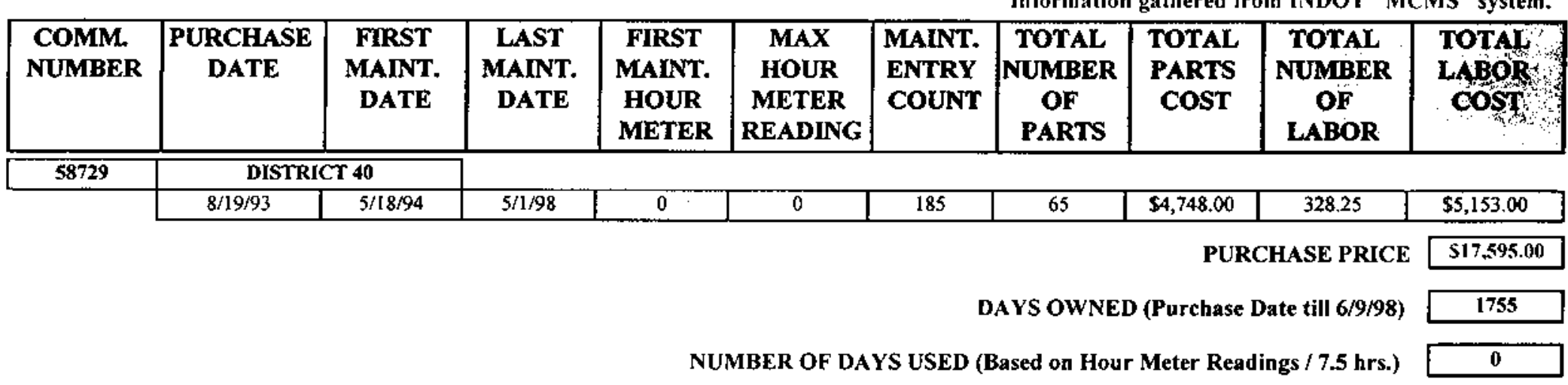

NOrE: If answer is " 0 ", the unit did not have an hour meter from which to get the readings.

AVERAGE NUMBER OF DAYS BETWEEN MAINTENANCE CALLS

TOTAL MAINTENANCE COST (Parts and Labor)

9

LABOR COST PER HOUR

AVERAGE COST PER PART

$\$ 15.70$

$\$ 73.05$

NOTES This unit did not have an Hour Meter. 


\section{MAINTENANCE DATA REPORT ON OIL JACKETED MELTERS PURCHASED FROM \#1 VENDOR}

Wednesday, April 07, 1999

Information gathered from INDOT "MCMS" system.

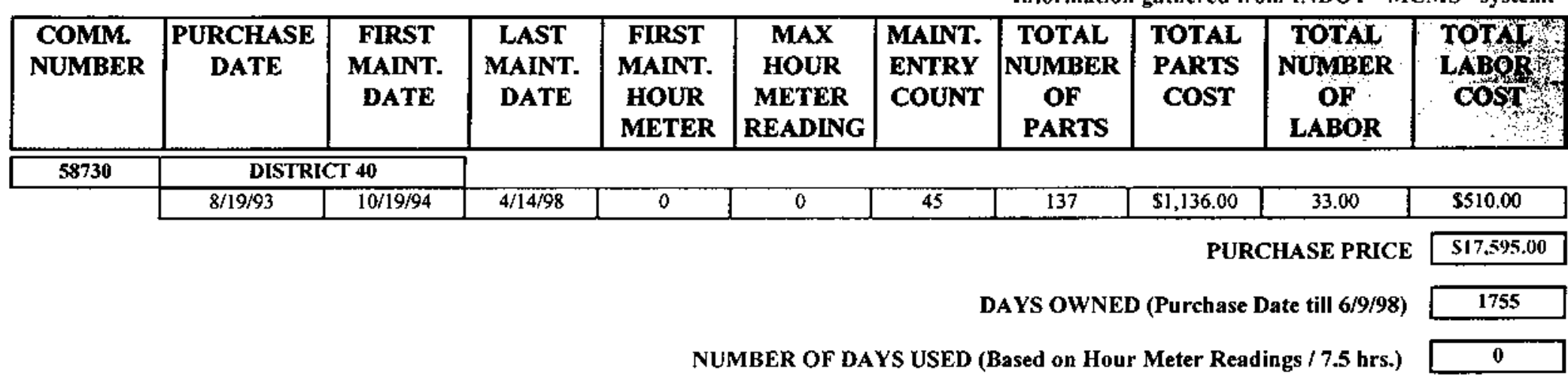

NOTE: If answer is " 0 ", the unit did not have an hour meter from which to get the readings.

AVERAGE NUMBER OF DAYS BETWEEN MAINTENANCE CALLS

TOtal MaINTENanCE COST (Parts and Labor)

LABOR COST PER HOUR

AVERAGE COST PER PART

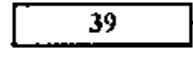

$\$ 1,6+6.00$

$\$ 15.45$

NOTES This unit did not have an Hour Meter. 


\section{MAINTENANCE DATA REPORT ON OIL JACKETED MELTERS PURCHASED FROM \#1 VENDOR}

Wednesday, April 07, 1999

Information gathered from INDOT "MCMS" system.

\begin{tabular}{|c|c|c|c|c|c|c|c|c|c|c|}
\hline $\begin{array}{l}\text { COMM. } \\
\text { NUMBER }\end{array}$ & $\begin{array}{c}\text { PURCKASE } \\
\text { DATE }\end{array}$ & $\begin{array}{c}\text { FIRST } \\
\text { MAINT. } \\
\text { DATE }\end{array}$ & $\begin{array}{c}\text { LAST } \\
\text { MAINT. } \\
\text { DATE }\end{array}$ & $\begin{array}{c}\text { FIRST } \\
\text { MAINT. } \\
\text { HOUR } \\
\text { METER }\end{array}$ & \begin{tabular}{|c|} 
MAX \\
HOUR \\
ME'TER \\
READING
\end{tabular} & $\begin{array}{l}\text { MAINT. } \\
\text { ENTRY } \\
\text { COUNT }\end{array}$ & $\begin{array}{c}\text { TOTAL } \\
\text { NUMBER } \\
\text { OF } \\
\text { PARTS }\end{array}$ & $\begin{array}{l}\text { TOTAL } \\
\text { PARTS } \\
\text { COST }\end{array}$ & $\begin{array}{c}\text { TOTAL } \\
\text { NUMBER } \\
\text { OF } \\
\text { LABOR }\end{array}$ & $\begin{array}{c}\text { TOTAL } \\
\text { LABOR } \\
\text { COST }\end{array}$ \\
\hline 58731 & \multicolumn{2}{|c|}{ DISTRICT 60 } & & & & & & & & \\
\hline & $10 / 4 / 93$ & $1 / 12 / 94$ & $5 / 7 / 98$ & 0 & 513 & 80 & 54 & $\$ 913.00$ & 93.50 & $\$ 1,527.00$ \\
\hline
\end{tabular}

PURCHASE PRICE $\$ 17,595.00$

DAYS OWNED (Purchase Date till 6/9/98)

NUMBER OF DAYS USED (Based on Hour Meter Readings / 7.5 hrs.)

1709

NOTE: If answer is " 0 ", the unit did not have an hour meter from which to get the readings.

AVERAGE NUMBER OF DAYS BETWEEN MAINTENANCE CALLS

TOTAL MAINTENANCE COST (Parts and Labor)

LABOR COST PER HOUR

$52,400,00$

AVERAGE COST PER PART

$\$ 16.33$

$\$ 16.91$

NOTES 


\section{MAINTENANCE DATA REPORT ON OIL JACKETED MELTERS PURCHASED FROM \#1 VENDOR}

Wednesday, April 07, 1999

Information gathered from INDOT "MCMS" system.

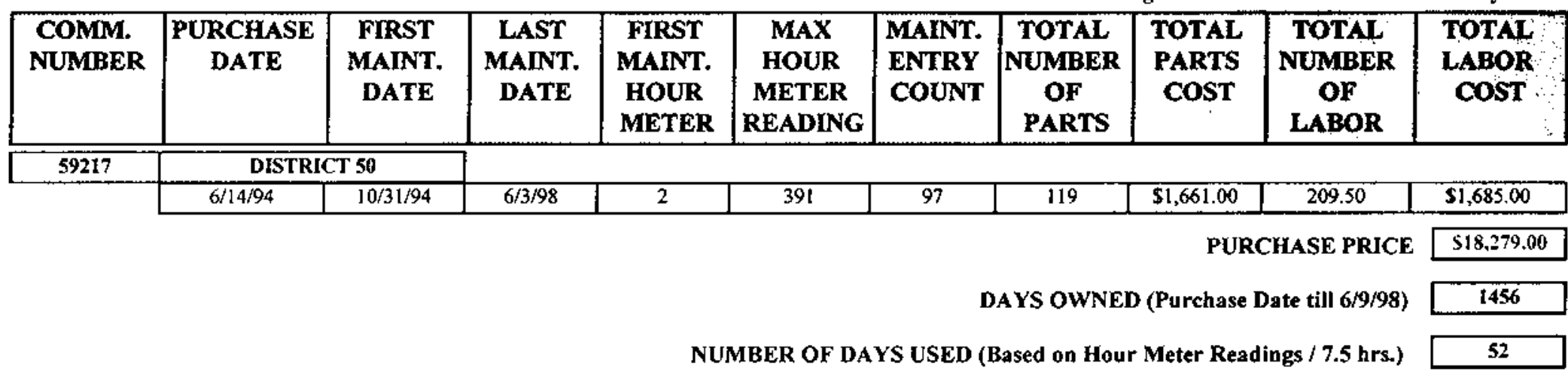

NOTE: If answer is " 0 ", the unit did not have an hour meter from which to get the readings.

AVERAGE NUMBER OF DAYS BETWEEN MAINTENANCE CALLS

TOTAL MAINTENANCE COST (Parts and Labor)

LABOR COST PER HOUR

AVERAGE COST PER PART

$\$ 3,346.00$

$\$ 8.04$

$\$ 13.96$

NOTES This unit is, overall, a well made unit. Maintenance problems stem from untrained crews using it incorrectly, thereby breaking it (Maintenance Foreman Statement). 


\section{MAINTENANCE DATA REPORT ON OIL JACKETED MELTERS PURCHASED FROM \#1 VENDOR}

Wednesday, April 07, 1999

Information gathered from INDOT "MCMS" system.

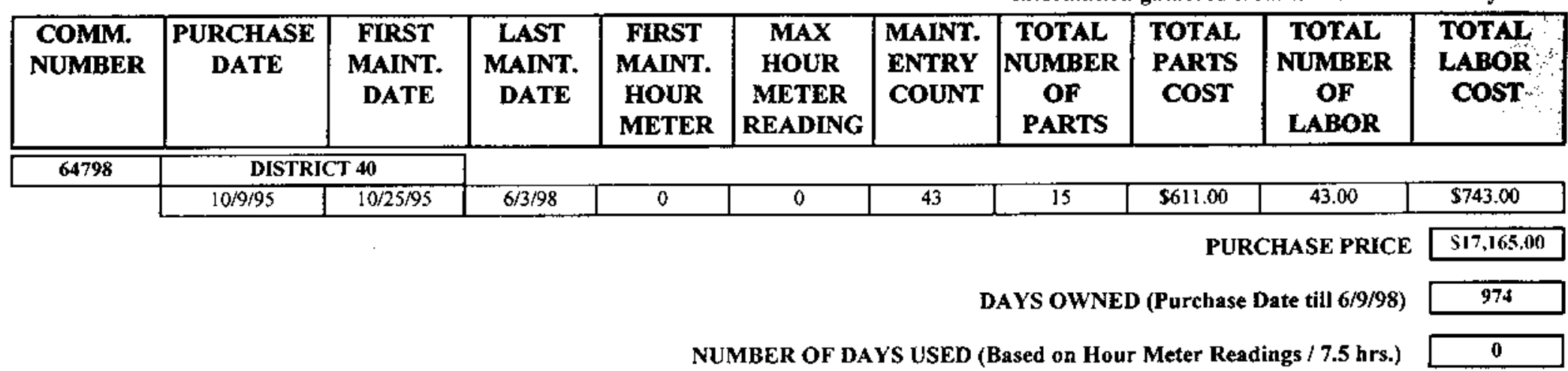

NOTE: If answer is "0", the unit did not have an hour meter from which to get the readings.

AVERAGE NUMBER OF DAYS BETWEEN MAINTENANCE CALLS

23

TOtal MaintenanCE Cost (Parts and Labor)

$\$ 1.354 .00$

LABOR COST PER HOUR

$\$ 17.28$

AVERAGE COST PER PART

$\$ 40.73$

NOTES The reason this unit did better than the others, is that the sub-district dedicated the "same" crew to operate it each time and th is crew was fully trained and also "use to" this unit. Other sub-districts used whatever crew was available. This unit did not have an Hour Meter. 


\section{MAINTENANCE DATA REPORT ON OIL JACKETED MELTERS PURCHASED FROM \#1 VENDOR}

Wednesday, April 07, 1999

Information gathered from INDOT "MCMS" system.

\begin{tabular}{|c|c|c|c|c|c|c|c|c|c|c|}
\hline $\begin{array}{l}\text { COMM. } \\
\text { NUMBER }\end{array}$ & $\begin{array}{c}\text { PURCHASE } \\
\text { DATE }\end{array}$ & $\begin{array}{c}\text { FIRST } \\
\text { MAINT. } \\
\text { DATE }\end{array}$ & $\begin{array}{c}\text { LAST } \\
\text { MAINT. } \\
\text { DATE }\end{array}$ & $\begin{array}{c}\text { FIRST } \\
\text { MAINT. } \\
\text { HOUR } \\
\text { METER }\end{array}$ & $\begin{array}{c}\text { MAX } \\
\text { HOUR } \\
\text { METER } \\
\text { READING }\end{array}$ & $\begin{array}{l}\text { MAINT. } \\
\text { ENTRY } \\
\text { COUNT }\end{array}$ & $\begin{array}{c}\text { TOTAL } \\
\text { NUMBER } \\
\text { OF } \\
\text { PARTS }\end{array}$ & $\begin{array}{l}\text { TOTAL } \\
\text { PARTS } \\
\text { COST }\end{array}$ & $\begin{array}{c}\text { TOTAL } \\
\text { NUMBER } \\
\text { OF : } \\
\text { LABOR }\end{array}$ & $\begin{array}{c}\text { TOTAL } \\
\text { LABOA } \\
\text { COST }\end{array}$ \\
\hline
\end{tabular}

\section{MAINTENANCE GRAND TOTALS}

\begin{tabular}{|c|c|}
\hline TOTAL PURCHASE PRICE & $\$ 141,014.00$ \\
\hline TOTAL NUMBER OF MAINTENANCE ENTRIES IN "MCMS" FOR ALL 7 UNITS & 916 \\
\hline TOTAL NUMBER OF LABOR HOURS & 1320 \\
\hline TOTAL LABOR COST FOR ALL 7 UNITS & $\$ 20,898.00$ \\
\hline TOTAL NUMBER OF PARTS PURCHASED & 898 \\
\hline TOTAL PARTS COST FOR ALL 7 UNITS & $\$ 29.075 .00$ \\
\hline RAND TOTAL FOR MAINTENANCE COST ON ALL 7 UNITS & $\$ 49,973.00$ \\
\hline
\end{tabular}


Indiana Department of Transportation Oil Jacketed Melter Data

\begin{tabular}{|c|c|c|c|c|c|c|c|c|c|c|}
\hline & District 10 & District 20 & District 30 & District 40 & District 40 & District 40 & District 50 & District 60 & Totals & Avolos \\
\hline 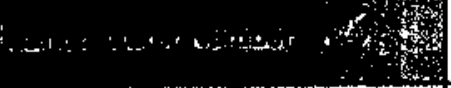 & 1 & 1 & 1 & 1 & 1 & 1 & 2 & 1 & & 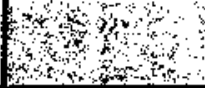 \\
\hline 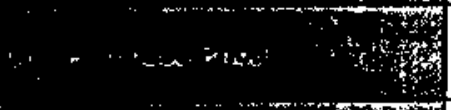 & $\$ 17,595.00$ & $\$ 17, \$ 95.00$ & $\$ 17,595.00$ & $\$ 17,595.00$ & $\$ 17,595.00$ & $\$ 17,165.00$ & $\$ 18,279.00$ & $\$ 17,595.00$. & $\$ 141,014,00$ & 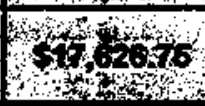 \\
\hline$\ldots$ & $7 / 19 / 93$ & $8 / 3 / 93$ & $9 / 24 / 93$ & $8 / 19 / 93$ & $8 / 19 / 93$ & $10 / 9 / 95$ & $6 / 14 / 94$ & $10 / 4 / 93$ & & 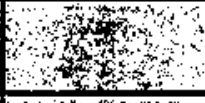 \\
\hline$\cdots \quad \ldots$ & 58726 & 58727 & 58728 & 58729 & 58730 & 64798 & 59217 & 58731 & . & 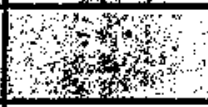 \\
\hline$\therefore \quad \therefore$ & 1786 & 1771 & 1719 & 1755 & 1755 & 974 & 1456 & 1709 & 12925 & 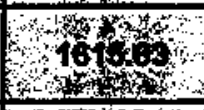 \\
\hline (1) & 116 & 97 & 186 & No Meter & No Meter & No Meter & 52 & 68 & 819 & xtots \\
\hline$\therefore \quad \cdots \quad \cdots \quad \therefore \quad \cdots$ & 869 & 727 & 1396 & No Meter & No Meter & No Meter & 391 & 513 & 3896 & 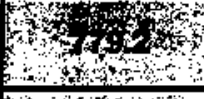 \\
\hline $\begin{array}{rr}1 \\
\cdots\end{array}$ & $4 / 27 / 98$ & $5 / 11 / 98$ & $5 / 14 / 98$ & $5 / 1 / 98$ & $4 / 14 / 98$ & $6 / 3 / 98$ & $6 / 3 / 98$ & $5 / 7 / 98$ & - & 28 \\
\hline$\therefore$. $\quad \therefore$. & 92 & 97 & 277 & 185 & 45 & 43 & 97 & 80 & 916 & of \\
\hline kt. & 19 & 18 & 6 & 9 & 39 & 23 & 15 & 21 & & 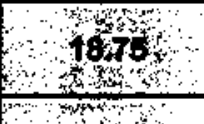 \\
\hline$\therefore \quad \cdots$ & 47 & 154 & 307 & 65 & 137 & 15 & 119 & 54 & 898 & 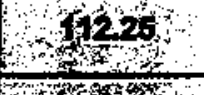 \\
\hline$\therefore \quad \cdots \quad c$ & $\$ 1,351.00$ & $\$ 2,426.00$ & $\$ 16,229.00$ & $\$ 4,748.00$ & $\$ 1,136,00$ & $\$ 611.00$ & $\$ 1,661.00$ & $\$ 913.00$ & $\$ 29,075.00$ & oforys \\
\hline$\therefore \quad \therefore \quad \therefore \quad \ldots$ & 117.25 & 135.75 & 359.75 & 328.25 & 33 & 43 & 209.5 & 93.5 & 1320 & 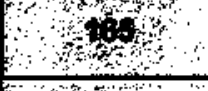 \\
\hline$\therefore \quad \ddots \quad \quad 4 \quad, \because 4$ & $\$ 1,915.00$ & $\$ 2,309,00$ & $\$ 7,056.00$ & $\$ 5,153.00$ & $\$ 510.00$ & $\$ 743.00$ & $\$ 1.685 .00$ & $\$ 1,527.00$ & $\$ 20,898.00$ & $\$ 26,2,25$ \\
\hline$\because \quad, \quad \cdots$ & $\$ 3,266,00$ & $\$ 4,735.00$ & $\$ 23,285.00$ & $\$ 9,901,00$ & $\$ 1,646,00$ & $\$ 1,354.00$ & $\$ 3,346.00$ & $\$ 2,440.00$ & $\$ 49,973.00$ & $\$ 6,803$ \\
\hline$\therefore \begin{array}{ccccc} & \cdots & 0\end{array}$ & 15.63 & 18.10 & 47.97 & 43.77 & 4.40 & 5.73 & 27.93 & 12.47 & 176.00 & 200 \\
\hline 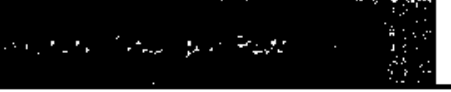 & $\$ 28.74$ & $\$ 15.75$ & $\$ 52.86$ & $\$ 73.05$ & $\$ 8.29$ & $\$ 40.73$ & $\$ 13.96$ & $\$ 16.91$ & & \% \\
\hline
\end{tabular}




\section{Indiana Department of Transportation Oil Jacketed Melter Data}

\begin{tabular}{|c|c|c|c|c|c|c|c|c|c|c|}
\hline 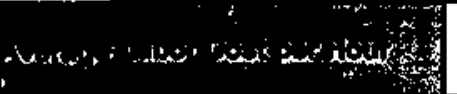 & $\$ 16.33$ & $\$ 17.01$ & $\$ 19.61$ & $\$ 15.70$ & $\$ 15.45$ & $\$ 17.28$ & $\$ 8.04$ & $\$ 16.33$ & & 795.72: \\
\hline 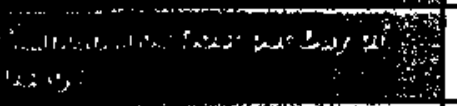 & $\$ 28.16$ & $\$ 48.81$ & $\$ 125.19$ & & & & $\$ 64.35$ & $\$ 35.88$ & & \\
\hline 年 & $\$ 7.06$ & $\$ 18.63$ & $\$ 43.05$ & $\$ 26.95$ & & & $\$ 56.05$ & $\$ 27.14$ & & \\
\hline 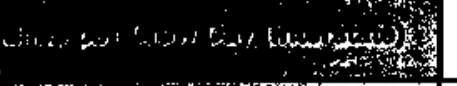 & 4.5 & 2.27 & 1.9 & & & & 3.6 & 1.2 & 13.47 & 269 \\
\hline 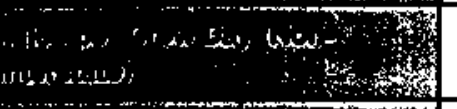 & 1.2 & 2.3 & 2.3 & 1.8 & & & 4.2 & 1.8 & 13.6 & $2 \pi$ \\
\hline 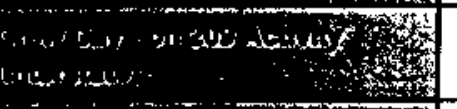 & 83.8 & 37.4 & 82.3 & & & & 14.5 & 2.7 & 220.7 & 444 \\
\hline 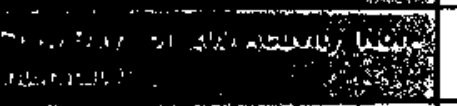 & 71.3 & 73.7 & 167.2 & 204.1 & & & 1.8 & 48.2 & 566.3 & \\
\hline 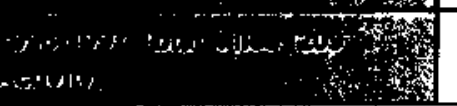 & 462.9 & 254.1 & 540.9 & 367.4 & & & 59.7 & 89.9 & 1774.9 & 2964 \\
\hline & & & & \multicolumn{3}{|c|}{$\begin{array}{c}\text { Information for all } 3 \text { District } 40 \text { melters } \\
\text { is combined into one (in last section } \\
\text { only). }\end{array}$} & & & & \\
\hline
\end{tabular}

\begin{tabular}{|c|c|c|}
\hline $\begin{array}{l}\text { Percentage: Malnt. Cost to } \\
\text { Purchases Price }\end{array}$ & $35.44 \%$ & \\
\hline $\begin{array}{l}\text { Percentage: Days Used to Days } \\
\text { Owned }\end{array}$ & $4.02 \%$ & \\
\hline $\begin{array}{l}\text { Wutinterpance Cost per Day of } \\
\text { Usege }\end{array}$ & $\$ 60.18$ & NOTE: This is assuming the average of 103.8 usage days for each of the 3 Non-Metered units. \\
\hline $\begin{array}{l}\text { Waintorance Cost per Mile of } \\
200 \text { Activity }\end{array}$ & $\$ 28.16$ & \\
\hline
\end{tabular}




\section{Crew Days on 209 Activity (Hot Pour Crack Sealing) Using Oil}

Jacketed Melters

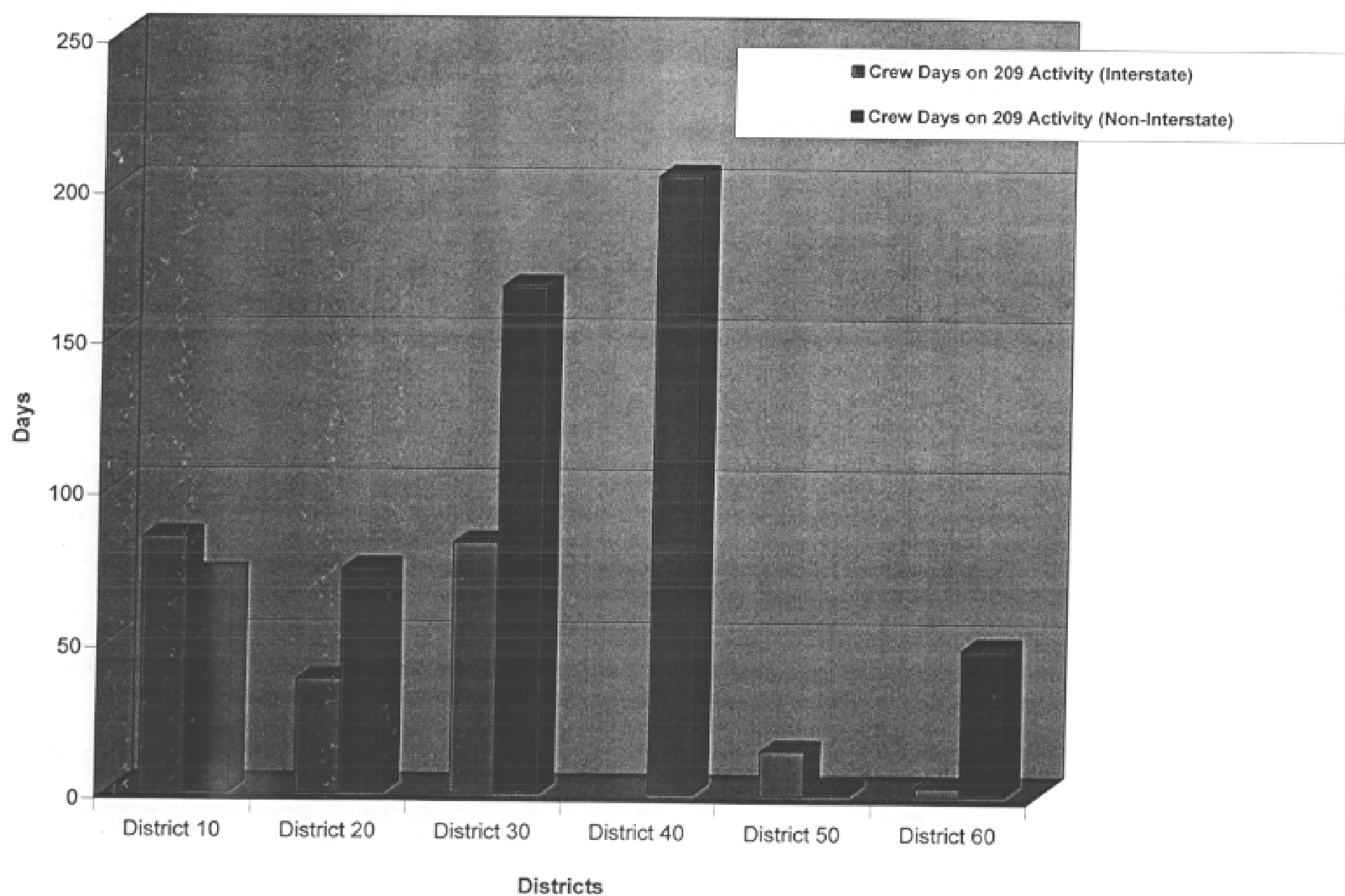


1995-1997 Total Miles 209 Activity (Hot Pour Crack Sealing)

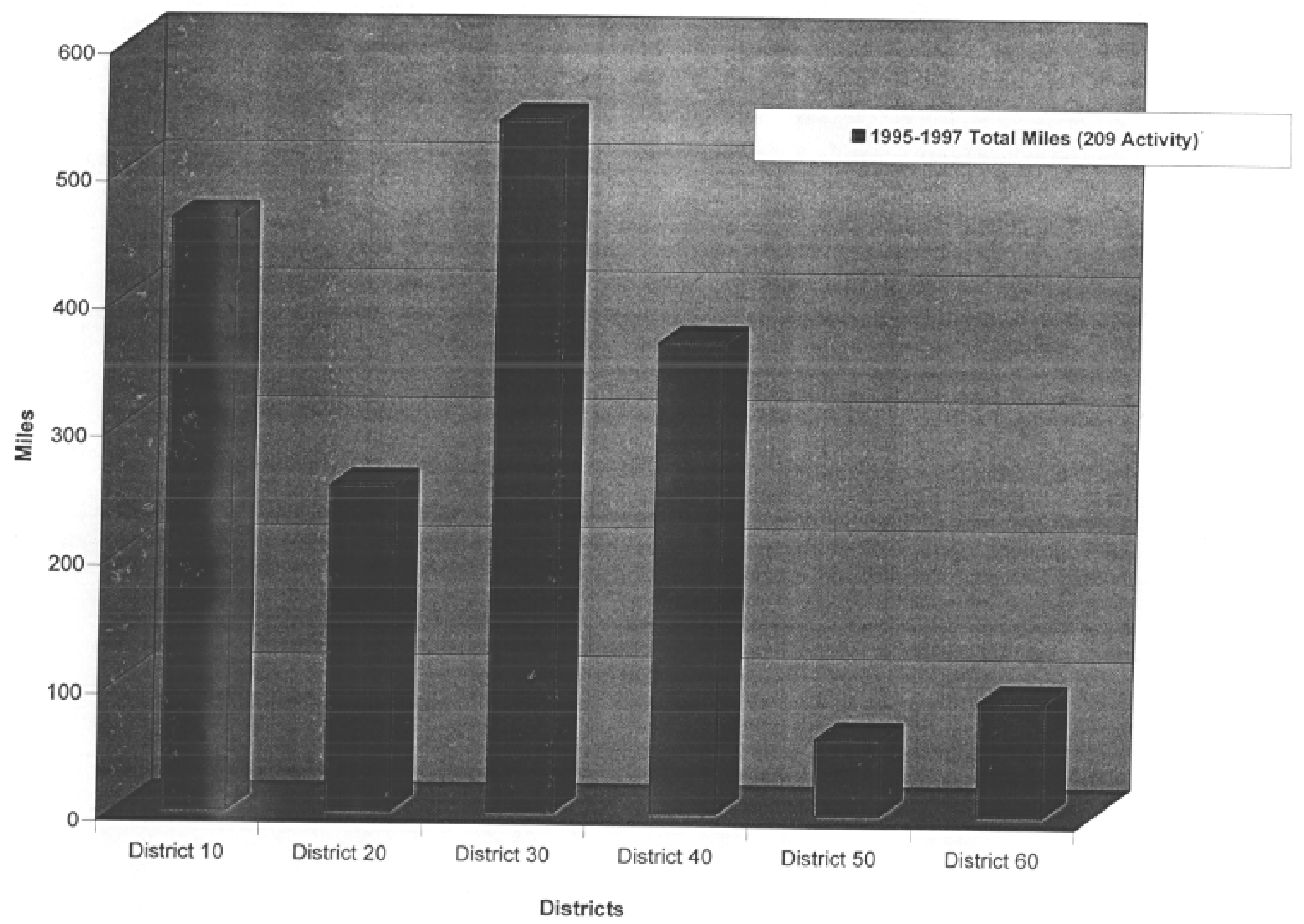


Miles Per Crew Day Using Hot Pour Melters (Interstate and NonInterstate)

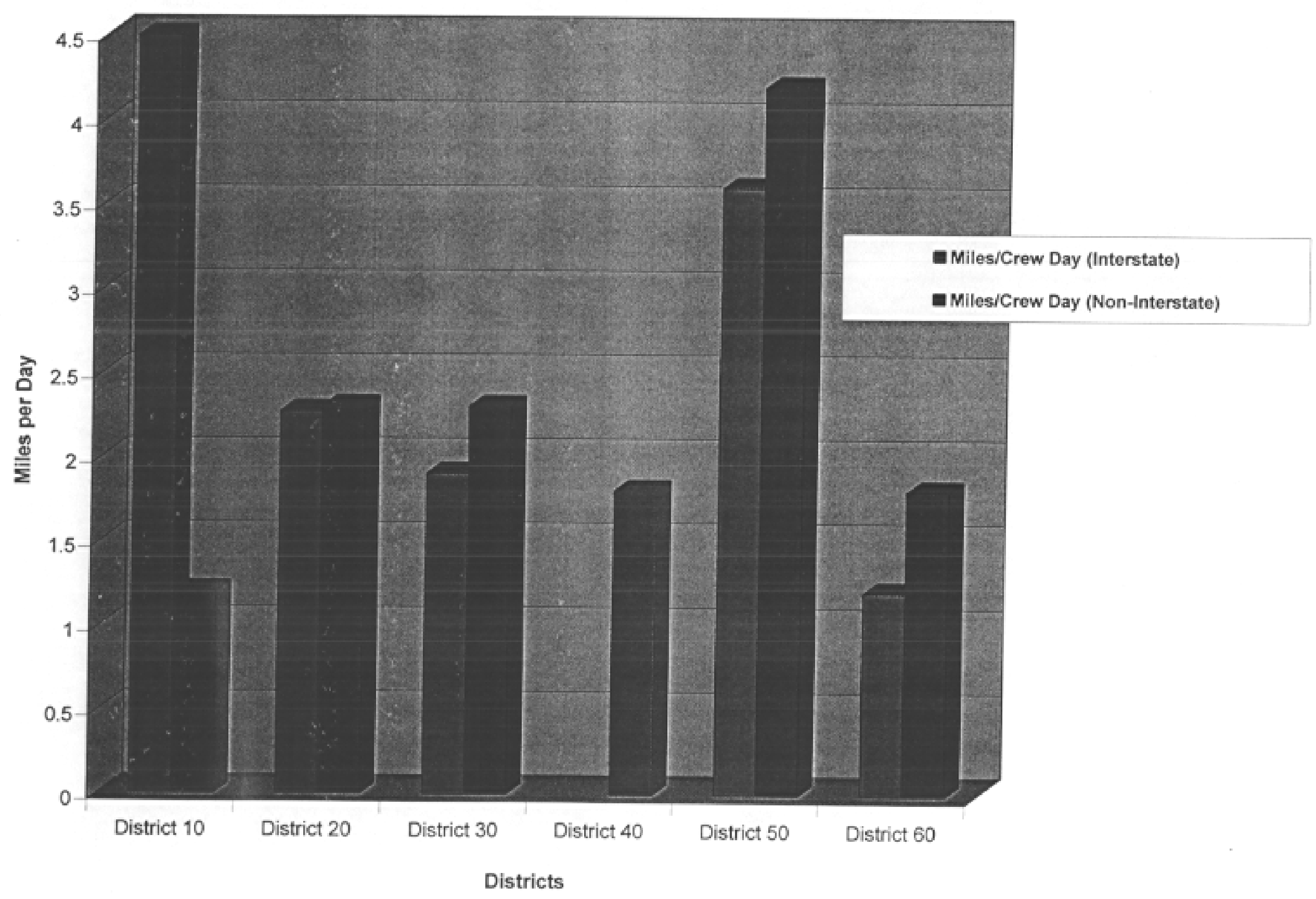


Number of Maintenance Entries, Parts, and Labor Hours (for Oil Jacketed Melters)

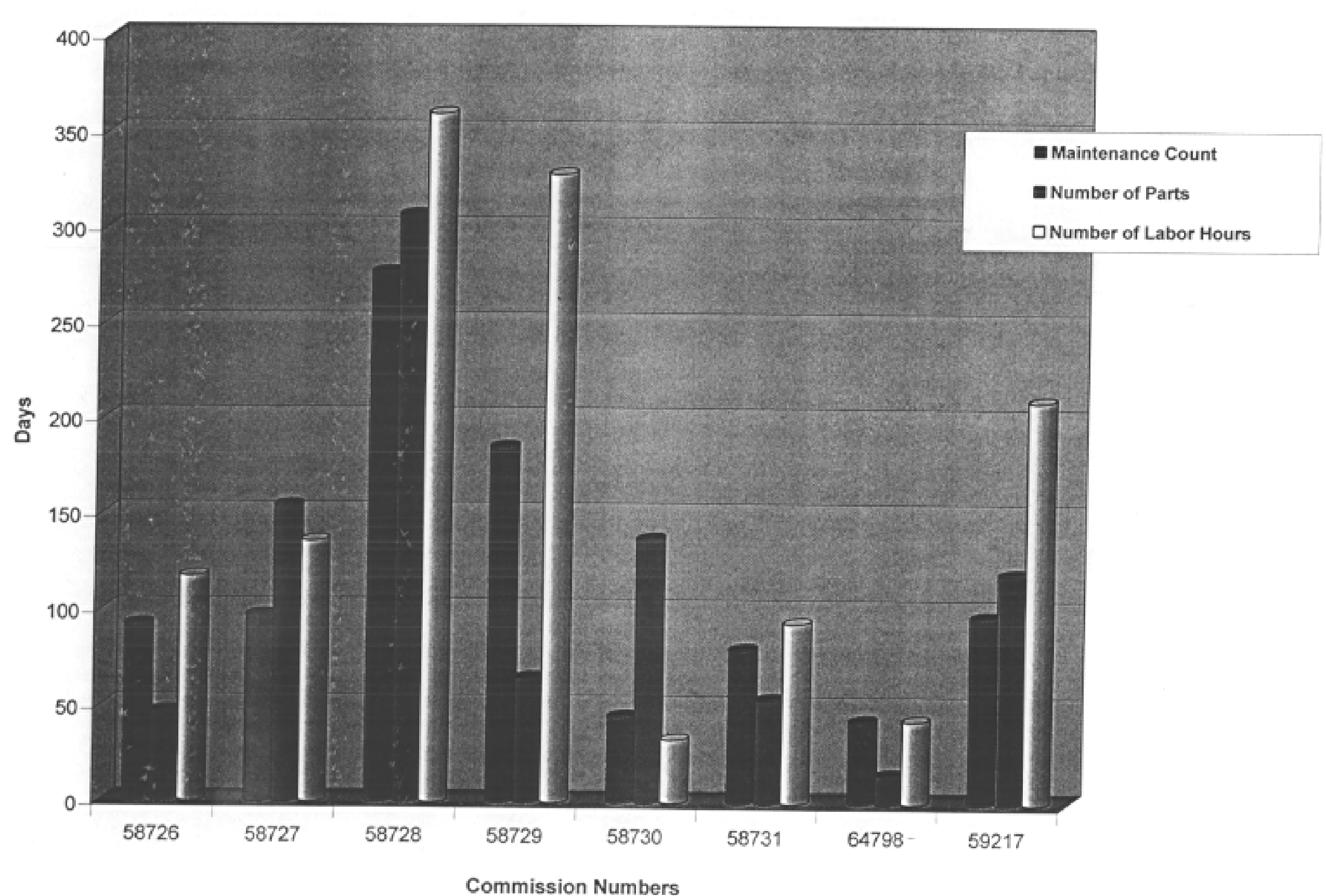




\section{Purchase Cost and Maintenance Cost of Oil Jacketed Melters}

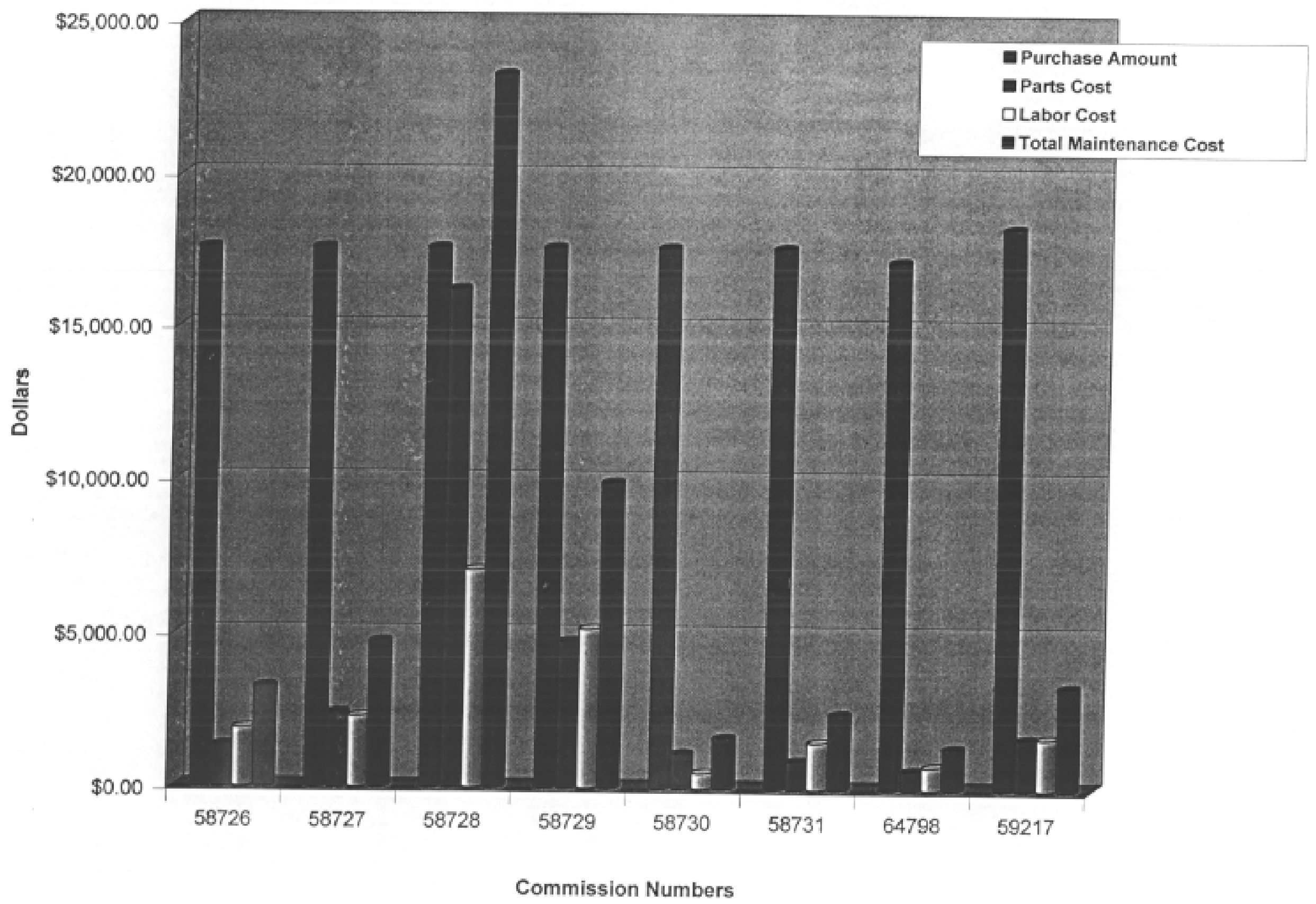


Comparison Between Number of Days Ownership and Number of Days Used (Oil Jacketed Melters)

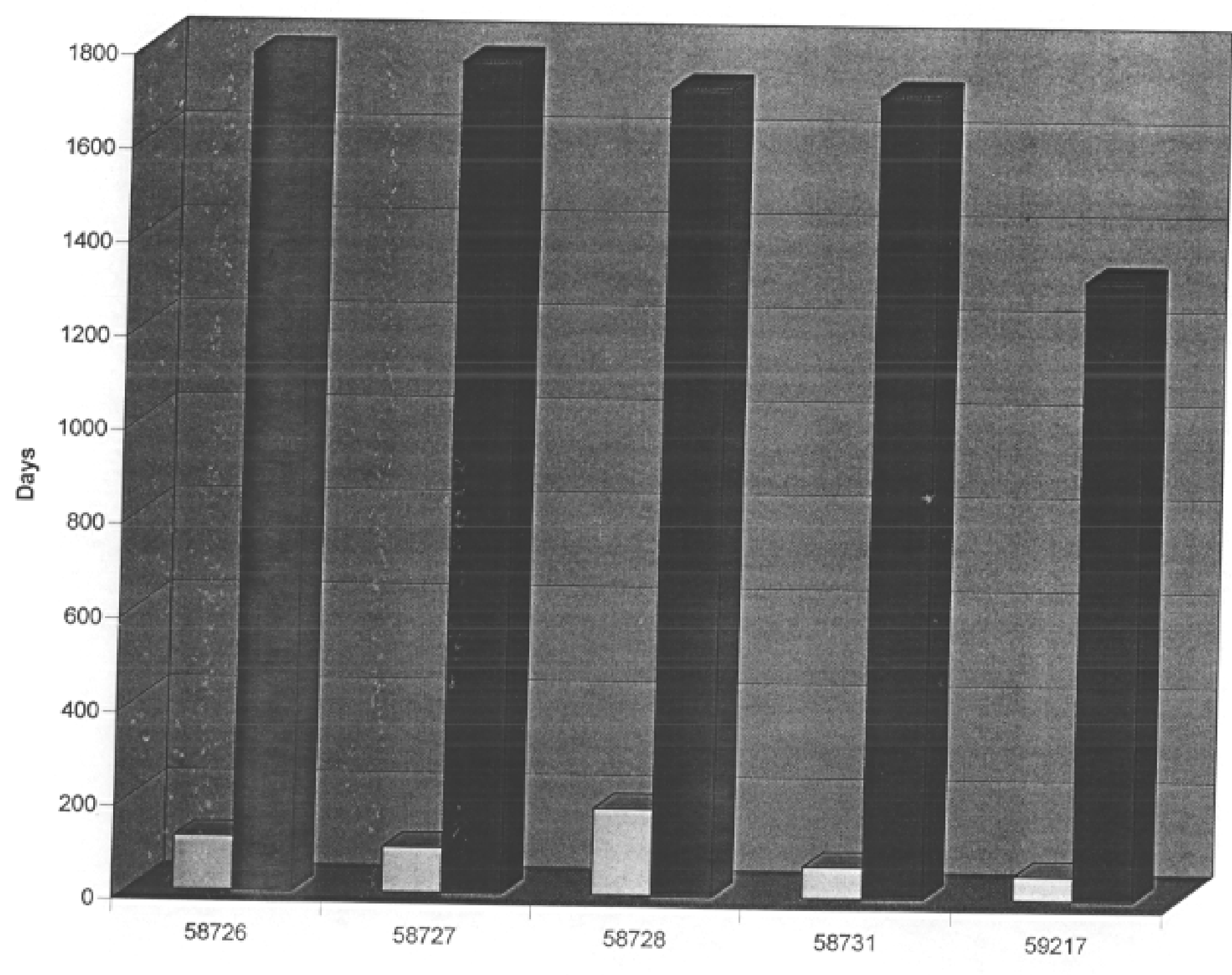

$\square$ Number of Days Usage

number of Days Ownership

Commission Numbers 


\section{OUT-OF-STATE CRACK SEALING SURVEY REPORT}

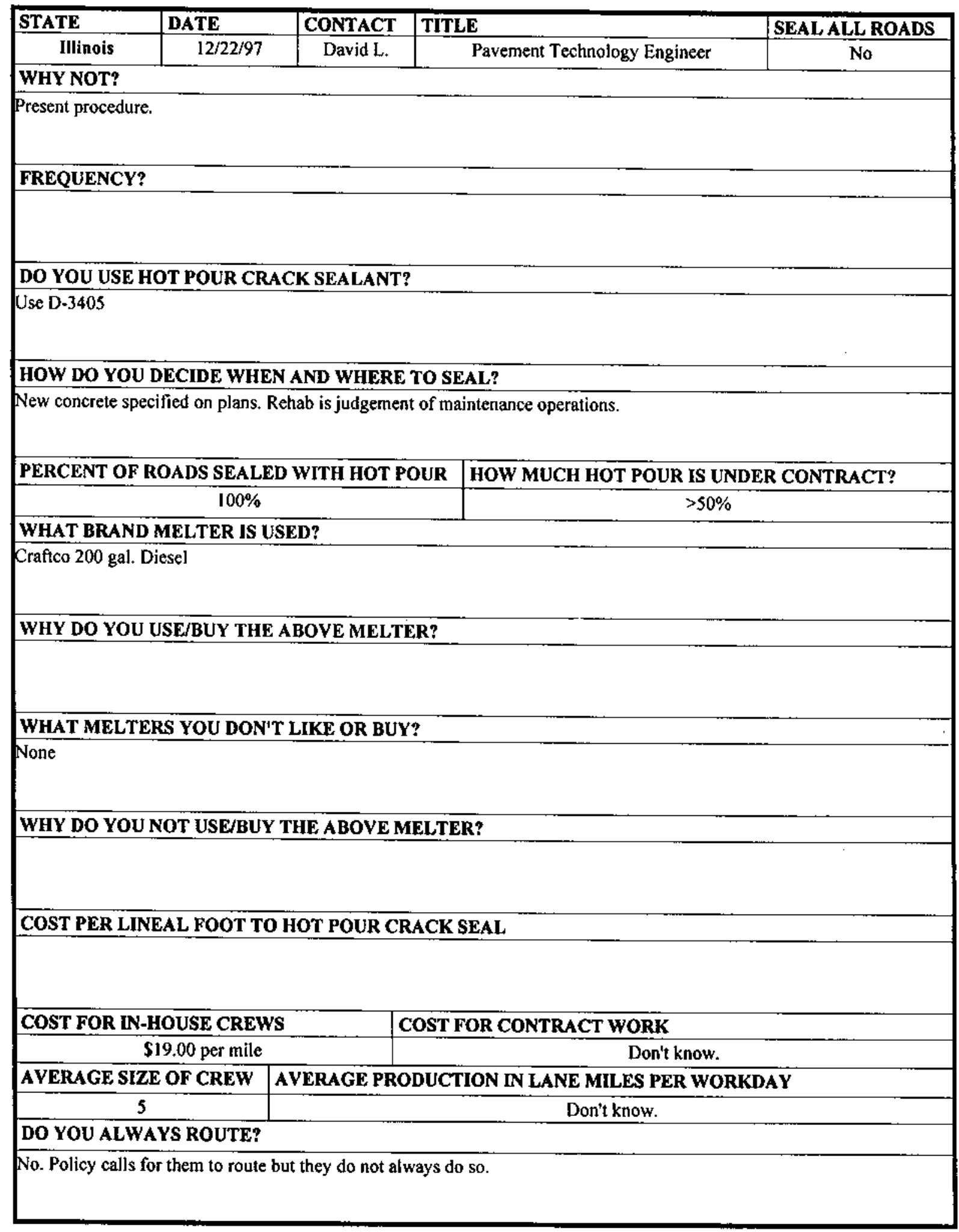




\section{OUT-OF-STATE CRACK SEALING SURVEY REPORT}

\begin{tabular}{|c|c|c|c|c|}
\hline STATE & DATE & CONTACT & TITLE & SEAL ALL ROADS \\
\hline Iowa & $1 / 23 / 98$ & Dick E. & Maintenance Operations Coordinator & No \\
\hline \multicolumn{5}{|c|}{ WHY NOT? } \\
\hline \multicolumn{5}{|c|}{ Left up to districts. } \\
\hline \multicolumn{5}{|c|}{ FREQUENCY? } \\
\hline \multicolumn{5}{|c|}{ DO YOU USE HOT POUR CRACK SEALANT? } \\
\hline \multicolumn{5}{|c|}{ Craftco 231 Roadsaver } \\
\hline \multicolumn{5}{|c|}{ HOW DO YOU DECIDE WHEN AND WHERE TO SEAL? } \\
\hline \multicolumn{5}{|c|}{ Visual inspection. } \\
\hline \multicolumn{3}{|c|}{ PERCENT OF ROADS SEALED WITH HOT POUR } & \multicolumn{2}{|c|}{ HOW MUCH HOT POUR IS UNDER CONTRACT? } \\
\hline \multicolumn{3}{|c|}{$35 \%-40 \%$} & \multicolumn{2}{|c|}{$95 \%$} \\
\hline \multicolumn{5}{|c|}{ WHAT BRAND MELTER IS USED? } \\
\hline \multicolumn{5}{|c|}{ Low bid. } \\
\hline \multicolumn{5}{|c|}{ WHY DO YOU USE/BUY THE ABOVE MELTER? } \\
\hline \multicolumn{5}{|c|}{ WHAT MELTERS YOU DON'T LIKE OR BUY? } \\
\hline \multicolumn{5}{|c|}{ None $2-2+3$} \\
\hline \multicolumn{5}{|c|}{ WHY DO YOU NOT USE/BUY THE ABOVE MELTER? } \\
\hline \multicolumn{5}{|c|}{ COST PER LINEAL FOOT TO HOT POUR CRACK SEAL } \\
\hline \multirow{2}{*}{\multicolumn{3}{|c|}{ COST FOR IN-HOUSE CREWS }} & \multicolumn{2}{|c|}{ COST FOR CONTRACT WORK } \\
\hline & & & \multicolumn{2}{|c|}{$.63-.75(\mathrm{AC})$ and $.90-\$ 2.50(\mathrm{PC})$} \\
\hline \multicolumn{2}{|c|}{ AVERAGE SIZE OF CREW } & \multicolumn{3}{|c|}{ AVERAGE PRODUCTION IN LANE MILES PER WORKDAY } \\
\hline 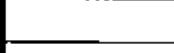 & & & 2.5 miles & \\
\hline \multicolumn{5}{|c|}{ DO YOU ALWAYS ROU'TE? } \\
\hline Yes & & & & \\
\hline
\end{tabular}




\section{OUT-OF-STATE CRACK SEALING SURVEY REPORT}

\begin{tabular}{|l|c|c|c|c|}
\hline STATE & DATE & CONTACT & TITLE & SEALALL ROADS \\
\hline \multicolumn{1}{|c|}{ Kentucky } & $1 / 23 / 98$ & Charlie B. & Engineering Branch Manager (Operations) & No \\
\hline WHY NOT? & & \\
\hline Lack of employees. & \\
FREQUENCY?
\end{tabular}

DO YOU USE HOT POUR CRACK SEALANT?

Not sure.

HOW DO YOU DECIDE WHEN AND WHERE TO SEAL?

Only in conjunction with concrete repairs or rehab.

PERCENT OF ROADS SEALED WITH HOT POUR HOW MUCH HOT POUR IS UNDER CONTRACT?

\begin{tabular}{l|l}
$1 \%$ & $100 \%$
\end{tabular}

WHAT BRAND MELTER IS USED?

WHY DO YOU USE/BUY THE ABOVE MELTER?

WHAT MELTERS YOU DON'T LIKE OR BUY?

WHY DO YOU NOT USE/BUY THE ABOVE MELTER?

COST PER LINEAL FOOT TO HOT POUR CRACK SEAL

COST FOR IN-HOUSE CREWS COST FOR CONTRACT WORK $\$ 3.00$ per lineal $\mathrm{ft}$.

AVERAGE SIZE OF CREW AVERAGE PRODUCTION IN LANE MILES PER WORKDAY

\begin{tabular}{l|l} 
Don't know. & Don't know. \\
\hline
\end{tabular}

DO YOU ALWAYS ROUTE?

Yes 


\section{OUT-OF-STATE CRACK SEALING SURVEY REPORT}

\begin{tabular}{|c|c|c|c|c|c|}
\hline STATE & DATE & CONTACT & \multicolumn{2}{|c|}{ TITLE } & SEAL ALL ROADS \\
\hline Michigan & $12 / 22 / 97$ & Larry G. & & ement and Roadside Section Engineer & No \\
\hline \multicolumn{6}{|l|}{ WHY NO'T? } \\
\hline \multicolumn{6}{|l|}{ Only new roads. } \\
\hline \multicolumn{6}{|c|}{ FREQUENCY? } \\
\hline \multicolumn{6}{|c|}{ Seal it 2 - 4 yrs after construction. } \\
\hline \multicolumn{6}{|c|}{ DO YOU USE HOT POUR CRACK SEALANT? } \\
\hline \multicolumn{6}{|c|}{ Use D-3405. } \\
\hline \multicolumn{6}{|c|}{ HOW DO YOU DECIDE WHEN AND WHERE TO SEAL? } \\
\hline \multicolumn{6}{|c|}{ New roads, tight cracking, and no secondary cracking. } \\
\hline \multicolumn{4}{|c|}{ PERCENT OF ROADS SEALED WITH HOT POUR } & \multicolumn{2}{|c|}{ HOW MUCH HOT POUR IS UNDER CONTRACT? } \\
\hline \multicolumn{4}{|c|}{$50 \%$} & \multicolumn{2}{|c|}{$100 \%$} \\
\hline \multicolumn{6}{|c|}{ WHAT BRAND MELTER IS USED? } \\
\hline \multicolumn{6}{|c|}{ We do not specify a brand. } \\
\hline \multicolumn{6}{|c|}{ WHY DO YOU USE/BUY THE ABOVE MELTER? } \\
\hline \multicolumn{6}{|c|}{ WHAT MELTERS YOU DON'T LIKE OR BUY? } \\
\hline \multicolumn{6}{|c|}{ None } \\
\hline \multicolumn{6}{|c|}{ WHY DO YOU NOT USE/BUY THE ABOVE MELTER? } \\
\hline \multicolumn{6}{|c|}{ COST PER LINEAL FOOT TO HOT POUR CRACK SEAL } \\
\hline \multicolumn{6}{|c|}{ Bid by road bed kilometer. Under 2 yr. Warranty. } \\
\hline \multicolumn{3}{|c|}{ COST FOR IN-HOUSE CREWS } & \multicolumn{3}{|c|}{ COST FOR CONTRACT WORK } \\
\hline \multicolumn{3}{|c|}{ Contracted } & \multicolumn{3}{|c|}{$\$ 5,700$ per lane kilometer } \\
\hline \multicolumn{2}{|c|}{ AVERAGE SIZE OF CREW } & \multicolumn{4}{|c|}{ AVERAGE PRODUCTION IN LANE MILES PER WORKDAY } \\
\hline \multirow{2}{*}{\multicolumn{3}{|c|}{$\frac{\text { N/A (Contracted out) }}{\text { DO YOU ALWAYS ROUTE? }}$}} & \multicolumn{2}{|c|}{6,000 lineal ft. per day } & \\
\hline & & & \\
\hline Leave it up to $t$ & contractor since & is under wartan & & & \\
\hline
\end{tabular}




\section{OUT-OF-STATE CRACK SEALING SURVEY REPORT}

\begin{tabular}{|c|c|c|c|c|c|}
\hline STATE & DATE & CONTACT & \multicolumn{2}{|c|}{ TITLE } & SEAL ALL ROADS \\
\hline Minnesota & $12 / 23 / 97$ & Dave J. & & Pavement Management Engineer & No \\
\hline \multicolumn{6}{|l|}{ WHY NOT? } \\
\hline \multicolumn{6}{|c|}{ Up to districts (different districts have different ideas about if and when sealing should be done). } \\
\hline \multicolumn{6}{|c|}{ FREQUENCY? } \\
\hline \multicolumn{6}{|c|}{ DO YOU USE HOT POUR CRACK SEALANT? } \\
\hline \multicolumn{6}{|c|}{ Use D-1 190, D-3405 (with slight modification), and D-3720 } \\
\hline \multicolumn{6}{|c|}{ HOW DO YOU DECIDE WHEN AND WHERE TO SEAL? } \\
\hline \multicolumn{6}{|c|}{ Up to districts (usually within first few years of overlay). } \\
\hline \multicolumn{4}{|c|}{ PERCENT OF ROADS SEALED WITH HOT POUR } & \multicolumn{2}{|c|}{ HOW MUCH HOT POUR IS UNDER CONTRACT? } \\
\hline \multicolumn{4}{|c|}{$100 \%$} & \multicolumn{2}{|c|}{$99 \%$} \\
\hline \multicolumn{6}{|c|}{ WHAT BRAND MELTER IS USED? } \\
\hline \multicolumn{6}{|c|}{ Contractor decides. } \\
\hline \multicolumn{6}{|c|}{ WHY DO YOU USE/BUY THE ABOVE MELTER? } \\
\hline \multicolumn{6}{|c|}{ WHAT MELTERS YOU DON'T LIKE OR BUY? } \\
\hline \multicolumn{6}{|c|}{ Contractor decides. } \\
\hline \multicolumn{6}{|c|}{ WHY DO YOU NOT USE/BUY THE ABOVE MELTER? } \\
\hline \multicolumn{6}{|c|}{ COST PER LINEAL FOOT TO HOT POUR CRACK SEAL } \\
\hline \multirow{2}{*}{\multicolumn{3}{|c|}{ COST FOR IN-HOUSE CREWS }} & \multicolumn{3}{|c|}{ COST FOR CONTRACT WORK } \\
\hline & & & \multicolumn{3}{|c|}{.34 or .35 per lineal foot } \\
\hline \multicolumn{2}{|c|}{ AVERAGE SIZE OF CREW } & \multicolumn{4}{|c|}{ AVERAGE PRODUCTION IN LANE MILES PER WORKDAY } \\
\hline Contracto & r decides. & & & Do not know. & \\
\hline \multicolumn{6}{|c|}{ DO YOU ALWAYS ROUTE? } \\
\hline No. Only route & new roads in $b$ & etter condition. & & & \\
\hline
\end{tabular}




\section{OUT-OF-STATE CRACK SEALING SURVEY REPORT}

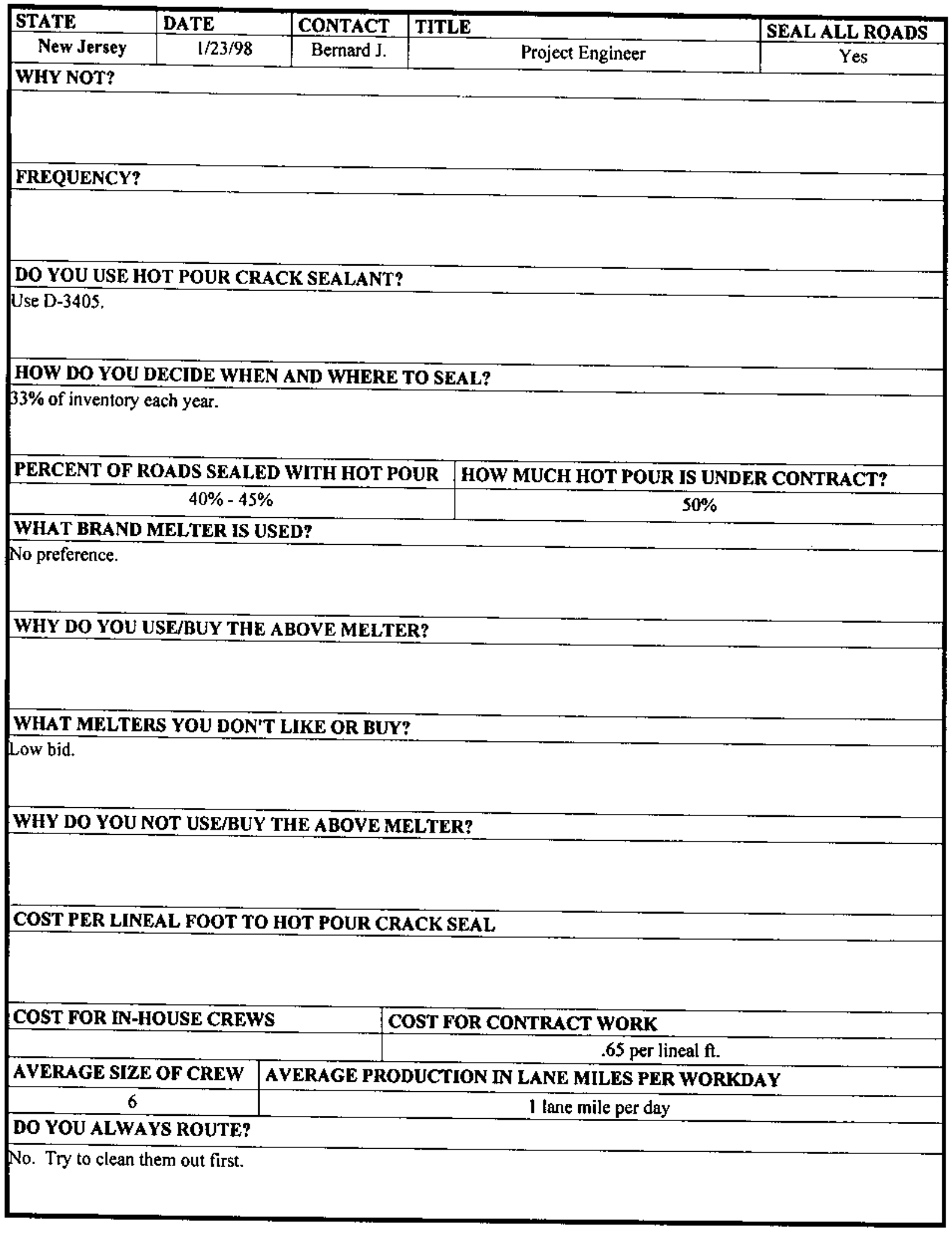




\section{OUT-OF-STATE CRACK SEALING SURVEY REPORT}

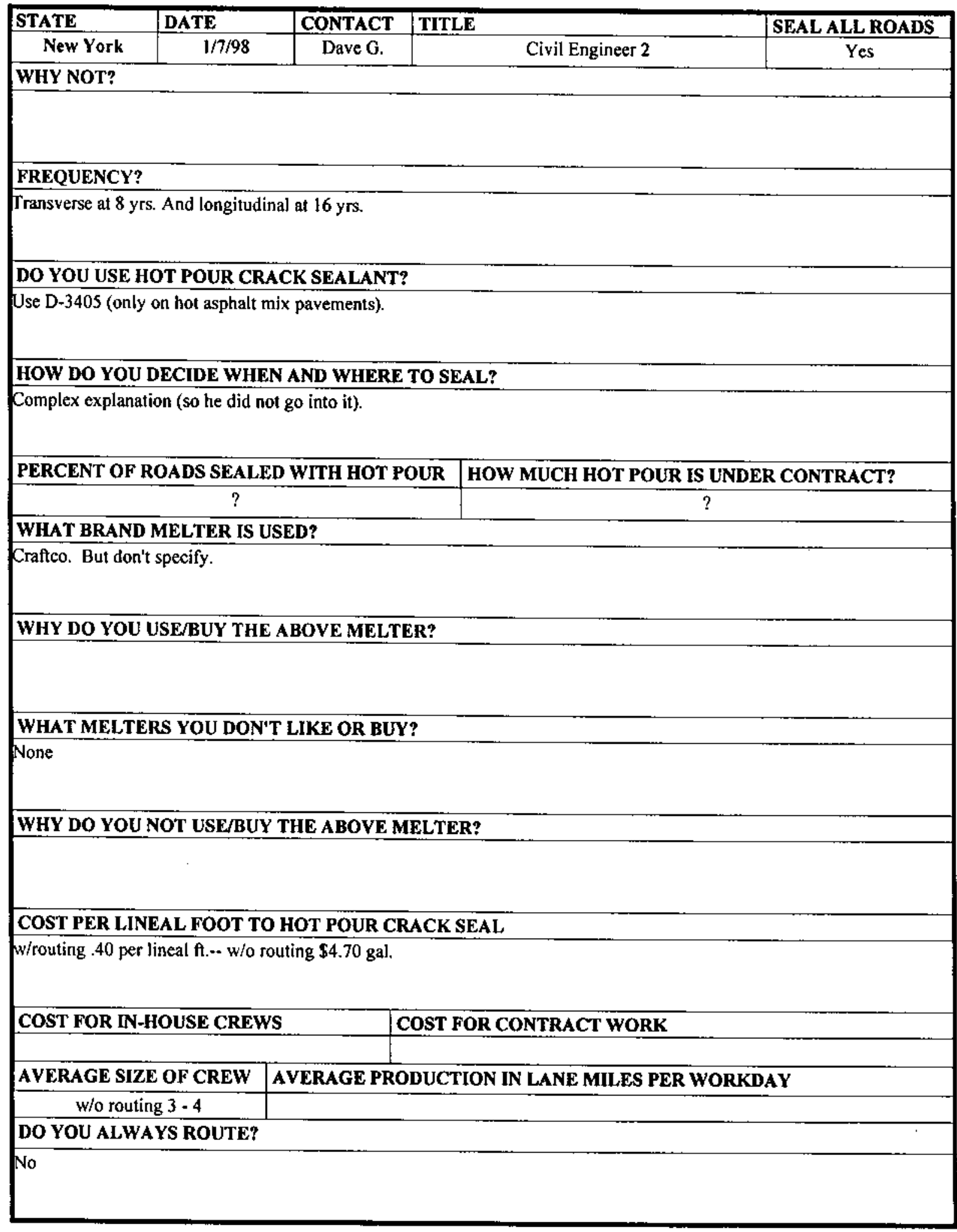




\section{OUT-OF-STATE CRACK SEALING SURVEY REPORT}

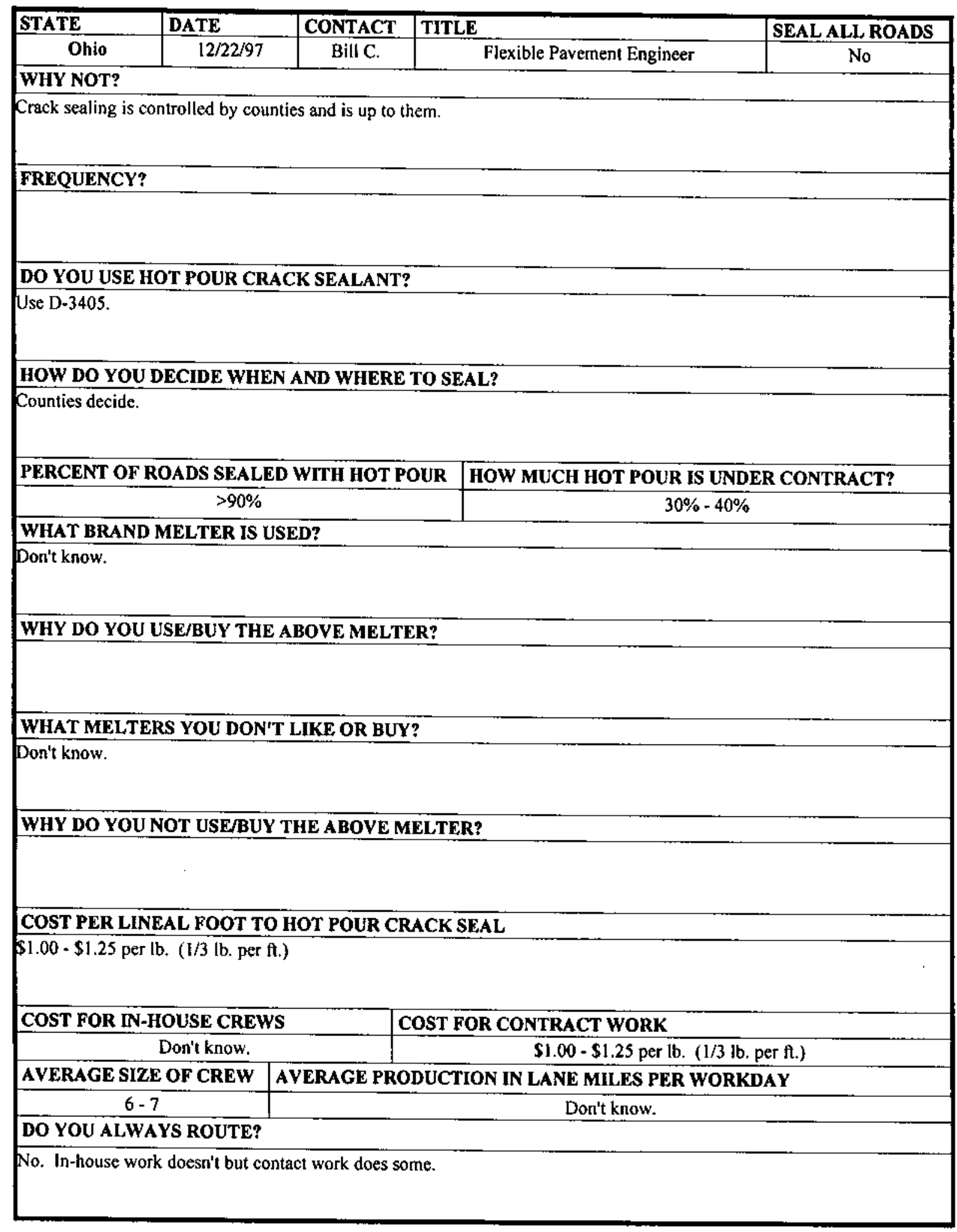




\section{OUT-OF-STATE CRACK SEALING SURVEY REPORT}

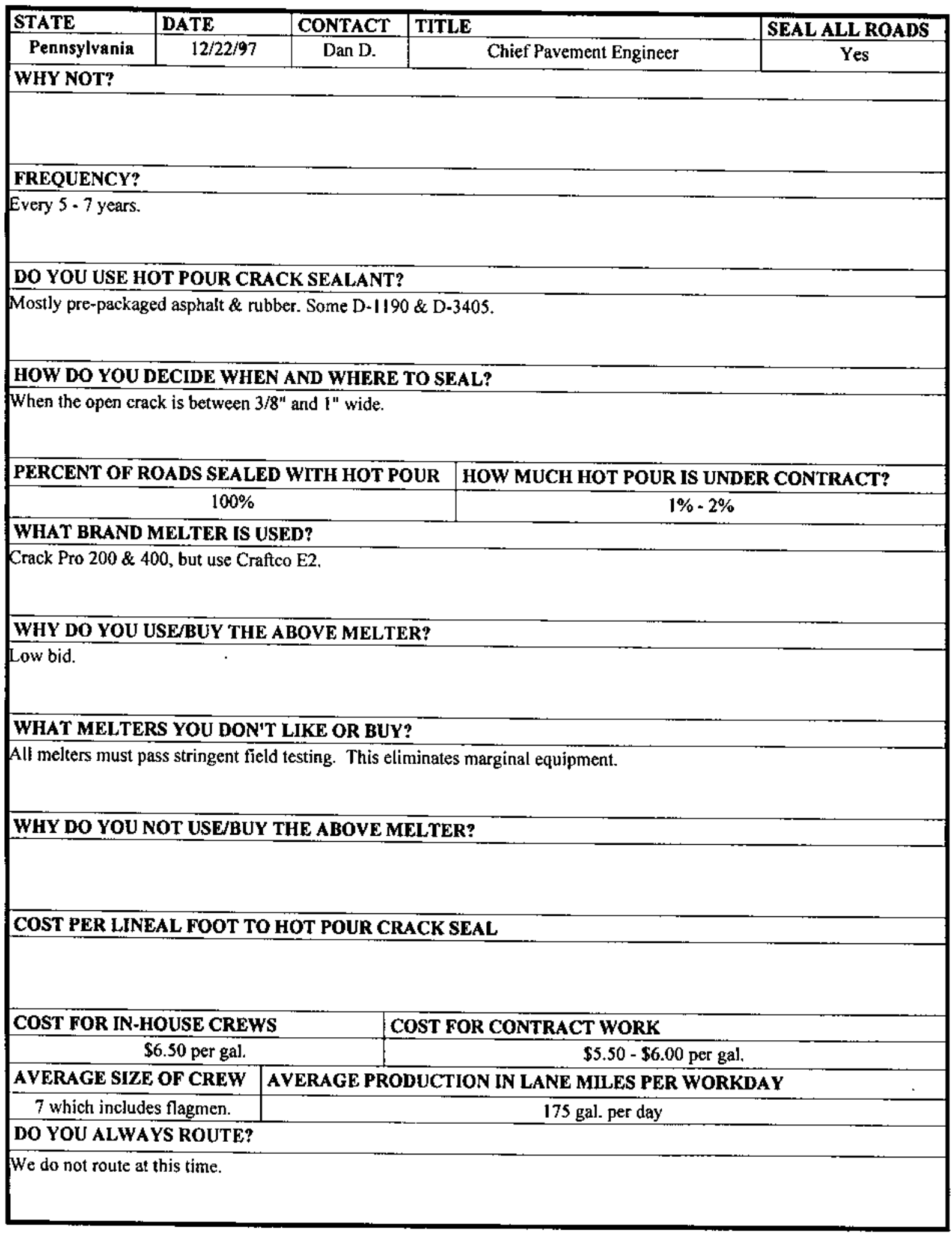


Appendix B 
TIME LINE

(Partial List of Study Activities)

09/92 Proposal development.

10/22/92 Proposal Approval (Original Completion Date 12/95).

11/11/93 Joe of Crawfordsville Subdistrict will inform us of meeting on when and how they will do the crack sealing.

11/15/93 Angola Subdistrict will be on I-69 and on SR-8 into Auburn.

11/15/93 Greenfield did a section of US-52 without a router. They are waiting on a router for use on US-231 in Tipton.

11/15/93 La Porte has 2 new melters and a $3^{\text {rd }}$ in budget, but no material or router.

$11 / 15 / 93$ Seymour did not have the money, but may get 2 melters next year.

11/15/93 Vincennes has a melter, material, and concrete saw, but no router.

11/19/93 I called Rick (M\&T) and they can do D-3405 testing. Just use an IT530 and submit sample. Also, they don't allow some sealants on concrete any more and that Wisconsin doesn't require seal on new concrete, because it is well drained. Districts should be requiring Type A certification.

11/19/93 Phil of IDOT 815-434-6131. Called to check on crack sealing.

11/19/93 Contacted Sam with La Porte District, "we'll call Mike"

11/24/93 Thoughts on life cycle cost comparison: Current procedure including, equipment, manpower, production, material use, 207? Updated cost - can we use Erma connection to get this cost because pavement doesn't get sealed?

12/10/93 Called Crafco about improving visibility of crack when operating router. We tried to install a mirror and dust deflector.

12/15/93 Kenny from Subdistrict called, they are crack sealing on US 52. Went there, but it was raining (10:30 am). Had rained previous days as well. Stopped and talked to arrow board truck driver. Melter was broken down.

12/15/93 Ned called and concurred with first crack sealing study report. 
12/15/93 Talked to Jerry of IDOT; he returned call for Dan, District \#5. They have been using hot pour for about 6 years. It has taken that long to implement. They still use $\mathrm{AE}$ also. Hot pours and routing used on newer resurfacing and better roads. Probably will not crack seal with hot pour the rest of this year due to temperature (40 degrees) and kettle's inability to keep sealant hot (reminder - gas/fuel use probably goes up in cold weather) and warm it up in reasonable length of time. A training tape was made. I call Ed (217) 782-2984.

$12 / 16 / 93$ Gordon and I, after several weeks of trying to retro fit the router with mirrors, have concluded dust problem can not be solved. Will make a few changes and let Fort Wayne use the machine for awhile.

12/16/93 Steve called from Bluffton Subdistrict to request router. Working on SR 1, Gordon and I may go to observe (219) 824-1050.

$12 / 16 / 93$ Ordered a disc and shoe fitting from Sherwin Inc. Cost was $\$ 51.00$.

12/17/93 Field Inspection Bluffton.

12/20/93 Conversation with Crafco's chemist, Mr. Saheed. Discussed overheating and polymers. They can gel if heated too long a time ( 16 hours). However, they need to be at proper temperature to drive out moisture so they will have good bond.

12/20/93 Sent a fax to Bluffton Subdistrict, (attention Steve) to provide him with hot pour crack sealing information.

01/05/94 Trying to contact Ed La Croix with IDOT, he indicated he will send crack sealing information to me.

01/19/94 Reviewing tape made by IDOT.

01/19/94 Memo to districts regarding proper procedures for hot pour crack sealing.

02/08/94 Memo providing Illinois training tape to districts.

03/23/94 SHPP Manuals distributed to districts.

05/10/94 Larry of C'ville called back 10:24 am. They are not using melter at present or as much as he would like. It is at Terre Haute and they plan to start using it on May 18 or 19. Larry will call to confirm with us on May 16 or 17 , when he has more information. I told him we plan to be there and would appreciate his call.

05/15/94 Issued to Flora Subdistrict: Crafco model 200 Router (Comm. No. 76987)

1 set carbide cutters

Manuals for router and Onan engine 
3 Maxon radios with chargers

2 ea. Metal applicator shoes

05/23/94 At Flora we found router cutters wearing out of round. Also called manufacturer about electronic box needing additional vent holes.

05/23/94 Called Monticello, they are sealing on US-421 N. Junction of SR-18.

05/24/94 Greg W. visited to demonstrate Crafco melter, sealant, and to answer questions. Things to watch for included proper depth, starting slow, going deeper, how to change cutter blades, etc.

05/26/94 Call Illinois DOT District 3, Ed \& Phil.

05/26/94 District 4, Jerry.

05/26/94 District 5, called to request crack sealing information Dennis \& Jan.

05/31/94 Greenfield is having problems with the melter and equipment. I-69 from I-465 to $100^{\text {th }}$ Street.

05/31/94 Discussed problems with Melter Corp.

05/31/94 Private heating and a/c company repaired melter for Greenfield. Also they are mounting hoist on melter to transport router.

05/31/94 Discussed problems with boiler and equipment with Greenfield district. Problems include heating elements need replaced, gauges not working, 3 hours to heat up if $1 / 3$ full, and the wand is big and bulky. Also the statement came up, "don't travel with the burner on," OSHA problem?

05/31/94 Jim of Melter Corp. said it is proper to run with burner on and to check with your state OSHA for specifics. He said if we have any problems to call and they will send parts, or arrange for repair. Also he can be here in $31 / 2$ hours if needed. In reference to the transfer oil, he said it should be changed every season, most likely in the off season (winter maintenance) if it is not changed it will oxidize or coat the heating jacket.

05/31/94 Tipton has 60 day rental on a different melter. Used several weeks on night shift.

$05 / 31 / 94$ Overall attitude is changing slowly as they can see sealing is staying in place, it will be big improvement.

06/01/94 Called Melter Corp. Heat shield to be put on all melters. Valves can be obtained locally and installed. Melter Corp. will call Greenfield. 
06/01/94 Greenfield District - Controller on melter was fried earlier, but was equipped with a heat shield. Wand valve was broke and the covering was off of the hose in several places.

06/02/94 Melter Corp. (Dennis G.) will send us a manual and video.

06/02/94 Jim M. Called with cost data, \$0.195 per lb.

06/03/94 Melter Corp. (Dennis G) called here then Greenfield.

06/03/94 Called Wabash Subdistrict, they mixed Crafco and Studebaker material.

06/03/94 Monticello Subdistrict found that if they didn't router to deep it was much easier to control the router.

06/06/94 Fort Wayne doing SR-18 between SR-1 and SR-3. Using hot air lance and no router.

06/07/94 La Porte is nearly finished for season. They have been experimenting with flow control to minimize material waste. Field inspection in Bluffton.

06/08/94 Follow up call using Crafco material temperature should be $380^{\circ} \mathrm{F}$ to $400^{\circ} \mathrm{F}$.

06/08/94 Melter Corp. called to get address to send hose cover to Greenfield. Valves were sent on $6 / 3 / 94$ ?

06/10/94 Called Todd G. about videotaping procedure.

06/13/94 Indianapolis has 70 blocks of material left. New valve and hose on wand. Will do I-69 on Wednesday.

06/15/94 Melter was malfunctioning so the manufacturer authorized a local heating contractor to repair the burner and controller. Repair not completed under after 6/16/94. We left 2 squeegees and a T.P. applicator with the unit to use.

06/27/94 Called LaPorte and was invited for demo of router.

06/27/94 LaPorte received two new routers so they will return ours. Next work will be Plymouth sub and work on US 31.

06/27/94 Talked to Crafco about improved "kill switch" as mentioned by field operators.

07/07/94 Called and received cost data from central office. It was not what we needed. 
07/12/94 Decision was made to convert our video van into a crack seal/video van so that we could show a short video to the field operator on site. On most visits we asked crew members if they have seen any training videos. Most responded no.

07/12/94 Received report from Fort Wayne on crumb rubber sealant locations for potential review.

07/15/94 Status of HPCS sent to districts.

07/15/94 Implementation status report issued to districts.

07/21/94 Field Inspection in Illinois.

07/25/94 Memo to Districts updating them on hot pour crack sealing research.

08/02/94 Field Inspection in La Porte.

08/11/94 Received crumb rubber useage from MO and proposed new work activity plus sent follow up response.

08/22/94 Field Inspection Fort Wayne District, various roads.

08/22/94 The following evaluates the 1993 crack sealing of SR 37 from 9 to 26 .

An uncertain cleaning method was used, but the road was definitely not routed. A flat squeegee was used to spread (and overband) the sealant. The sealant was damaged in certain areas by a snowplow. Judging by the way the material formed a rough crown over the crack it may have been applied during cool weather.

Overall, the road was in moderate condition, i.e. the ride was slightly bumpy. This road was not a good choice for crack sealing because of the high degree of longitudinal and branched cracks. These longitudinal cracks were also sealed. In some places, there were over one foot wide strips of material on longitudinal cracks.

The following evaluates the 1992 crack sealing of SR 18 from SR 3 to 1.

This road probably was not a good candidate for D-3405 crack sealing. The cracks were not singular nor very well defined. Additionally, there is a considerable amount of "widening" cracks with branching that is longitudinal. All of the sealing is overbanded of lower quality workmanship. Much of the sealant was spread in mass over widening cracks. While most of this material is still in place, it was not effective in holding the road together and was likely very expensive per foot. Some transverse cracks that were sealed still have form half to two thirds for the seal intact.

These two sites were in very similar condition. The success rate was somewhere in the area of $40-55 \%$. 
8/29/94 The following two sites were evaluated on August 29, 1994.

The following evaluates the 1991 crack sealing of SR 3 from I-69 to Shoaff Road. Only the transverse cracks were sealed. The overband was excessively damaged by snowplows. This again was a poor road to crack seal due to heavy longitudinal and secondary cracking. Overall this road was in fair/poor condition. The cracks were sealed form shoulder to shoulder with the material width being about 3" to 12 ". Some cracks were widening and branching. This road was very heavily traveled and had a success rate of only $20-45 \%$.

The following evaluates the 1991 crack sealing of I-69 from SR 8 t County Road 11 A.

This road was a good choice for crack sealing. Due to the relatively straight cracks on the road, routing would have been a better choice rather than overbanding. Inexperience is showed in that some of the cracks were missed by the sealant. Again, the overband has taken a tremendous beating form snowplows. Minor branching is starting on these cracks. The longitudinal cracks have also been sealed. This road was in fair condition.

Unfortunately, most of the sealant has been rubbed off from traffic friction or snowplow. There is less than a $20 \%$ success rate. In conclusion, several mistakes were repeated on the above sites.

First, longitudinal cracks should not be sealed using rubberized asphalt. Remember that the reason for the use of this more expensive material is its elastic properties. These properties are needed for the expansion and contraction of cracks during hot and cold temperatures. However, the expansion of longitudinal cracks is negligible. Only transverse cracks should be sealed when using this application.

Second, if a road is too far damaged (excessive longitudinal, alligator or branched cracks) crack sealing will not preserve the life of the road. Therefore, the choice of if and when to crack seal is paramount to the cost effectiveness of this project. Refer to the SHRP manual, "asphalt Pavement Repair Manuals of Practice", SHRP-H_348, if uncertain crack sealing conditions exists. This manual also provides other insights concerning rubberized asphalt crack sealing. This should be read by all operators.

These sites were among the first in the state to be crack sealed.

09/07/94 Called Plymouth Subdistrict for work schedule.

09/07/94 Called Indianapolis Subdistrict, said Melter was "trashed". Had to weld the tank and that the state bought a "lemon". Also Greenfield has a rental melter for use on I-65 south of I-465.

09/08/94 Field Inspection on I-65 South of I-465. 
I-65 south of I-465, 11:00 am. Talked to Mike who seems involved in operations. He stated the Melter has several oil leaks in the tank (main), the expansion tank, and the heater plug areas. They have tried to weld up the leaks. He was not sure if Melter Corp has been informed. He also was concerned with not having a safety shut off on the router - I told him I would check with Crafco again. The switch on the electric hoist doesn't work and is not accessible. I told him I would buy one and get it to him. While gauge appears heavy (6-8). Router bits have held up pretty well. Router really creates one hell of a lot of debris. Muffler on router went bad, end pipe fell off, Warrantee - Hoist switch, Muffler, Melter.

Observations:

They are wasting less material.

Still doing longitudinal.

They have dust marks on router operators.

Longitudinal joint is at least visible $80 \%$ of time.

Bumper (stop) bar on router worn out, they are ordering some.

Rout size appears about right.

Hose is strapped to side of truck, appears to be working o.k. Force at tip is strong, no moisture on oil blow by is obvious.

Sealant is still staying pretty tacky $200-300$ behind operations.

Lots of debris on road from router, doesn't seem to be causing any problems.

Operation. When moving is a fast paced walk.

Sealant temp in rout right behind operations is 330 degrees, tank temp is 340

degrees, Gordon, however, says tank gauge may be wrong.

Tip replaced every 2-3 days.

Wand valve still doesn't work for shit, Paul thinks Berry sent valve replaced once.

Paul Expansion tank leaked, new tank coming, shop welded old one.

Shop put on new hose but messed up connection to hose melter.

Over night heater parts just started to leak today.

Two wire things on top started leaking oil out the top.

Shop needs to cap hoses before new hose is put on, otherwise liner gets soaked

with oil, and then heat gets transfer and melts protective liner.

Road selection is ok, in good shape, however I still question economics of doing longitudinal joints.

Crew $\quad 5$ dump trucks, one sign truck

$1 \mathrm{AC}$

1 router

1 melter

About 10 people

Not sure where their thermometer is at, shop.

Squeegee is getting worn out.

$\mathrm{Bad}$ set of router bits.

Maybe order extra set of bits and carry more squeegees.

Paul suggests a big spring for cross cracks.

09/09/94 New crack sealing activity officially established. 
80 degrees, cool evenings, clear, same crew that did US 31 by Argos, this location is west of Plymouth on US 30 west, US 30 east has already been done in same area. US 30 at this location is probably not an ideal road. Has quite a bit of secondary cracking that is most longitudinal. Crew had many questions...when is safety switch coming, can we leave burners on oven during lunch, router bits are wobbling. I told them about OSHA concerns but thought it was more cost effective to burn diesel fuel than wait a $1 / 2$ hour to get material back up to temp, safety switch is suppose to be coming, router pins may need to be replaced. Their squeegees are a little wider (bend), therefore there is some waste but operations are still ok. They did not have many negative comments about the melter. One useful comment about pump slow down may be due to plastic wrap getting in pump, so just hit reverse and go. I told them again about toilet paper blotting, even though today shows no sign of tracking. Router man (regular operator) complained other guys weren't changing air filter and greasing router, sub still doesn't have fillers. Maybe we should make up a list of replacement stuff to keep on hand.

They asked about the new AE90 and when districts would be using it, temperature gauges on melter appear ok. They were putting sealant down at a little cooler temp than specs, but all seemed ok. They also were running out of material. Routing and cleansing ok, slag aggregate appears to be making edges chip. I noticed lock was missing from pour spout on melter. They did see the video, but haven't read the SHRP stuff, do have access to Berry manual. I told them some of the problems INDY sub was having. Need to figure in cost of lance fuel etc.

3D various, some areas were ok for this type of scaling.

Running out of sealant and planning to borrow some

Hand grip John F. \& Steve G.

10/04/94 Field Inspection in Illinois.

10/11/94 Meeting with Melter Corporation representative (Dennis G.) to remediate problems. Informed us that INDOT bought another brand.

10/25/94 Picked up router from Flora.

10/25/94 Issued to Tell city Subdistrict: Crafco model 200 Router (Comm. No. 76987) with manuals and video tape.

1 set carbide cutters

1 set pins w/ cutters

manuals and maintenance log

thermometer for melter 
dispenser for T.P. crack seal blotter

1 Crafco squeegee

1 LSC squeegee

10/27/94 Called vendor on router blade pricing.

10/27/94 Delivery by study personnel of router to Tell City Subdistrict.

11/03/94 Training Committee established Crumb rubber Crack Sealing as number one priority.

12/06/94 Summary of hot pour crack sealing questionnaire distributed.

12/12/94 Contact with Crawfordsville Maintenance regarding use of hot lance (B. V.) and pavement temperature.

12/22/94 Received response concerning request for HPCS data.

01/05/95 Training Committee reviewed the North Carolina videocassette titled "Crack Seal". It was determined that the video was not sufficient. Committee decided to contact Dave before the next meeting.

02/14/95 Confirmed the router had been moved to Fort Wayne Subdistrict.

02/14/95 Wabash Subdistrict to inspect cutters on router.

02/14/95 Dale Subdistrict to inspect cutters on router.

02/21/95 Gordon provided two videocassettes on crack sealing to Training Committee and also provided supplemental information for creating a crack sealing script. Dave volunteered to work with the crack sealing script committee.

05/16/95 Gordon and Dave provided the SHRP booklet on Crack Sealing to training Committee. Also, reviewed the Illinois DOT videocassette titled "Crack Joint Seal". The film was good, but they still want their own. Dave will contact a professor in Ontario, Canada to request approval to purchase enough copies of the Illinois video for INDOT interim use.

05/23/95 B.V. of Crawfordsville will call back.

05/23/95 Indianapolis Subdistrict will start up again after race day. They like to "rent" Melter because if it breaks they can take it back and get another.

06/12/95 Fowler Subdistrict will call when starting hot pour crack seal. 
06/14/95 LaPorte let a contract in May for US-30 (m21505). They are way behind on preventive maintenance as one melter is broke and they plan to install 2 wands on the other

06/19/95 Contractor is doing concrete joint repair with hot pour sealant on US-41 from SR18 to Boswell.

06/22/95 Field Inspection La Porte District on US-41.

On June 22, $1995 \mathrm{GH}$ and myself visited a project on US 41 in Benton County. This project was a joint concrete repair job, which was originally set up to use silicone sealant. Because maintenance forces were very aggressive in sealing the joints with emulsion prior to the project beginning, the longitudinal joints sealing had to be changed to a hot pour.

Upon visiting the project we talked with the Project Supervisor and, the owner of the sealing company. He was very helpful in pointing out several items. He indicated his crews use carbide router bits on asphalt and obtain about 13,000 feet of use. They never use carbide on concrete because the bits just break off due to the hard impacts. However, you can use the "worn out" carbides on concrete because it is cost effective and the steel base material is harder than the regular steel bits. His operators have no trouble following random cracks. Illinois is letting a contract where they are going to try an anti-tracking agent. We also, talked about the upcoming contract job in the La Porte District. He uses nothing but Crafco equipment and materials.

It was difficult to judge the quality of work on this contract as maintenance forces had literally covered everything with emulsion. However, upon close examination of the silicone I found evidence of bond failure and moisture. The Proj. Sup. Had almost no knowledge of proper crack sealing techniques. This was a concern. Also, the contractors work habits with regard to traffic control safety were not impressive.

06/29/95 Informed Fort Wayne we would be over with manuals and cutters.

07/17/95 Contacted Crawfordsville to request hot pour crack sealing activities for field inspections.

07/17/95 Crawfordsville sealing on SR-47 (between US-52 and Thorntown) with double boiler and router, Chris $\mathrm{H}$.

07/17/95 Crawfordsville informed us they would be working on SR-47 between US-52 and Thorntown. 
07/18/95 Training Committee members agreed to review the SHRP booklet. Professor from Ontario gave INDOT approval to copy his videotape "Illinois DOT Crack Joint Seal."

09/26/95 Training Committee members discussed the SHRP booklet and it was decided to form a subcommittee.

10/04/95 Field Inspection at Plymouth Subdistrict on US-30.

Stopped at Plymouth sub and talked to Carl K. and Fred M. They have a new melter coming in a couple of weeks. They have a considerable amount of Roadsaver on hand and plan on doing 40 lane miles this year. Also they have a new Aeroil router that looks pretty well designed. They have not yet operated it. Milepost 63 west of Plymouth on 30.

Stopped at the US 30 site that was sealed last spring. The material is in very good condition, but US 30 was not a good candidate as it was already in advanced stages of deterioration. There does appear to be a big difference between the travel lane, which was sealed and the travel lane that wasn't. This section of road looks like it will soon be resurfaced.

Checked SR 31 site and took several pictures. Overall in very good condition. Some cracking of material on surface. Not sure what this cracking indicates. This site begins north of SR 10 .

10/25/95 Called Tell City to get update on router.

10/25/95 Vincennes District one melter is down, but will be starting soon.

10/26/95 Tipton Subdistrict will start on SR-2 in Kokomo on Monday. Will meet them.

10/26/95 Field Inspection at Tipton Subdistrict.

10/26/95 Committee members discussed the SHRP booklet and it was decided to form a subcommittee also conducted interview.

\section{Crack Sealing Interview}

Gordon and I met with Ron of the Tipton Subdistrict at Kokomo to discuss hot pour crack sealing that they intend to accomplish on SR 22 west of US 31 on Monday. The discussion was about one hour long and Greg M. sat in on the last fifteen minutes. Afterwards we went to the job site to see what type of cracking was present.

The discussion touched on many subjects. They did US 31 about a year ago and chose not to squeegee. They also plan not to squeegee on SR 22 either. I gave them the reasoning 
behind crack sealing and indicated the proof was in the field performance. I told him most subdistricts squeegee and that the literature seemed to support squeegee operations. We asked whether or not they had received any of the training/information we sent out. They indicated no. We also talked about the Melter and the problems that had occurred. They didn't think the "Corp". was very helpful and felt INDOT personnel knew more about the unit than the person sent out by the "Corp." to fix the melter. Also they felt the chain of command believed the subdistrict was creating some of the problems. We discussed the various problems and indicated we are willing to contact the Melter Corp. on their behalf if needed. Ron explained what Greenfield's original concept was regarding training. They intended to have operators training by the Melter Corp. and then these people would accompany the melters on their rounds. Overall the plan has worked ok, but a lot of specifics got lost in the shuffle. Mostly the subdistrict crews have been learning by trial and error. Ron thought the Tipton subdistrict was planning to do about 50 lane miles this year. One thing Ron mentioned that I may want to pass along is proper storage of sealant. I also mentioned the reasons the material should be sampled and how to do it. They expressed concern that hot pour crack sealing may not be the best thing to do on SR 22 . The new surface was done as a hurry up measure late last year and it is not holding up to well. When we visited the job it wasn't as bad as I thought it was going to be. However, hot pour is probably not the best treatment. This road is suppose to be totally redone before the year 2000 . Therefore, the best treatment would probably be modified emulsion just to get them by.

10/30/95 Called then went to Tipton, showed and left a videotape. They were not going to crack seal as they had problems with the router and melter. Conducted interview.

Crack Seal Interview

Went to the Tipton Subdistrict to deliver training/information materials in lieu of observing crack sealing on SR 22 as they had equipment problems with the router and melter. The melters hoist was not working and the router had a push button kill switch that was hard to use so they by-passed it. Met Ron B. and he introduced Kerry L. who will be running the Kokomo crew after the equipment is ready to go. We showed the part of the tape Gordon had copied of Canadian crews doing sealing and then talked with Kerry. He has used the Melter and really believes it is too big and the wand is not user friendly. Gordon and I examined the melter and noted it is not in very good condition. This is not necessarily the crews fault as the Melter does have some recurring problems and gets passed from one crew to the next. I suggested to Kerry he request a demo from Crafco to see the difference between various melters.

Afterwards Gordon and I went and looked at US 31 (thru Kokomo) and US 35 (Kokomo to Galveston). Quite frankly I was not to happy with the way the roads looked. It wasn't so much the sealing operation as it was all the secondary cracking that was showing up. The sealant was still in the routed cracks and was still flexible with fairly good bond, but the edges looked bad, probably because they didn't use a squeegee. In retrospect these roads may not have been good candidates for hot pour sealing, but there is no easy way at 
this time to tell in advance. Maybe Illinois has the right idea of going wide to begin with to cover the secondary cracking when it occurs.

10/31/95 A subcommittee was formed to review the SHRP booklet and, from that booklet, produce a script. Subcommittee members are: Ron A., Fred K., B. V., and Rusty F. Marvin M. will be invited to provide assistance.

11/01/95 Informed Sam E, of La Porte, that router was on way back and we would take it to Valparaiso Subdistrict on US-30

11/13/95 Received a call about subcommittee being formed to prepare script for crumb rubber crack sealing video.

11/13/95 A memo went out scheduling script subcommittee meeting at PCD on 11/28/95. Members were notified.

11/30/95 Fort Wayne has router Comm. No. 77424 with 30 hours on the meter. CS 25 form will be prepared to transfer router to Fort Wayne District. Also CS 25 form to transfer other router Comm. No. 76987 with 54 hours on meter to La Porte. Also each district will receive a manual, set of carbide cutters, pins, and washers.

12/04/95 Field Inspection at Valparaiso Subdistrict, various locations including US-30. Conducted interview

\section{Crack Sealing Interview}

On 12/4/95 Gordon Hooker and myself went to SR 53 by Merrillville to put down traffic counters. As we were in the La Porte District we decided to stop at the Valpo. Sub. to check on their crack sealing operations. No supervisory personnel were available to discuss crack sealing, therefore, we asked a crew leader about sealing operations. $\mathrm{He}$ indicated he had not yet tried the hot pour, but was scheduled to do so this year. He did indicate that US 30 right in front of the Sub. had been done recently. Based on this Gordon and I made an inspection of the work.

The sealing operation appeared to be mainly in the WBL. The EBL had been recently resurfaced. The WBL lane appeared to have different treatments between the travel and passing lane. The longitudinal joint had been routered and sealed as well.. the passing lane was routered, but had a wide spread squeegee look, where as the travel lane was routered with a narrow appearance. Could be that the travel lane was done sooner and ahs had significantly more traffic and has worn down. Most of the sealing looked pretty good, but missed and secondary cracking was present. Maybe Illinois idea of going wide to begin with makes sense. Took several pictures.

After inspecting US 30 by the Sub we decided to go to the La Porte District and talked to Sam E. W had herd La Porte was trying a new type sealer and asked Sam about it. It 
turns out that Strawser of Ohio makes it. Essentially, it is Extrudamat with a little rubber. Sam says it costs about the same as hot pour. I told him from our previous study that this type of stuff works pretty good for about two years. He says they would target roads with flexible bases with this stuff because of the bigger random pattern cracks (secondary as well) that come through as the disc covers a wide patch. The hot pour would be use over concrete resurfaced with bituminous because the reflected joint is straighter and can be routered and sealed better. Whether or not this idea holds up is not certain. Also Sam admitted that getting the $\mathrm{AC} 10$ is going to be a problem as this paving grade had to be picked up in small quantities hot, and stay hot. Vendors may not be able to supply.

La Porte has put two wands on a Melter, mainly to mimic the Strawser operation. The cost was about $\$ 3000$. They have not yet had a chance to try this out. Sam did have several complaints about the melter and appeared to be unsatisfied with Melter Corp assistance. To have some repair work done they had to deliver a Melter just North of the Kentucky line. They did this in July and did not get the Melter aback until October.

La Porte has done contract work (H Crafco D-3405) on the Valpo SR 49 by-pass (maybe it was US 35.) Estimated cost $\$ 200,000(\$ 1.75 \mathrm{ft})$, actual $\$ 63,000(\$ .70 \mathrm{ft})$. They plan to do more because that is the only way to get "caught up".

Sam told me that a fleet size of two melters per district my go into effect. That would preclude buying any other kinds for the time being.

They still do emulsion sealing. Tried some modified AE, but didn't think there was any difference, but Sam thinks when they picked the stuff up they may have pulled from the wrong tank.

Each sub had about 40 days scheduled for crack sealing in work program. On two lane roads they do a one mile wrap...4 lane roads a three mile closure with cones.

Sam said passing the equipment around makes it hard to maintain the equipment properly.

12/12/95 Training Committee discussed the rough draft of the script. The subcommittee scheduled a meeting to finalize a script for 1/16/96 at PDC.

12/22/95 Received crack sealing information from Maintenance Operation.

02/13/96 The Committee discussed the final script for Crumb Rubber Crack Sealing (apparently, the subcommittee did meet on January $16^{\text {th }}$ and come up with a final script). We are now simply waiting to film this procedure.

04/23/96 The Committee provided no further discussion for the matter since we were simply waiting to film.

10/29/96 Field inspection in Cloverdale.

11/13/96 Report sent to Crawfordsville. 
12/06/96 Field inspection sent to Dale Subdistrict.

12/16/96 Results of questionnaire sent to districts.

01/23/97 Report sent to Crawfordsville.

01/25/97 Report sent to Seymour.

01/28/97 Report sent to Vincennes.

05/19/97 Transmitted infrared temperature guns to all Districts.

09/18/97 Copies of "draft" Training Manual done by Research sent to Central Office for input/review.

12/06/97 Field Inspection Falls City.

06/08/98 Contacted Dan. He said district personnel liked manuals and he is having more printed. Not much crack sealing has been done because the material has failed the bond test. Also some material tested in the past had failed. I understood him to say that there appears to be too much limestone dust in the mix and not only does it wear out the pump faster, it settles to the bottom thus insulating the heat transfer process. Out of 10 gal. of material only 7 is usable. The state will be buying more melters and routers. Some have had good luck with different melters and would like to get away from the original melter purchased.

06/10/98 Contacted Jerry of Vincennes District - He said a corporation located in Cheyenne, WY made material that failed. I understand that Vincennes bought this material on their own requisition, then sent it in to be tested and found that it failed and never applied any of it to pavement. Then Vincennes borrowed material from Seymour and did not have any problems. Subdistrict Managers meeting just over and the overall consensus is they need more material and would do more sealing. They had lots of problems with the original melter (e.g. : wand too heavy, temperature gauge went bad), and they never did find who got the temperature gun sent out by the Research Division.

State has statewide QPA effective June 1, 1998 with McAsphalt Industries Limited of Ontario, Canada.

06/10/98 Contacted M \& Test. They did testing of failed material in the presence of the manufacturer. Manufacturers say to get rid of all material left at end of day. Also effort should be made to heat and use quickly. Overheating and heating for an extended period of time will damage sealant or allow a chemical change in the material that reduces its performances. This might be a bid advantage for using a 
smaller capacity boiler. He will send ASTM D 3405-96 and other documents that might be helpful.

06/10/98 Contacted Randy of Dale Subdistrict Vincennes - He went to Seymour last 11/97 to get sealant. Used with original melter and did not have any problems. Overall does fine on new roads. Will meet with crew on Thursday and confirm what other types of melters have been used and call back.

06/10/98 Contacted Fall City Subdistrict - They like the new melter very well. Loaned it to Crawfordsville. Presently it is in the shop getting the burner tubes replaced. They plan to do a lot of interstate and concrete sealing. The model 250 indicates gallons of sealant. They received videotapes about the unit but no manual.

06/10/98 Contacted Gordon of Crawfordsville Subdistrict - Their original melter was used every year. Last year it was "210ed" and are waiting for new melter to arrive. As of today he has not seen the new manual or video.

06/10/98 Contacted Mike of Evansville Subdistrict, finished crack sealing with AE 90. No hot crack sealing scheduled. Petersburg had some scheduled but could not get material as per meeting on $6 / 10 / 98$.

06/12/98 Contacted Roger of Tell City Subdistrict - They used the old material on concrete and it worked fairly well. They prefer to use it on bridge ends and concrete.

06/12/98 Contacted Crafco Customer Service, Kathy faxed the specifications for Roadsaver 201. Also see ergon.com/crafco.

Midwest Construction Products, Herb faxed specifications for material that failed.

06/12/98 Christine of Accounting and Control faxed the QPA specifications for material effective 6/1/98.

06/12/98 Contacted Steve of Bluffton Subdistrict and requested cost of hot pour crack sealing per lineal foot and left message.

06/13/98 Contacted Paul of Indianapolis Subdistrict. He will send cost per $\mathrm{ft}$. in a couple of days.

06/13/98 Contacted Rusty, on cost per lineal foot of crack sealing (transverse cracks) recomputed to $1 \mathrm{ft}$. of pavement. Cost per ft. of crack computed $\$ 0.29$ to $\$ 0.11$ per ft. pavement.

06/13/98 Contacted Rick of Plymouth Subdistrict, will send fax on cost per foot of pavement. 
06/16/98 Contacted Dennis, and he indicated long range plan is to continue the activity. The equipment fleet size has been set at 3 melters per District. Present status is Crawfordsville 1 and 1 on order, Fort Wayne 1, Greenfield 2 and 1 on order, La Porte 3, Seymour 1, and Vincennes 2. A total of 9 with 2 on order. The low bidder is Stepp. Seymour was the first to get a Stepp melter. The expected life of a "rubberized asphalt kettle" is six (6) years unless tank is stainless steel.

06/16/98 Doug and Chris provided state cost data and provided several updated corrections. Data is confirmed to be accurate, however, I disagree with Crawfordsville Subdistrict data for 3.2 miles at a cost of $\$ 7,214.00$ or a rate of $\$ 2,246$ per mile. On 7/14/98 contacted Ross of Fowler Subdistrict who agreed that something was very wrong with data. He will find out and call me. NOTE: Asked if this big expense could be caused by equipment breakdown, rainout, or what. He said they have a code \#120 for all such things.

06/29/98 Called Operation Support for crack sealing costs.

07/02/98 Called Roadway Management for crack data.

07/08/98 Contacted John of Roadway Management - Will have Bill find the number of cracks per lane mile for Interstate and non-Interstate roads. This information may be available in the databank for 500 foot sections of road, but may take several weeks to sort and retrieve. Friday, July 10, Roy picked up the $52 \mathrm{MB}$ data disc Bill is going to be out of the office for a week. It was the wrong data as it did not include the number of hairline cracks (cracks $<1 / 4$ and cracks $>1 / 4$ ). Will return disk with memo to get more data.

07/09/98 Received ASTM sealant data from Material and Test

07/09/98 Contacted MO regarding crack sealing cost data

9/2-10/98 Various discussions with Roadway Management

09/17/98 Called Crawfordsville, said schedule would be made within month.

09/17/98 Called Fort Wayne District to get location of work being done.

09/17/98 Called Greenfield to get work schedule.

09/17/98 Called La Porte to get work schedule.

09/17/98 Called Seymour to get work schedule.

09/17/98 Called Vincennes to get work schedule.

10/23/98 Review of random sampling memo to check applicability to crack sealing. 
10/26/98 Rusty of Fowler said they are doing Wabash Correction Facility then will be at Paxton and Linton and will call with date. October 30, Rusty called. Linton to do SR-63 and SR-48 next week.

10/29/98 Larry said Veedersburg would be cracking sealing on November 2, 4 and 6, 9 then the boiler goes to Cloverdale.

11/02/98 Veedersburg is doing US-36 on Thursday and Friday, then will be finished for the year.

11/05/98 Called Linton - and they are not sure when they will do cracksealing. They will call me when ready as they are waiting on router parts from Tennessee.

11/13/98 Vincennes moved equipment to Payola.

11/17/98 Final visit to Tipton Subdistrict on SR-37.

11/17/98 During visit Ray B. mentioned need for Melter parts. I told him I had address and internet site address and would sent it to him. Supply of parts is limited to what they have in stock as they are looking for a buyer to take over the Melter line.

11/17/98 Called Anderson Subdistrict for work schedule.

11/17/98 Greenfield, Tipton Sub, SR 37 N of Noblesville.

11/18/98 Jim M said on November 19 they would finish SR-29 which is a resurfaced full depth asphalt road.

11/18/98 Ross C said they will do some crack sealing after Thanksgiving and Gary B would give me a call.

11/18/98 Jim M said Melter was at Logansport and had some problems.

11/18/98 Called Winamac and Wabash Subdistrict.

11/19/98 Final visit to Monticello Subdistrict on SR-29.

11/19/98 La Porte, SR 292 mile N of SR 218.

11/20/98 Bill K. said Monday and Tuesday they rented new melter and it would be used on SR-119 and they were pleased with the horseshoe shaped tip on the wand which reduces the need for a squeegee.

11/20/98 Gary W. said the Wabash Subdistrict would be doing SR-9 (concrete) on Friday, Monday, and maybe Tuesday. 
11/23/98 Called Fort Wayne District to get location of work being done.

11/23/98 Called Linton and router broke and he will call with schedule when finished.

11/23/98 La Porte site visit at Winamac SR 119 SB, N of SR 16.

11/23/98 F.W., Wabash, SR 9-NBTL - N of SR 124

11/25/98 Called Winamac to get crew day card information

11/25/98 Called Columbus - never had a melter at Columbus

11/25/98 Called Fall City in Seymour District. They are not doing any now, but maybe in 3-4 weeks. Move one Stepp and did some refurbishing on it.

11/30/98 James D of Linton Subdistrict called with schedule for December.

11/30/98 Called Tipton to get crew day card information.

11/30/98 Called Wabash to get crew day card information.

12/03/98 Called new owner of Melter Corp. for spec sheet on transfer oil. Also checked on availability of repair parts.

12/03/98 Contacted Chris to obtain MSDS sheet for heat transfer oil.

12/04/98 Called Leffert Oil Company for Spec sheet on transfer oil and received $4 \mathrm{pg}$ fax. Both sets were faxed to Wabash and Fort Wayne District Office.

12/04/98 Contacted Bill regarding heat transfer oil MSDS.

12/04/98 Called Fort Wayne to get sample of transfer oil. Turns out to be difficult to do as drain plug is not set up to take a small sample.

12/07/98 Called to confirm work at Linton

12/07/98 Called Crawfordsville Subdistrict for work scheduled.

12/08/98 Final visit to Terre Haute Subdistrict and found out Stepp melter is in operation. Crawfordsville Melter was 210'd in 1997.

12/08/98 Final visit to Linton Subdistrict on SR-48.

12/08/98 Crawfordsville, Terra Haute, SR 340. 
12/08/98 Vincennes, Linton, SR 63 S of SR 48.

12/04/98 Pursuing inquiries regarding properties of heat transfer oils in hopes of finding higher quality.

12/09/98 Called Stepp Mfg. To discuss operation, maintenance, transfer oil requirement, and training program.

12/09/98 Contacted "new" melter vendor to request information and assistance on behalf of districts.

12/10/98 Message from Bill B "no task listed for level B PM or reference to transfer oil." Maybe there should be and also to check firebox for diesel soot.

12/14/98 Received Operation and Maintenance manual along with a parts manual for 3 different sizes of new oil jacketed kettles. Also photos and a videotape was included. Stepp Mfg. gives the State of Indiana permission to use any of the above as needed.

12/14/98 Called Tipton Subdistrict to get updated crack sealing cost from computer printout. They said that was the updated version that was received.

12/18/98 Called Central Office (Carolyn L) for correct melter and other costs for Tipton Subdistrict.

12/22/98 Called Milestone for standard equipment cost of basic vehicles and air compressors. They use bare equipment costs plus fuel and maintenance, which equals about $20 \%$ of cost. Page was received later that day.

12/22/98 Talked to Doug T. Central Office about corrected equipment cost. He said he recently sent another list to Tipton Subdistrict and that he would send us a list as well. List (8 pages) was received shortly thereafter.

12/22/98 . Contacting contractor s regarding equipment costs.

01/25/99 Contacted local company to inquire about a better sealant handle

03/08/99 Road School was held and we gave support to the presentation and attended to lobby for use of temperature gun and other issues.

03/08/99 Preparing final report is last entry. 
Appendix C 


\section{CRACK SEALING ON SITE EVALUATION FORM PROJECT HPR 2076}

GENERAL

\begin{tabular}{|c|c|c|c|c|c|}
\hline $\begin{array}{l}\text { Name (s) } \\
\text { D. WARD, C. ROSSMAN }\end{array}$ & \begin{tabular}{|l|} 
Date \\
$10 / 4 / 94$
\end{tabular} & $\begin{array}{l}\text { Time } \\
10: 00 \quad A M\end{array}$ & \begin{tabular}{|l} 
Dist \\
ILLINOIS
\end{tabular} & Subdistrict & $\begin{array}{l}\text { Location (Road) } \\
\text { MILE MARK } 194 \text { ON I- }\end{array}$ \\
\hline $\begin{array}{l}\text { Weather } \\
\text { SUNNY-COOL NO RAIN }\end{array}$ & & & & $\begin{array}{l}\text { Ambient Te } \\
\text { Pavement }\end{array}$ & $\begin{array}{l}\mathrm{mp} .66 \\
\mathrm{emp} .0\end{array}$ \\
\hline
\end{tabular}

MANPOWER

\begin{tabular}{|l|l|}
\hline Crew Supervisor's Name DENNY K & INU \\
\hline Experience / Training Received 4 YEARS - VERY GOOD CREW
\end{tabular}

Number of Personnel $\quad 9-10$

ROAD CONDITION O TO 10

Traverse cracking

Longitudinal cracking

Secondary cracking:

Alligator Cracking:

Other:

General Road Condition

\begin{tabular}{|c|}
\hline 4 \\
\hline $4-5$ \\
\hline 1 \\
\hline 1 \\
\hline
\end{tabular}

(O Is zero defects) Comments / Frequency $1 / 30$ YARD

MATERIAL

Material used / Company / Lot \# CRAFCO ROADSAVER 201

Sealant level in melter

Sealant Temperature 350 DEGREES

Amt. of Sealant reheated from previous day AS LITTLE AS POSSIBLE

Material Handling / type of applicator / seal configuration

EQUIPMENT

Pick-ups 1 FOR MELTRMelter

Trucks

Air Comp

Other

Traffic Control - if unique

NO. Type of Squeegue 2 FLASHING ARROWS - SEE VIDEOTAPE

No/Make Model Condition

Ty of Squeegees available

1 IN A U SHAPE / OVERBAND WIDE

\section{SAFETY / SUPPORT / CONCERNS}

Appropriate Safety procedures / problems

Tips to pass On IF CRACKS ARE CLEAN AND NOT WET MATERIAL HAS GOOD BOND

\begin{tabular}{|c|c|c|c|}
\hline Video/ Pictures taken & Slides Prints & Reference: \\
\hline $\mathrm{x}$ & $\mathrm{x}$ & & \\
\hline
\end{tabular}

\section{PRODUCTION / EFFICIENCY}

\begin{tabular}{|l|l|l}
\hline Time start $8: 30$ & Time stop 3:00 & Efficiency Factor \\
\hline Length of Production & &
\end{tabular}

Production Information 
Appendix D 


\section{SUMMARY OF SHRP MANUAL ON CRACK SEALING}

(\#H-348, "Materials and Procedures for Sealing and Filling Cracks in Asphalt Surface Pavements).

This summary of SHRP-H-348 was prepared as a quick reference training aid to assist INDOT in distributing information to help improve crack sealing operations. It was prepared to reflect the perceived needs of maintenance personnel. Suggestions and the author's comments appear in parenthesis of italicized.

\section{Planning}

Like most worthwhile efforts, crack sealing needs to be preceded by careful planning, followed by execution of the work activity and an assessment of effectiveness. The SHRP Manual provides an outline of how this should be accomplished.

\section{Filling Versus Sealing}

Cracks can be treated by filling or sealing. Filling is typically appropriate for wide cracks ( $3 / 4$ " plus) that do not show very much vertical or horizontal movement on an annual basis (most longitudinal or edge cracks do move very much). Emulsion materials or fine grain hot asphalt mixes are best suited for these "non-working cracks."

Cracks that show movement of more than about a tenth of an inch per year (most transverse cracks across the pavement) are best sealed with materials that have elastic properties (hot pour sealant). Field measurements can verify this movement by checking the difference between the width of cracks at mid summer and mid winter with a ruler. (choose and mark specific sample locations with nails). 


\section{Road Selection}

Road sections with high crack density or significant deterioration (e.g., repeated transverse cracks closer than 5 feet or secondary cracking or alligator patterns) are not good candidates for hot pour sealing. The SHRP "Manual" outlines a process for road section evaluation that includes a form and example distress pictures.

\section{Sealing Options}

Crack sealing can be accomplished using a number of finishing techniques including:

- Flush-fill (no squeegee)

- Reservoir (routing)

- Overband (shaped squeegee)

Each has advantages.

Overbanding is acceptable for roads with low traffic or roads that have cracks with widths of $1 / 4$ " to $3 / 4 "$. Wide overbands can help seal existing or expected secondary cracking. Overbands use more sealant and can be clipped off by snowplows.

Routing provides a recessed seal that snow plows will not clip off. However, it requires more equipment and personnel, which increases costs (about ten per cent). Also, if performed incorrectly it can damage pavement and precipitate deterioration. If it is determined narrow cracks ( $1 / 4$ " or less) will be sealed then routing is appropriate. Routing with carbide blades is recommended as the cut is smoother and blades need to be changed less frequently (saves on labor of changing blades frequently). 


\section{Cleaning (quote from SHRP Manual)}

"Compressed air units should have a minimum blast pressure of $100 \mathrm{psi}$ and a blast flow of $150 \mathrm{cu}$. $\mathrm{f} / \mathrm{min}$. In addition, compressed air units equipped with oil and moisture filtering systems are highly recommended, as the introduction of oil or moisture to the crack channel can seriously inhibit bonding of the sealant to the sidewall.

The importance of a clean dry crack prior to sealing with hot pour materials can not be over emphasized.

\section{Costs/Evaluations}

The SHRP Manual has several sections on cost effectiveness and treatment evaluation. It is important to make this part of the "crack sealing program". These sections provide a good basis for initiating such efforts.

\section{Material Preparation/Production}

- Follow the manufacturers guidelines

- Dissimilar sealant should not be mixed

- Be aware of two temperatures

* Recommended application temperature

* Safe heating temperature

- Begin heating material early on so the crew does not waste time. Cost analysis will show that down time waiting on the material to heat up is very expensive.

- Add material at a rate that matches production

- In general, it is best to run the melter down at the end of the day leaving only a small amount of sealant in the lank. 
- If using a squeegee, stay fairly close behind the wand so the material is spread while still hot as this promotes a good bond.

- Blot the material with toilet paper to control tracking

\section{Additional Items In the SHRP Manual}

- Material Specifications

- Sample Cost-Effectiveness

- Check List Calculations 
Appendix E 
TO: $\quad$ District Directors

THRU: Barry K. Partridge, Chief

Division of Research

FROM: Dave Ward, Section Manager

Research Division

SUBJECT: Summary Results of Hot Pour Crack Sealing Questionaire

Last fall as part of a research project the Division of Research distributed a questionaire to all subdistricts to solicit opinions/experiences regarding hot pour crack sealing. A summary of the responses (26 subdistricts) is attached for your review. Because there were numerous questions (34) and some reqested a written response, the summary was divided into two parts.

Attachment \#1 is the original questionaire as it was distributed.

Attachment \#2 (Part 1) is a summary by subdistrict of "multiple choice/yes-no" answers and attactment \#3 (Part 2) is a consolidation of written responses to questions $6,7,28,30,31,32,33$ and 34 .

Part 1 lists the subdistricts across the top of the page with an abbreviation of each question down the page. The last page of Part 1 totals the responses for the subdistricts in the first column. The second column shows the range of responses, and the third column lists an average value (if applicable). submitted.

Part 2 lists questions followed by a sampling of the remarks

The results of the questionnaire reflect a broad range of responses because subdistricts have different levels of experience with hot pour crack sealing (none to experienced). Additionally, some questions appear to have been misinterpreted and have have been answered inappropriately. Nevertheless some generalizations can be drawn from the results: 
* at least five subdistricts do more than $40 \%$ of their crack sealing with hot pours (question 2)

* most hot pour work is done in October (question 5)

* $\quad 18$ subdistricts plan to expand hot pour operations (question 7 )

* $\quad$ many subdistricts do not send in hot pour samples (question 8 )

* $\quad 15$ subdistricts planned to seal an average of 30 miles with hot pour sealants (question 9)

* $\quad 7$ subdistricts always route for hot pour and 8 said it depends on the road ( question 12)

* 6 out of 11 subdistricts indicated carbide cutters last 3 times longer than steel ( qestion 14)

* of the five subdistricts that have used melters other than Berry most would prefer to use Aeroil or Crafco (question 18)

* 13 out of 18 subdistricts have someone come inearly to fire up the melter (question 21)

* $\quad$ more than half the Berry melter users said overall they were seem satisfied, but felt the hose is to heavy ( question 20 )

* approximately half those responding think Activity 209 should be changed ( question 28 )

\section{Conclusions - Comments from the Division of Research}

First, thanks to all who responded to the questionnaire. All of the comments will be addressed at some time, even though they are not specially mentioned in this memo.

From the responses and the field visits with the crews, we believe the top priority should be to re-evaluate the melters to determine if there is any hope of upgrading/modifying them to 
improve the reliability so that they are productive. The hot material must be ready when the crews and the weather is right. The following step might be to rent/lease melters from different manufacturers to evaluate their performance.

Next priority might be to refine the policy and procedures and training. We feel these would help to establish more uniformity state wide. Starting with the proper selection of roads for crack seal.

Activity 209 should some how take into account the wide range in the number of cracks possessed by some roads. The answer might be if your production in miles per day is low; the road was too bad to hot crack seal in the first place.

More training and/or passing along tips on how to work better, appears to be needed. A video tape is being developed that will address some of these items. However we find that video tapes often are not viewed by the individuals who need the information. One tip learned in the field is have one operator assigned to the melter and to accompany it to the other subs. 
SUBBMITTED BY: SUBDISTRICT LOCATION: DISTRICT :

1. How many miles of road is your subdistrict responsible for maintaining?

2. What percent are cracked sealed each year? (e.g. 20\%)

of the total percent sealed each year what is the breakdown between Emulsion?

Hot pour?

(for example; subdistrict tries to seal $30 \%$ of total with hot
pour) 3. Do you perform longitudinal and transverse sealing as one operation (check appropriate line)?

Emulsions :

Frequently

Occasionali $\overline{l y}$

Infrequently

Hot Pour:

Frequently
Occasionaly
Infrequently

4. What type/grade of emulsion do you use the most (check one)?

AE 150

AE 90

AE modified

Other List name

5. What month(s) is your peak time for performing crack sealing
(circle month(s))?

Emulsion:

$$
\mathrm{J}-\mathrm{F}-\mathrm{M}-\mathrm{A}-\mathrm{M}-\mathrm{J}-\mathrm{J}-\mathrm{A}-\mathrm{S}-\mathrm{O}-\mathrm{N}-\mathrm{D}
$$

Hot Pour:

$$
\mathrm{J}-\mathrm{F}-\mathrm{M}-\mathrm{A}-\mathrm{M}-\mathrm{J}-\mathrm{J}-\mathrm{A}-\mathrm{S}-\mathrm{O}-\mathrm{N}-\mathrm{D}
$$

6. List factors/processes/road conditions in order of importance which your subdistrict uses to determine if a road should be scheduled for crack sealing (e.g., visual road check, age,
complaints, policy) 
Emulsion:

a.

b.

c.

d.

e.

f.

Hot Pour:

a.

b.

c.

d.

e.

f.

Additional Comments:

7. Does your subdistrict plan to expand the use of hot pour crack sealing (circle one)? Yes No

Why:

8. Do you sample sealants and send them to Materials \& Tests for testing (circle one)?

Emulsion: Yes No

Hot Pour: Yes No

9. How many miles/lane miles of road do you plan to seal with hot pour sealant this year (work program)?

10. Do you use hot pour crack sealing for concrete roads (circle one)?

$$
\text { Yes No }
$$

11. Have you received/referred to a black/white spiral bound SHRP manual (size, 8" by 10") which presents information on how to set up and manage an effective crack sealing program (circle one)?

$$
\text { Yes No }
$$

12. Do you route when using hot pour sealants (check one)? 
Always

Never

Occasionally

Depends on road conditions

13. If you route, what width and depth do you try to achieve (check one)?

\begin{tabular}{l} 
depends on the road \\
$1 / 2 "$ wide, $1 / 2$ " deep \\
$1 / 2 "$ wide, $3 / 4$ " deep \\
$3 / 4 "$ wide, $1 / 2 "$ deep \\
\hline other dide, deep
\end{tabular}

14. What type of blades do you use when routing (check one)?

\section{steel}

carbide

If you used carbide how did they compare to the steel ones (check one)?

about the same

lasted twice as long
lasted three times as long
other

15. What type of squeegee do you use for most hot pour crack sealing (check one)?

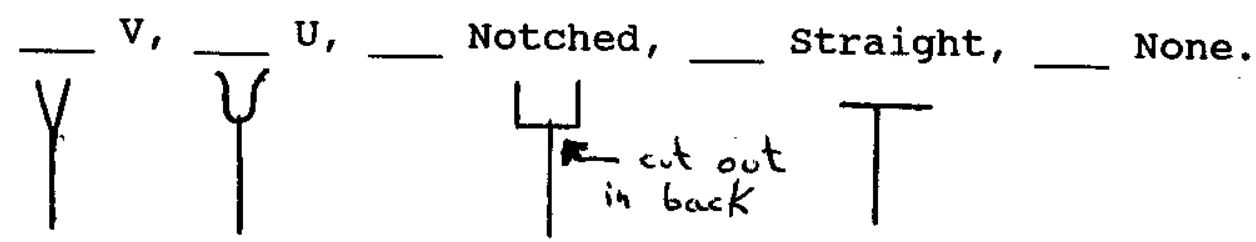

16. What brands of routers have you used (owned by INDOT, rented)? Crafco

Aeroil

Other(s), Please list

17. Most of the routers the Department owns/uses are made by Crafco. Have you been satisfied with their performance (circle
one).

$$
\text { Yes No }
$$

Why:

18. What brands of double boiler melters have you used (check
those that apply)? 
Berry

Crafco

Aeroil

Other(s), Please list

19. If you have used different double boiler melters do you have a preference? If so, what brand do you favor and why?

20. Most double boiler melters now used by the Department are made by the Berry Corporation. If you have used this melter please check the statements which apply.

Overall satisfied with melter performance

Dissatisfied with melter performance

Crew members have complained about heavy hoses

Temperature gauges inaccurate

Automatic thermostat unit has failed

Hose or couplings have failed

Pump will not maintain constant flow of sealant

Frequent maintenance has increased down time

Did the melter have a lighter weight aluminum wand

Sealant level was difficult to determine

Warranty provisions were used to cover most problems

Training on using the melter was provided by the vendor or an experienced INDOT employee

Maintenance and operating manuals came with the melter

A training tape was provided with the melter

other comments you may have about the Berry melter.

21. Do personnel come in early to fire up the Berry melter (circle one)?

Yes No

If No, how do you manage delays waiting for sealant to heat up?

22. What modifications/improvements have you made to the Berry 
melter and why?

23. How frequently do you use a hot air lance for hot pour crack sealing (check one)?

Never

Always

occasionally

Special conditions. Please describe

24. Based on actual reportable incidents how would you rate the safety risks of performing hot pour crack sealing?

Higher than other maintenance activities

About the same Safer

25. Please list the types of accidents which have occurred while performing hot pour crack sealing (e.g., operator burned hand on wand).

26. Do you require router operators to wear dust masks (circle one)?

$$
\text { Yes No }
$$

27. When you perform hot pour crack sealing how often do you meet the requirements of activity 209 (e.g., use larger crew, use smaller crew)?

Always

Usually

Infrequently 
28. Do you think activity 209 should be changed (circle one)? Yes No

If Yes, what changes do you recommend?

29. What can the Department do to improve hot pour crack sealing?

30. Have you tried to combined pieces of equipment in different combinations (e.g. piggybacked compressor on truck which pulls the melter, circle one)?

Yes No

If yes, what did you do and how did it help.

31. In your opinion what is the single most important action/equipment which you believe would help improve hot pour crack sealing? 32. What is the single biggest problem associated with hot pour
crack sealing? 
33. Have you attempted to reseal any roads originally sealed with hot pour crack sealant (circle one)?

Yes No

What problems did this create if any?

34. Has anyone explained to you why the Department is starting to use hot pour sealants (circle one)?

$$
\text { Yes No }
$$

If Yes, what were you told and by whom (title only no names)? 
RESPONSE OF

CRACK SEALING

QUESTIONNAIRE

1 Total miles of road?

2 What \% to Crack seal ea. yr?

$\%$ with emulsion?

$\%$ with hot pour?

3 Do you perform Longitudinal \& Emulsions:

Hot pour:

4 Emulsion Type/grade

5 Months peak time for Emulsions:

Hot pour:

6 See Other Format.

7 Plan to expand hot crack seal?

8 Send samples to M\&T? Emulsions:

Hot pour:

9 Ln miles planned to hot seal?

10 Use Hot pour on concrete?

11 Rec/refer SHRP manual?

12 Do you route for hot pour?

13 If yes, width \& depth?

14 Blade type? steel/ carbide How did they compare?

15 Type squeegee for hot $\mathrm{cs}$ s?

16 Brand of routers used?

17 You satisfied w/ Crafco router?

18 Brands of melters used?

19 If 2 or more, your preference?

20 Berry Melter Check applicable Overall satisfied

Dissatisfied

Complained heavy hose

Temp gauge inaccurate

Thermostat failure

Hose or coupling failure

Pump output not constant

Frequent down time

Have aluminum wand

Sealant level difficult to see

Warranty covered most prob.

Trng was vendor/INDOT

Maint/operation manuals

Video tape provided $w /$ melter

Other comments about melter

21 Personnel come early to fire up melter? comments?

22 Modifications/improvement?

23 Frequency of hot air lance?

24 Safety risks of hot pour cs?

25 list of accidents- hot pour cs.

26 Require router oper. wear mask

27 Meet requirements of act 209

28 Should act. 209 be changed? Comments see attached

29 What can dept. do improve cs

29 Comments see attached

30 Combined pieces of equip?

30-34 Comments see attached c: hiuldavewhistques.wk4
GFD

GFD

Greenfield

Centerville

GFD

GFD

LAP

LAP

LAP

632

633

Anderson

Tipton

Laporte

Monticello

642

Rensselaer

\begin{tabular}{|c|c|c|c|c|c|c|}
\hline 632 & 633 & 634 & 635 & 641 & 642 & 644 \\
\hline 786 & 1200 & 634 & 800 & 641 & 680 & 690 \\
\hline $20 \%$ & $15 \%$ & $13 \%$ & $8 \%$ & $20 \%$ & $10 \%$ & $23 \%$ \\
\hline $85 \%$ & $90 \%$ & $70 \%$ & $0 \%$ & $80 \%$ & $50 \%$ & $75 \%$ \\
\hline $15 \%$ & $10 \%$ & $30 \%$ & $100 \%$ & $20 \%$ & $50 \%$ & $25 \%$ \\
\hline
\end{tabular}

\begin{tabular}{|c|c|c|c|c|c|c|}
\hline frequently & frequently & frequently & na & occasionally & Occasionally & Frequently \\
\hline
\end{tabular}

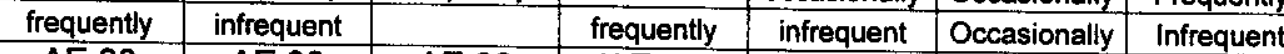

\begin{tabular}{|c|c|c|c|c|c|c|}
\hline $\mathrm{AE} 90$ & $\mathrm{AE} 90$ & $\mathrm{AE} 90$ & $(\mathrm{AE} 90)$ & $\mathrm{AE} \mathrm{90} \mathrm{S}$ & $\mathrm{AE} 90-\mathrm{S}$ & $\mathrm{AE} \mathrm{90-S}$ \\
\hline
\end{tabular}

\begin{tabular}{|l|ll|ll|lllllllllll}
\hline$, F, M, A$ & $N$, & $, F, M$ & $N$, & $J$ & $N, D$ & $(M, A$ & $N, D)$ & $M, A$ & $S, O, N$ & $M, A$ & $S, O, N$ & $J, F$ & $N, D$ \\
\hline
\end{tabular}

\begin{tabular}{|c|c|c|}
\hline S,O & S,O & $\mathrm{S}, \mathrm{O}, \mathrm{N}$ \\
\hline
\end{tabular}

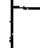

yes"

no

no

24

yes

yes

yes

yes

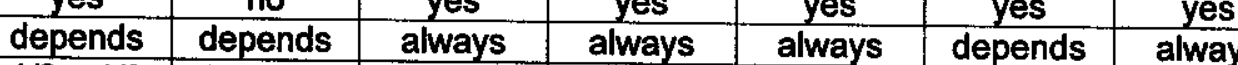

\begin{tabular}{|c|c|c|c|c|c|c|}
$1 / 2 \times 1 / 2$ & $1 / 2 \times 1 / 2$ & $1 / 2 \times 1 / 2$ & $1 / 2 \times 1 / 285 / 8$ & $3 / 4 \times 3 / 4$ & $3 / 4 \times 1 / 2$ & $1 / 2 \times 1 / 2$ \\
\hline
\end{tabular}

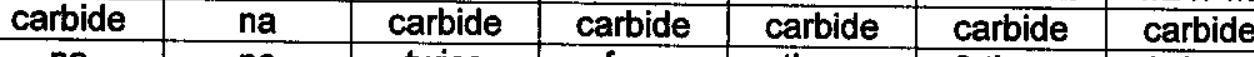

na

\begin{tabular}{c|cc|c}
\hline U & straight & U & \\
\hline Crafco-Aeroil & Aeroil & Aeroil & Craf \\
\hline
\end{tabular}

yes

no

NA

Crafco-Aeroi

three

3 times

3 times

\begin{tabular}{|c|c|c|}
\hline Berry\&Aeroil & Ber\&Aer & Berry\&Aeroil \\
\hline
\end{tabular}

Aeroil

each

Cra, Aer

Cra

yes

na

notched

$\mathrm{V}, \mathrm{U}$

\begin{tabular}{|c|c|c|c|c|c|c|}
\hline Aeroil & each & Crafco? & Cra, Aer & na & na & na \\
\hline & yes & & & yes-new & yes & ves \\
\hline \multirow[t]{4}{*}{ yes } & & & yes & yes-used & & \\
\hline & & yes & yes & & yes & \\
\hline & & yes & yes & yes & & \\
\hline & yes & yes & yes & & & \\
\hline yes & yes & & yes & yes & & \\
\hline yes & & yes & yes & & & \\
\hline yes & yes & & yes & & & \\
\hline \multirow[t]{2}{*}{ yes } & yes & & & yes & & \\
\hline & yes & & & & yes & \\
\hline yes & & & yes & & & yes \\
\hline yes & & & no & yes & & yes \\
\hline \multirow[t]{2}{*}{ yes } & no & & no & yes & yes & yes \\
\hline & yes & & & yes & & yes \\
\hline yes & yes & yes & yes & yes & yes & yes \\
\hline & & & & & & \\
\hline none & & none & & na & none & 2 alum. $w$ \\
\hline spec cond & always & never & never & never & never & always \\
\hline same & higher & same & same & same & same & safer \\
\hline none & router-leg & none & none & load-face & none & none \\
\hline no & no & yes & yes & yes & no & yes \\
\hline infrequently & usually & usually & usually & usually & usually & always \\
\hline no & no & no & yes & no & no & yes \\
\hline & & & & & & Pm activity \\
\hline rubber on bid & better router & improve equip & better equip & more routers & none & \\
\hline & 2 wands & & & & & \\
\hline no & no & no & no & no & no & no \\
\hline ee commen & & & & & & \\
\hline
\end{tabular}


RESPONSE OF

CRACK SEALING

QUESTIONNAIRE

1 Total miles of road?

2 What \% to Crack seal ea. yr?

$\%$ with emulsion?

$\%$ with hot pour?

3 Do you perform Longitudinal \& Emulsions:

Hot pour:

4 Emulsion Type/grade

5 Months peak time for Emulsions:

Hot pour:

6 See Other Format.

7 Plan to expand hot crack seal?

8 Send samples to M\&T? Emulsions:

Hot pour:

9 Ln miles planned to hot seal?

10 Use Hot pour on concrete?

$11 \mathrm{Rec} /$ refer SHRP manual?

12 Do you route for hot pour?

13 If yes, width \& depth?

14 Blade type? steel/ carbide

How did they compare?

15 Type squeegee for hot $\mathrm{cs}$ ?

16 Brand of routers used?

17 You satisfied w/ Crafco router?

18 Brands of melters used?

19 If 2 or more, your preference?

20 Berry Melter Check applicable

Overall satisfied

Dissatisfied

Complained heavy hose

Temp gauge inaccurate

Thermostat failure

Hose or coupling failure

Pump output not constant

Frequent down time

Have aluminum wand

Sealant level difficult to see

Warranty covered most prob.

Trng was vendor/INDOT

Maint/operation manuals

Video tape provided w/melter

Other comments about melter

21 Personnel come early to fire up melter? comments?

22 Modifications/improvement?

23 Frequency of hot air lance?

24 Safety risks of hot pour cs?

25 list of accidents- hot pour cs.

26 Require router oper. wear mask

27 Meet requirements of act 209

28 Should act. 209 be changed? Comments see attached

29 What can dept. do improve cs

29 Comments see attached

30 Combined pieces of equip?

30-34 Comments see attached c:LiwidavewiDistques.wk4

\begin{tabular}{c|c|c|c|c|c|c|}
$\begin{array}{c}\text { LAP } \\
\text { Valparaiso } \\
645\end{array}$ & $\begin{array}{c}\text { LAP } \\
\text { Winamac } \\
646\end{array}$ & $\begin{array}{c}\text { LAP } \\
\text { Gary }\end{array}$ & $\begin{array}{c}\text { SEY } \\
\text { Bloomington } \\
647\end{array}$ & $\begin{array}{c}652 \\
\text { Fall City } \\
654\end{array}$ & $\begin{array}{c}\text { SEY } \\
\text { Madison } \\
655\end{array}$ & $\begin{array}{c}\text { SEY } \\
\text { Scottsburg } \\
656\end{array}$ \\
\hline 683 & 716 & 900 & 716 & 1000 & 652 & 720 \\
\hline $10 \%$ & $20 \%$ & $15 \%$ & $33 \%$ & $12 \%$ & $25 \%$ & $33 \%$ \\
\hline $60 \%$ & $50 \%$ & $80 \%$ & $100 \%$ & $83 \%$ & $100 \%$ & $100 \%$ \\
\hline $40 \%$ & $50 \%$ & $20 \%$ & $0 \%$ & $17 \%$ & $0 \%$ & $0 \%$ \\
\hline
\end{tabular}

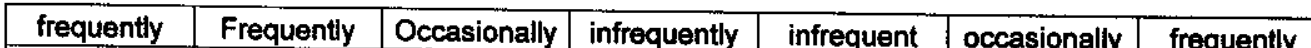

\begin{tabular}{|c|c|c|c|c|c|c|}
\hline frequently & Infrequent & Infrequent & na & infrequent & occasionally & frequently \\
\hline $\mathrm{AE} \mathrm{90}$ & $\mathrm{AE} \mathrm{90}$ & $\mathrm{AE} \mathrm{90}$ & $\mathrm{AE} 150$ & $\mathrm{AE} \mathrm{90}$ & $\mathrm{AE150}$ & $\mathrm{AE} 150$ \\
\hline & & & & & & \\
\hline
\end{tabular}

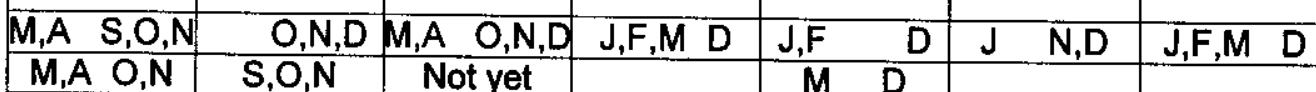

\begin{tabular}{|c|c|c|}
\hline \\
\hline
\end{tabular}

\begin{tabular}{|c|c|c|c|c|c|c|}
\hline yes & yes & na & no & yes & na & no \\
\hline & & & & & & \\
\hline yes & yes & no & no & no & na & yes \\
\hline yes & yes & na & & no & & \\
\hline & 28 & 86 & 122 ?ae150 & & & none \\
\hline no & yes & na & no & yes & $"$ & no \\
\hline yes & no & $"$ & no & yes & $"$ & no \\
\hline Occasionally & always & $"$ & never & never & $"$ & $"$ \\
\hline $3 / 4 \times 1 / 2$ & $1 / 2 \times 3 / 4$ & $"$ & $n$ & na & $"$ & $"$ \\
\hline carbide & carbide & $"$ & & na & $"$ & $"$ \\
\hline twice & 3 times & $"$ & $"$ & na & $"$ & $"$ \\
\hline U & straight & $"$ & $"$ & U & $"$ & $"$ \\
\hline Crafco & Crafco & $"$ & & & & \\
\hline
\end{tabular}

\begin{tabular}{|c|c|c|c|c|c|c|}
\hline & 10 & & & 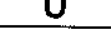 & & \\
\hline Crafco & Crafco & $"$ & $"$ & & $"$ & $\bar{"}$ \\
\hline yes & yes & " & $"$ & & $"$ & $\bar{"}$ \\
\hline Berry & Berry & $"$ & " & Stepp & $"$ & $\pi$ \\
\hline & & $"$ & " & & $"$ & $"$ \\
\hline
\end{tabular}

\begin{tabular}{|c|c|c|c|c|c|c|}
\hline & & & & & & \\
\hline & & II & & & & \\
\hline & ves & " & 7 & & & \\
\hline & & & " & & $"$ & " \\
\hline
\end{tabular}


RESPONSE OF
CRACK SEALING
QUESTIONNAIRE

1 Total miles of road?

2 What \% to Crack seal ea. yr?

$\%$ with emulsion?

$\%$ with hot pour?

3 Do you perform Longitudinal \& Emulsions:

Hot pour:

4 Emulsion Type/grade

5 Months peak time for Emulsions:

Hot pour:

6 See Other Format.

7 Plan to expand hot crack seal?

8 Send samples to M\&T? Emulsions:

Hot pour:

9 Ln miles planned to hot seal?

10 Use Hot pour on concrete?

$11 \mathrm{Rec} / \mathrm{refer}$ SHRP manual?

12 Do you route for hot pour?

13 If yes, width \& depth?

14 Blade type? steel/ carbide How did they compare?

15 Type squeegee for hot $\mathrm{c} \mathrm{s}$ ?

16 Brand of routers used?

17 You satisfied w/ Crafco router?

18 Brands of melters used?

19 If 2 or more, your preference?

20 Berry Melter Check applicable Overall satisfied

Dissatisfied

Complained heavy hose

Temp gauge inaccurate

Thermostat failure

Hose or coupling failure

Pump output not constant

Frequent down time

Have aluminum wand

Sealant level difficult to see

Warranty covered most prob.

Trng was vendor/INDOT

Maint/operation manuals

Video tape provided w/melter

Other comments about melter

21 Personnel come early to fire up melter? comments?

22 Modifications/improvement?

23 Frequency of hot air lance?

24 Safety risks of hot pour cs?

25 list of accidents- hot pour cs.

26 Require router oper. wear mask

27 Meet requirements of act 209

28 Should act. 209 be changed? Comments see attached

29 What can dept. do improve cs

29 Comments see attached

30 Combined pieces of equip?

30-34 Comments see attached c:ViwldavewlDistques.wk4

\section{$\begin{array}{llll}\text { VIN VIN VIN } & \text { VIN }\end{array}$ \\ Linton Dale Evansville Tell City \\ 662 \\ 663 \\ 665 \\ TOTALS-SUMMARY \\ 6 Dist.- 25 Subdistricts}

\begin{tabular}{|c|c|c|c|}
\hline & & 663 & 65 \\
\hline 846 & 765 & 925 & 595 \\
\hline $38 \%$ & $21 \%$ & $20 \%$ & $20 \%$ \\
\hline $99 \%$ & $95 \%$ & $90 \%$ & $90 \%$ \\
\hline $1 \%$ & $5 \%$ & $10 \%$ & $10 \%$ \\
\hline
\end{tabular}

\begin{tabular}{|c|c|c|c|}
\hline frequently & frequently & frequently & infrequent \\
\hline na & frequently & frequently & infrequent \\
\hline$A E 90$ & $A E 90$ & $A E 90$ & $A E 90$ \\
\hline & & & \\
\hline
\end{tabular}

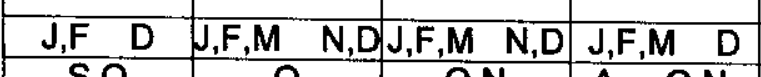

\begin{tabular}{|c|c|c|c|}
\hline$S, O$ & $O$ & $O, N$ & $A \quad O, N$ \\
\hline & & & \\
\hline yes & yes & no & yes \\
\hline
\end{tabular}

-

\begin{tabular}{|c|c|c|c|c|c|c|}
\hline yes & yes & no & yes & yes 17 & no 6 & \\
\hline & & & & & & \\
\hline yes & yes & no & yes & yes 11 & no 13 & \\
\hline no & yes & yes & yes & yes 6 & no 13 & \\
\hline
\end{tabular}

\begin{tabular}{|c|c|c|c|c|c|c|}
\hline no & yes & yes & yes & yes 6 & no 13 & \\
\hline starting & 6 & 25 & 0 & total-397 & for 13 subs & avg-22 mi \\
\hline not yet & yes & yes & yes & yes 10 & no 9 & \\
\hline no & no & no & yes & yes 12 & no 10 & \\
\hline
\end{tabular}

\begin{tabular}{|c|c|c|c|c|c|c|}
\hline occasionally & danondo & donanda & & 20. & & \\
\hline $3 / 4 \times 1 / 2$ & $314 \times 1 / 2$ & uepenus & ueperios & & & \\
\hline carbide & $\frac{014 \times 112}{?}$ & $1 / \angle \times 1 / 2$ & $1 / 2 \times 1 / 2$ & $1 / 2 \times 1 / 2(8)$ & $1 / 2 \times 3 / 4(2)$ & $3 / 4 \times 1 / 2(5)$ \\
\hline
\end{tabular}

\begin{tabular}{|c|c|c|c|c|c|c|}
\hline Aeroil & Aeroil & Crafco & Crafco & Aeroil-7 & Crafco-13 & none-2 \\
\hline
\end{tabular}

\begin{tabular}{|c|c|c|c|c|c|c|}
\hline & & yes & na & yes 9 & no 6 & \\
\hline Berry & Berry & Berry & Berry & Aeroil-5 & Berry-16 & Crafco-2 \\
\hline na & & na & na & & & \\
\hline
\end{tabular}

\begin{tabular}{|c|c|c|c|c|c|c|}
\hline na & & na & na & & & \\
\hline & & & yes & yes-10 & & \\
\hline & & yes & & yes- 6 & & \\
\hline & yes & yes & yes & yes- 8 & & \\
\hline & & & & yes -4 & & \\
\hline & & yes & & yes-7 & & \\
\hline & & & & yes-5 & & \\
\hline & & & & yes -4 & & \\
\hline & yes & & & yes-5 & & \\
\hline & & & yes & yes -4 & & \\
\hline & & & & yes-3 & & \\
\hline & & & & yes -5 & & \\
\hline & yes & yes & yes & yes- 8 & no-1 & \\
\hline & yes & yes & yes & yes-9 & no-2 & \\
\hline & yes & & yes & yes-6 & & \\
\hline no & yes & yes & no & yes-12 & no-5 & \\
\hline & & & & & & \\
\hline na & none & na & na & & special & condion-2 \\
\hline never & never & & always & never-8 & always -6 & occasion-2 \\
\hline same & same & same & same & safer-2 & same-14 & higher-4 \\
\hline & none & none & none & none-16 & accidents-4 & \\
\hline no & yes & yes & no & yes-12 & no-7 & \\
\hline usually & infrequently & infrequently & infrequently & always-2 & usually-13 & infreg-5 \\
\hline no & yes & yes & yes & yes-9 & no-12 & \\
\hline & 1/2-1 mi.day & & lower rates & & & \\
\hline training & boiler & better setup & na & & & \\
\hline no & yes & no & yes & yes-3 & no-18 & \\
\hline & & & & & & \\
\hline & & & & & & \\
\hline
\end{tabular}


Appendix F 
The following is an abridged description of the maintenance and basic operation of the Melter.

1. When towing the melter make sure it is level. This prevents spilling of the melted material.

2. The heat transfer oil should have a flash point below $500 \mathrm{~F}$. Berry Corp. can supply a list of companies and their products.

3. The heat transfer oil should be between the first notch and the end of the stick on the fill cap when cold.

4. The oil jacket must be vented to the atmosphere at all times. A clogged vent pipe can cause extreme and dangerous pressure on the oil jacket.

5. Never exceed $480 \mathrm{~F}$ oil temperature, because the teflon hose will be damaged (as much as $\$ 2000$ ).

6. Do not bend the teflon hose sharply.

7. If it takes too long to push the cold viscous oil out of the hose in the morning, blow it out with an air compressor while it is still hot (the night before).

8. Never fill the material tank more than $2 / 3$ full because volumetric expansion will cause it to overflow after it gets hot.

9. The material pump (located at the bottom of the tall box on the passenger's side of the tank) may be engaged only after the engine has been started, the agitator is turning and the starting load of sealant has begun to melt.

10. Before turning the pump on, make sure that at least 4-6" of liquid is present and agitator is turning freely. When the hatch is open, the stream of material being returned to the tank should be visible. No attempt should be made to operate the pump unless the material thermometer reads more than $300 \mathrm{~F}$. This should be checked for accuracy every day with a hand held thermometer.

11. The hand by-pass valve should be open, except when ready to pour from the wand.

12. This hand by-pass valve will also relieve vapor lock. Vapor lock occurs when the dissolved gases in the material becomes heated and entrapped in the pump gears. Usually, this will occur only if there is a large pressure drop on the nozzle.

13. For complete operating instructions refer to the Handbook on pages 6-8.

A. Check the engine crankcase oil every four hours. Change it 
after every 24 hour period of use.

B. Located in the middle of the material tank, the agitator shaft bearing should be lubricated every two hours with heat resistant grease.

C. Adjust the hydraulic system pressure relief only if engine bogs at highest RPM. This is located near the hydraulic operator on top of the tank.

D. Four way relief valve - If you need additional hydraulic pressure at either the agitator motor or the material pump motor, loosen the lock nut on the operator and turn the screw clockwise. NOTE: In doing this you use up valuable engine horsepower. Always make these adjustments with operator engaged and engine running to determine the effect on engine.

E. Set the speed adjuster while engine is running and appropriate operator engaged.

F. Periodically tighten packing nuts on material pump if too much leakage occurs.

G. For pump troubleshooting see the Manual pp. 10-11.

H. Inspect daily the hydraulic fluid in the reservoir. Make sure it is $1 / 3$ full when cold.

I. Check the heat transfer oil during each heating cycle. After every 50 hours of use open drain cock and draw of a sample of oil (when it is cool). If there is a black appearance to the oil, drain and refill with fresh oil.

J. Replace heat transfer oil at least once every 6 months. A maintenance $\log$ should be kept on the side of the kettle.

K. For complete details on operation and maintenance of the temperature controller, hydraulic control valve and spin-on filter, see section 7 in the Manual.

$\mathrm{K}$ a. For the hydraulic control valve - Make sure the reservoir has been filled with the proper hydraulic fluid. Bleed all air from hydraulic system to prevent erratic operation of the pump. Move the handle from center in each direction to ensure the system is operating properly. Moving the handle from one off-set position to the other should result in reversing the hydraulic motor or cylinder. Returning the handle to the center position should stop the motor and allow the flow of oil to pass from inlet to tank. To adjust the relief, remove the acorn nut. These are located near the hydraulic operator on top of the tank. Turn the adjusting screw clockwise to increase pressure and counterclockwise to decrease pressure. To adjust the pressure release detent, loosen the jam nut. Turn adjusting screw counter clockwise to decrease release pressure. Release is preset at $1400 \mathrm{psi}$. 
$K \mathrm{~b}$. For the spin-on filter - Cycle the system several times to make sure that fluid is flowing in the return-line where the filter is installed. Check all connections around the filter to make sure there are no leaks. If leaks are noted, shut down system, and retighten connections or add pipe compound until leaks are eliminated. If a pressure gauge is installed on the filter head, record the reading on the gauge while fluid is flowing in the line where filter is located. When gauge reads 15 PSI higher than initial reading, it is time to replace the canister. If the canister has been neglected, the system may be extremely dirty and require several canister replacements in rapid succession to clean the system.

When the pressure build-up reaches 15 PSI, the bypass valve opens and no filtration takes place. If this valve opens, the canister should be replaced immediately. After the initial installation, replace the canister after the first 50 hours of operation. Replace again after the next 100 hours. Replace canister every 250 hours after the first two changes. A log should be kept on the side of the kettle.

L. For complete information pertaining to the motor and burner see section 8 of the Manual.

L a. Oil burner maintenance - Periodically the oil filter cartridge should be replaced or sediment cleaned. Located between the tank shut-off valve and the burner, this will prevent the fuel oil from becoming contaminated, plugging up the fuel pump and nozzle of oil burner. The nozzle should be changed at least once each year. If the cleaning equipment is used daily the nozzle should be changed twice a year (or whenever poor combustion occurs). The electrode settings should be checked once a year in accordance with the instructions provided in the manual. Replace if worn excessively or if porcelain insulator is oil soaked or cracked. The fan and blower housing must be kept clean; free of dirt and lint. Open transformer to check fan blades from above. Be sure electric power is off on the burner when the transformer is opened up for inspection. Should the blower wheel be removed for replacement or cleaning, reinstall as shown in the manual.

M. For complete information on the pump, see section 9 of the Manual.

M a. Periodic external lubrication should be applied slowly with a grease gun at all fittings provided. A good quality of general purpose grease is satisfactory in the majority of cases. However, applications involving very high or low temperatures may require other types of lubrication. Suggested frequency is once every 500 hours of operations. Do not over grease.

Newly packed pumps require initial packing adjustment to control leakage as packing "runs in". Make initial adjustments carefully and do not over-tighten packing gland adjustment or packing replacement. Refer to instruction under Disassembly, page 6 (Berry Manual), and Assembly, page 6, regarding packing pump. 
Keep pump as clean as possible. This will facilitate inspection, adjustment and repair work and help prevent overlooking a dirt covered grease fitting.

If pump is to be stored or not used for six months or more, pump must be drained and a light coat of non-detergent SAE 30 weight oil must be applied to all internal pump parts. Lubricate fittings and apply grease to pump shaft extension. Viking suggests rotating pump shaft by hand one complete revolution every 30 days to circulate the oil.

N. Warranty and fire hazard information are found in section 10 of the Manual. 
Appendix G 
GUIDELINES FOR FIELD EVALUATION OF SEALANT INSTALIATIONS

The final test of a sealant material and installation configuration is how it performs over time in the field. Performing field evaluations therefore plays a critical role in advancing the practice of crack and joint sealing.

The sealant Installations which need to be evaluated fall into two categories: ordinary installations and test sites. Ordinary installations are those which are placed as ongoing maintenance operations, whereas test sites are placed primarily to determine how well particular materials, installation techniques or configurations will perform.

In order to study the relative merits of various seal systems placed as ordinary installations, it is necessary to evaluate very many sites and include many replicates of each seal system to be considered so that the particular conditions which exist at each site become less significant to the conclusions.

A valid test site installation must involve comparison between two or more seal systems placed in very close proximfty with as little variation between samples as possible. It is generally useless to place only one material in one configuration and call this a test site because the particular conditions at that location may have an overwhelming influence on the effectiveness of the seal system. Ideally, each test site will include at least one control sample which consists of a material and configuration with which considerable experience has been gained and for which the effectiveness and longevicy may be predicted with considerable confidence.

Whether an ordinary installation or a test site is to be evaluated, an objective evaluation procedure is required. Evaluation should be performed periodically in order to trace the variation of seal effectiveness with

time. A reasonable plan is to perform an evaluation three months after the seal is placed, six months after placement and then every six months. This schedule may be adjusted somewhat in order to meet the important objectives of performing at least one evaluation before the first winter period and of including evaluations during low temperatures when the cracks and joints will be open to their fullest.

The field evaluation form given in Figure F.1 provides a useful checklist of data to be recorded. Two of the ratings shown on this form, Watertightness and Pavement Condition, are essential and the third, General 
In the guide for assigning general appearance ratings for the seal:

Sinking into Crack refers to cases where the sealant has flowed or dropped down into the crack or joint. If this is substantial so that openings cause a watertightness rating, a bond fallure penalty may also be assessed.

Migration (Flow) refers to the lateral flow of sealant in an overband configuration across the paverent.

Edge Ravelling refers to the deterioration of the edges of the pavement at the crack or joint. It involves material within about two inches of the crack or joint and, if in an advanced state, may give the cracks and joints rounded shoulders.

Cupping is the depression of the surface of the pavement at the crack while Lipplng refers to the raising of the pavement along the crack.

Parallel Cracking refers to the formation of additional cracks parallel to and near the main crack or the joint. The most common occurrence is at transverse cracks in asphalt along with cupping.

In the guide for assigning pavement condition rating for PCCP:

Dlagonal Cracks refer to those cracks which form a triangle along with two edges of a slab panel. If the crack intersects the two adjacent edges within about 16 inches of the corner, the distress is assumed to be a joint distress item and is called Corner Cracking.

Fragmentation is the division of a slab panel into several pieces due to multiple cracks which are often in an approximately rectangular pattern.

Spalling as a joint and crack distress item refers to deterioration of the edges of the pavement at the joint or crack. Spalling is one form of edge ravelling described above. D-cracking is one form of spalling.

Ravelling as a joint and crack distress item is somewhat similar to parallel cracking in asphalt pavement. In concrete pavements, ravelling often occurs in the leave slab when faulting occurs at the transverse joint.

Widening refers to the opening of the crack or joint which progresses with time and is not fully reversed at warm temperatures when the pavements expand. 


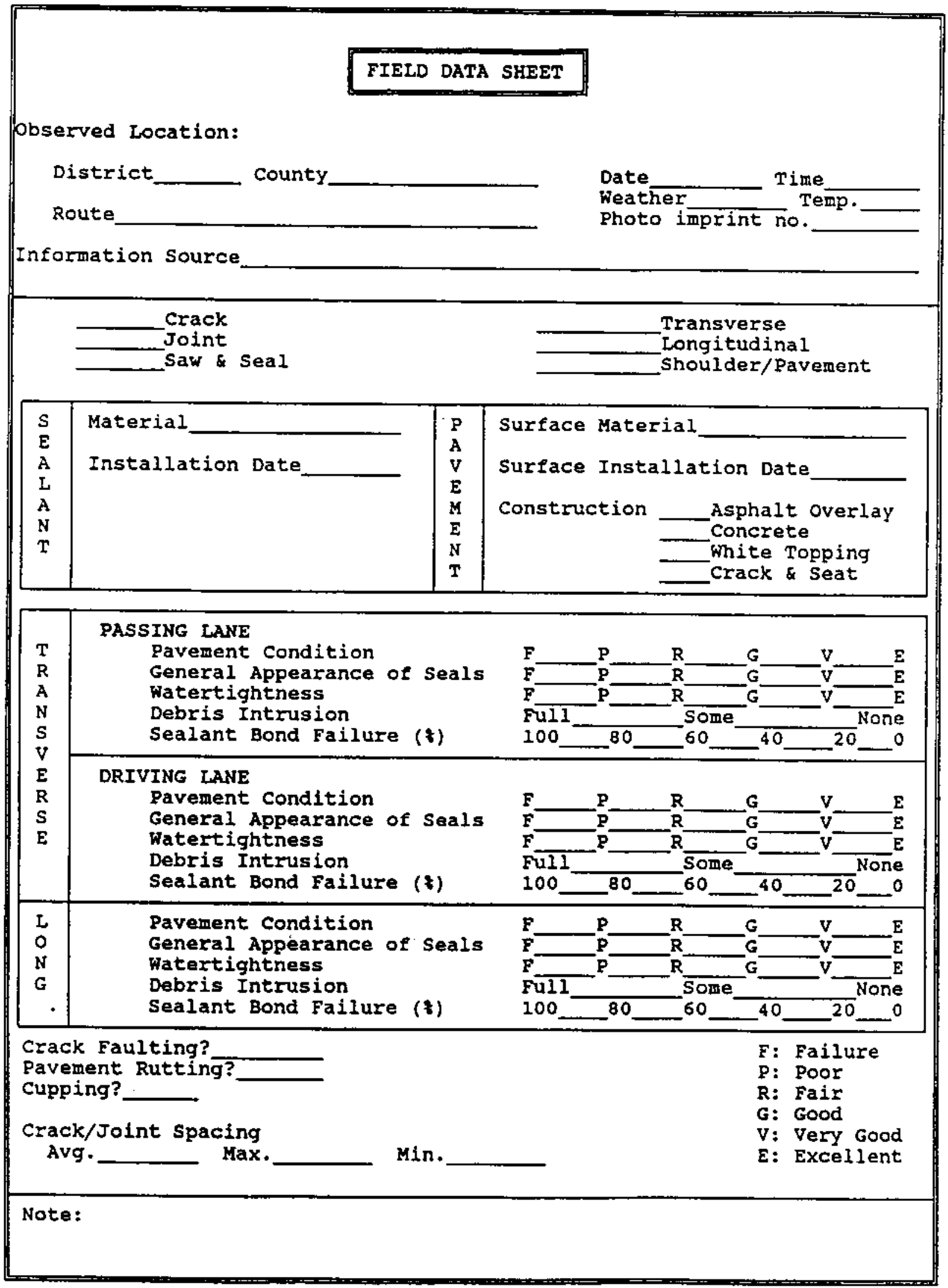

Figure F.1 Field Evaluation Data Sheet. 
GUIDE FOR ASSIGNING GENERAL APPEARANCE RATING FOR THE SEAL

\begin{tabular}{|c|c|c|c|}
\hline \multicolumn{4}{|c|}{ A: SEVERITY FACTOR KEY } \\
\hline Slight & Moderate & Heavy & Severe \\
\hline 1.0 & 2.0 & 3.0 & 4.0 \\
\hline
\end{tabular}

\begin{tabular}{|l|c|c|c|c|}
\hline \multicolumn{5}{|c|}{ B: EXTENT FACTOR KEY } \\
\hline 58 & $10-158$ & $20-35 \%$ & $40-658$ & $70-1008$ \\
\hline 1.0 & 2.0 & 4.0 & 7.0 & 10.0 \\
\hline
\end{tabular}

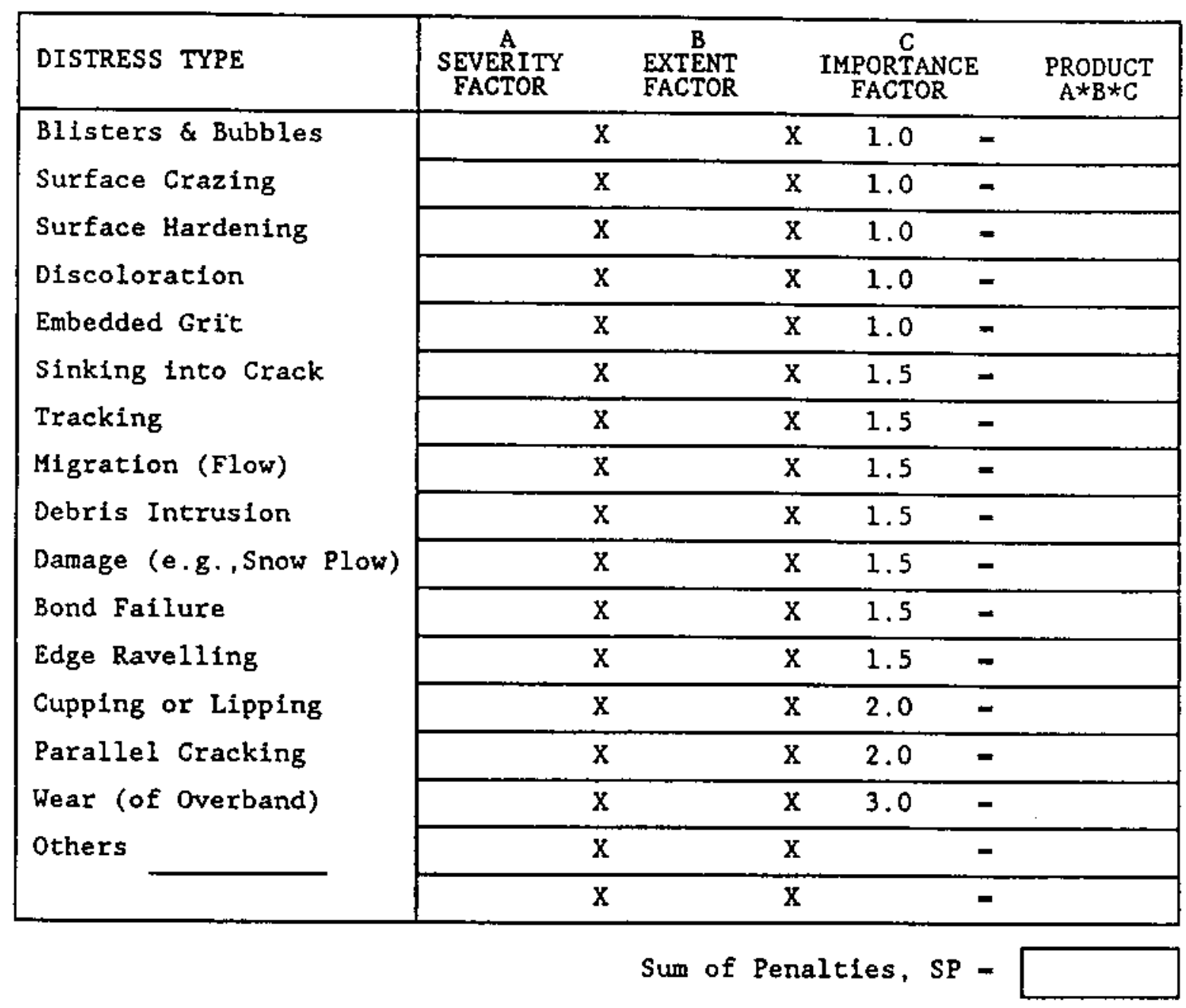

Rating $-\frac{200 \cdot S P}{200} \times 5.0=\square$

Figure F.4 Guide for Rating General Appearance of Seals. 
GUIDE FOR ASSIGNING PAVEMENT CONDITION RATING:

PORTLAND CEMENT CONCRETE PAVEMENT

\begin{tabular}{|c|c|c|c|}
\hline \multicolumn{4}{|c|}{ A: SEVERITY FACTOR KEY } \\
\hline Slight & Moderate & Heavy & Severe \\
\hline 1.0 & 2.0 & 3.0 & 4.0 \\
\hline
\end{tabular}

\begin{tabular}{|l|c|c|c|c|}
\hline \multicolumn{5}{|c|}{ B: EXTENT FACTOR KEY } \\
\hline 58 & $10-158$ & $20-358$ & $40-658$ & $70-1008$ \\
\hline 1.0 & 2.0 & 4.0 & 7.0 & 10.0 \\
\hline
\end{tabular}

\begin{tabular}{|c|c|c|c|c|c|c|}
\hline DISTRESS TYPE & $\begin{array}{c}\text { A } \\
\text { SEVERITY } \\
\text { FACTOR }\end{array}$ & $\begin{array}{l}\text { B } \\
\text { EXTENT } \\
\text { FACTOR }\end{array}$ & & $\begin{array}{c}\stackrel{C}{\mathrm{C}} \\
\text { IMPORTANCE } \\
\text { FACTOR }\end{array}$ & & $\begin{array}{c}\text { PRODUCT } \\
\mathrm{A} * \mathrm{~B} * \mathrm{C}\end{array}$ \\
\hline \multirow{5}{*}{$\begin{array}{l}\text { CRACKING } \\
\text { Transverse } \\
\text { Longitudinal } \\
\text { Random } \\
\text { Diagonal } \\
\text { Fragmentation }\end{array}$} & $x$ & & $\mathrm{x}$ & 1.0 & - & \\
\hline & $\mathrm{x}$ & & $x$ & 1.0 & - & \\
\hline & $\mathrm{x}$ & & $\mathrm{x}$ & 1.0 & - & \\
\hline & $\mathrm{x}$ & & $\mathrm{x}$ & 1.0 & - & \\
\hline & $\mathrm{x}$ & & $x$ & 3.0 & - & \\
\hline \multirow{3}{*}{$\begin{array}{l}\text { FAULTING } \\
\text { Trans. \& Long1. Jts. } \\
\text { Crack } \\
\text { Shoulder }\end{array}$} & $\mathrm{x}$ & & $\mathrm{X}$ & 2.0 & - & \\
\hline & $\mathrm{x}$ & & $\mathrm{x}$ & 2.0 & $=$ & \\
\hline & $\mathrm{x}$ & & $\mathrm{x}$ & 1.0 & $=$ & \\
\hline PANEL SETTLING & $\mathrm{x}$ & & $\mathrm{x}$ & 2.0 & $=$ & \\
\hline \multirow{4}{*}{$\begin{array}{l}\text { SURFACE DISTRESS } \\
\text { Spalling } \\
\text { Wear/Polishing } \\
\text { Crazing } \\
\text { Other }\end{array}$} & $\mathrm{x}$ & & $\mathrm{x}$ & 2.0 & - & \\
\hline & $\mathrm{x}$ & & $\mathrm{X}$ & 1.5 & 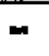 & \\
\hline & $\mathrm{x}$ & & $\mathrm{X}$ & 1.0 & $=$ & \\
\hline & $\mathrm{x}$ & & $\mathrm{X}$ & & $=$ & \\
\hline \multirow{5}{*}{$\begin{array}{l}\text { JOINT \& CRACK DISTRESS } \\
\text { Spalling } \\
\text { Ravelling } \\
\text { Corner Cracking } \\
\text { Debris Intrusion } \\
\text { Widening }\end{array}$} & $\mathrm{x}$ & & $\mathrm{x}$ & 1.0 & $=$ & \\
\hline & $\mathrm{x}$ & & $\mathrm{X}$ & 1.5 & $=$ & \\
\hline & $\mathrm{x}$ & & $\mathrm{X}$ & 1.0 & $=$ & \\
\hline & $\mathrm{x}$ & & $\mathrm{x}$ & 1.0 & $=$ & \\
\hline & $\mathrm{x}$ & & $\mathbf{x}$ & 1.0 & - & \\
\hline OTHER & $\mathrm{x}$ & & $\mathrm{x}$ & & $=$ & \\
\hline OTHER & $\mathrm{x}$ & & $\mathrm{x}$ & & - & \\
\hline
\end{tabular}

Rating $=\frac{200-S P}{200} \times 5.0=\square$

Figure F.6 Guide for Rating Pavement Condition, PCCP. 
Appendix $\mathrm{H}$ 
November 13, 1996

TO: $\quad$ Larry $\quad$, Operations Engineer

FROM: $\quad$ Dave Ward, Section Manager

Research Division

SUBJECT:

HOT POUR CRACK SEALING FIELD INSPECTIONS, DISTRICT, SUBDISTRICT, 10/29/96 - Highway Research Project 2076

Background

As you are probably aware there is a research project underway to study the implementation of hot pour crack sealing (rubberized crack sealing) by the districts. As part of this effort the Division of Research has been making field visits to observe hot pour implementation efforts and provide feedback. Due to weather and scheduling problems these field visits were suspended last "construction season," but are now being resumed. As a result of previous field visits (Fort Wayne, Greenfield, La Porte) and research findings, $\quad$ should have received information on crack sealing including, the SHRP Manual (this should be mandatory reading for all who perform crack sealing), video tapes/training materials from vendors/DOTs, plus summary results of field inspections. This year rather than provide summary information on inspections, each district will receive individual reports on their crews/locations that are observed.

This memo represents the first of the field inspection reports for 1996 . The information provided should help improve the effectiveness of the individual crews observed and operations in general. Because the continued cooperation of crews is desirable we hope the report(s) will be accepted as 
helpful hints/suggestions. The only persons receiving copies will be yourself and Study Advisory Committee Members. Distribution to your staff is at your discretion. The comments provided will not necessarily reflect limitations that crews/districts face in dealing with actual operational logistics.

\section{Inspection Report}

Some weeks ago your staff was contacted to determine if and where $\cdots$. would be conducting hot pour crack sealing. We were advised that the Subdistrict would be performing this operation on SR 267 south of Brownsburg. On October 29, 1996 Gordon Hooker and I visited the crew to evaluate their operations. At the time of the visit the crew was sealing concrete pavement close to I-70 using the Melter and Crafco RoadSaver 201 which is an ASTM D-1190 sealant. Generally, D3405, which is a slightly higher grade sealant that costs about the same, will last longer (if applied properly). The cleaning operations ahead of the sealing were being accomplished with an air compressor having the recommended delivery pressure of $100 \mathrm{psi}$.

Overall, most of the crew members indicated they were relatively new to the hot pour sealing operation. The setup was as expected for a short stretch of road adjoining a bridge and ramp area. The concrete pavement was in fair condition, but had significant deep spauling along the joints. Some of the concrete chunks being removed were larger than a baseball (see video tape enclosed - yours to keep). More than half of the joints were in excess of one inch wide. Given the size of cracks and volume of the spauled areas it may have been more cost effective to fill these areas with a hot asphalt "sand mix". Some DOTs use a 3/4 "maximum width criteria to designate between crack filling (HAC) and crack sealing (SHRP MANUAL indicates smaller width). I discussed with the crew chief (Darrell ) the possibility of sealing the large voids with a chip/sealant combination as RoadSaver costs about twenty cents a pound. He indicated they had tried this on some roads, but using chips impacts labor and equipment needs.

A possible down side to filling deep large voids with pure sealant is that during hot weather they may expand to create bumps and/or soften and be tracked on to the pavement. In general, research has shown the best application for the hot pour sealants is on pavements with fairly good 
integrity with well defined singular cracks of widths less than 3/4". Pavements with extensive and badly deteriorated cracks require large volumes of sealant, therefore, they are usually not good candidates for hot pour crack sealing. Additionally, pavements in this condition probably will not have their service life extended by surface treatments, such as crack sealing, because they likely need resurfacing or extensive rehabilitation.

In talking to the crew it appears that most of the roads they try to seal are not typified by the SR 267 section. I indicated we would try to make another visit to situation. when a crew is in a typical production

While at the job site the crew had to temporally shut down due to light rain. The crew chief was aware that moisture from any source (air compressor/cleaning operations or residuals from previous rains) will break the bond between the sealant and pavement. Moisture sensitivity is a price that must be paid to achieve a seal that lasts longer than the emulsions.

An important consideration that was discussed with the melter operator (Jack ) is using the manufactures recommended application temperature. When we checked the dial thermometers, the temperatures were 40 to 50 degrees below the manufactures recommendation. A check of these thermometers with our infrared heat gun verified the dial gauges were fairly accurate (these gauges can be faulty and should be independently checked). A check of the sealant temperature coming out of the wand indicated the sealant was about eighty degrees colder than it should have been. A recent research report indicates that keeping hot pour sealants close to the maximum safe heating temperature without over heating produces a significantly better bond. I asked the melter operator if they were having difficulty maintaining temperature and he indicated that while they have had troubles with the melter they could run the sealant hotter if necessary.

I would encourage all crews to at least run the sealant at the manufactures recommended minimum application temperature because the material will have improved flow characteristics, especially in colder weather and also have better bond (check the shipping containers as every manufacture's product has different temperature ranges). During the hot summer months the minimum temperature is probably more desirable to 
control tracking. Hot pour tracking problems can be economically controlled by using toilet paper as a blotter applied via a paint roller adapted with a long handle. The Illinois DOT mandates the use of the toilet paper blotter.

While at the site we questioned the melter operator and crew regarding the Berry equipment. Their replies lead me to believe that the problems that have been experienced with the melter are continuing (see attachment \#1). In retrospect I wish the purchasing effort that lead to buying the melters could be revisited. I think that purchasing the smaller proven units (Crafco or Aeroil) with lighter weigh hoses would have been a better option. I think operations would have been improved and the added cost would have been quickly offset by less down time and higher production. I have recommended to some districts that they try and rent other brand melters and let crews who have used the melter make a comparison. Assuming the comments and production would be more positive, the purchase of the Crafco or Aeroil (or similar units) could probably be supported.

When I asked the crew about routing I was told the router was in for repairs due to an engine failure. One individual indicated the failure of the router was probably due to a poor design that directs the dust from routing towards the carburetor intake. Evidently the rebuilding of the engine, or purchase of a new one, was to include a solution to this problem.

While we were observing the sealing operation the wand control valve broke in the closed position. Operations were shut down for about one hour until a new valve was purchased and installed by a mechanic. I was curious as to why the melter operator didn't keep a spare onboard and make the repairs. He indicated it only breaks a few times each season and is not really much of a problem. Fortunately the replacement valve is a common one available from most any hardware store. Last season we made arrangements to purchase and have. deliver a light weight replacement wand made of aluminum. It appeared. $\quad: \quad \therefore \quad$ unit had a steel wand, therefore, you may want to consider switching to aluminum as they are significantly lighter.

In talking to Jack srruse we determined that the melter's heat exchange oil had been recently changed. The : ${ }^{\prime}$ Corporation has stressed 
the importance of this because it impacts tank integrity and the ability of the oil to transfer heat. Jack evidently travels with the melter and for this reason seemed fairly knowledgeable about all aspects of it's operation and maintenance.

\section{Other Comments}

If we make further inspections in the report you receive will be similar to attachment \#2. As this was the first one, I supplemented it with this memo.

I was hoping the Districts would have received the long awaited video "commissioned" by the Training Committee by now, but evidently they have not begun shooting any footage as of yet. My original recommendation to them was to use the tapes we obtained from other DOTs (for training in the short run) or make informal functional level videos. My own personal experience in producing "polished" training videos is that they are very time consuming and resource intensive, therefore, they frequently lag behind the need and when produced are already out of date.

Approximately one year ago we polled the subdistricts regarding their hot pour crack sealing operations. The results of that questionnaire will be mailed out in the near future. Overall, I was surprised at the range of responses.

If we can be of further assistance please do not hesitate to contact me.

$\mathrm{DRW} / \mathrm{drw}$

DOC ID: CRSLFDIN.1

cc: Rick Smutzer, Marvin Motuliak (Study Advisory Committee Members) - memo only

Attachments 
July 25, 1994

To: District Maintenance and Operations Engineers, Subdistrict Managers

Thru: Barry Partridge, Chief, Division of Research

From: David Ward, Section Engineer, Division of Research

Subject: Project Status : "Crack Sealing Using New Materials and

Equipment," HPR-2076 - Equipment / Materials and Field Performance

The purpose of this memorandum is to update the status of HPR Research Project 2076 "Crack Sealing Using New Materials and Equipment" .

The project's field operations were to start last fall. This was to begin with visits to observe subdistrict maintenance crews using new melters and sealants. Unfortunately, most melters were delivered late in the year and the districts had difficulty bringing them on line. Therefore, in lieu of fall visits, various training materials (videos/manuals) were made available to the districts during the winter months to help prepare crews who would use new equipment and sealants.

This Spring most districts were able to bring new sealing operations on line. Research's personnel have been able to visit some subdistrict locations to inspect sealing operations. As of the present time, about five crews who were using the . melter and router have been observed. Information to improve their operations has been passed on and special problems have been addressed. Some of the suggestions have differed from district directives. However, some difference of opinion was expected as each district has their own approach in introducing new operations. Moreover, there is still debate among experts regarding sealing procedures, equipment and materials.

Listed below is a summary of information which has been complied during the subdistricts visits. These findings are being distributed to help districts improve their operations.

WHAT AND WHEN TO CRACKSEAL

-Guidelines for the selection of roads for cracksealing need to be improved. Review the SHRP manual for directions.

-Upper and lower temperature limits need to be established for 
cracksealing applications. In this case, pavement temperature may be more important than ambient temperature. If the pavement temperature is too high, the material may track before it has a chance to bond. If this is a problem, toilet paper may be used for a blotter.

MELTER

-Most subdistricts have $\quad \cdots$ Corporation melters. These melters came with a short training video. Unfortunately, most melter operators have not viewed this tape. It addresses some problems the subdistricts are having. If a copy of the tape is not available, Research will provide it promptly (call Mr. Gordon Hooker, 317-463-1521). All operators should view the tape. A maintenance manual came with the melter. However, many operators are not reading or reviewing it. For successful use of the new sealants, proper use of the melter is important.

-The Melter has had some reoccurring problems, which the company seems willing to solve. However, it is the subdistrict's responsibility to voice complaints to the corporation (especially while the melters are covered by the warrantee). Berry's phone number is (800)-477-1951. Research would like to be informed of these problems and the action taken by the Berry Corporation. A fax to Gordon Hooker at 317-497-0017 would be appreciated.

* The most frequent and troublesome problem is the fluctuation of the material flow valve. The pump controlled by this valve should operate nearly all the time, but it keeps changing speed and stopping. A solution cannot be offered at this time, but a request has been made to Berry to solve this problem. Because of this frequent valve adjustment, the flow to the wand fluctuates. This in turn makes it difficult for the wand operator to deliver the proper, consistent amount of sealant.

* The burner control unit on the side of the boiler gets hot causing the electronics to melt. Some subdistricts have cut additional ventilation holes to help cool the electronics. One subdistrict called and arranged to have the melter fixed by a local heating and air conditioning company at no cost to INDOT. During this repair a heat shield was installed to protect the electronics from the radiant heat of the flames. Berry is working on a redesign to solve this problem.

* The wand valve breaks. The solution appears to be a replacement using a high quality ball valve that is more durable. Berry should be asked to cover this expense.

* The wand is heavy and bulky. A harness can be used to hold most of the weight of the wand. However, one operator said that this makes it difficult to escape if a vehicle enters the traffic control area. Most subdistricts rotate other brand melters can be purchased which have lighter wands 
(without the heating oil tubes), but subdistricts will need to voice their concerns before INDOT prepares a requisition for additional melters.

* The protective covering on the wands wears out quickly. This could become a maintenance headache. Once this covering is worn away, hoses having hot oil at temperatures above 400 degrees fahrenheit are exposed. This could result in a direct burn or the heating hoses could become worn and spray hot oil. Subdistricts should keep spare hose coverings in stock or seek ways to spot repair the hoses with heat resistant material. Research is working on the second alternative.

* Wand tip becomes clogged. Most subdistricts use a heat lance or a propane torch to unclog the tip. Some crews have tried dipping the wand tip into the tank, but the bulky hose makes this difficult and somewhat dangerous.

* The operator cannot see into the melter to determine sealant level because of "smoke". A dipstick can be used to determine the level, but the agitator needs to be turned off.

* The temperature gauges are faulty. This is definitely a concern as proper sealant temperature is important. Research is providing armored thermometers for each subdistrict to keep with their melters. Frequent checks on the gauge thermometers are absolutely necessary. There are convenient hand held

to infrared thermometers which can be pointed at an object around check temperature. However, the current price is obtaining less expensive models. Restigating the possibility of determine the temperature of pavements, sealants, double boiler oil, hot engines, asphalt mixes etc.

Note: The melter manual specifically warns that hot transfer oil must not exceed 480 degrees fahrenheit or the teflon hoses will be damaged.

* Uneven distribution of flame causes hot spots to appear on exterior of double boiler. This may cause burn or corrosion problems. This is unresolved at this time.

* The electric heater is too small to be effective. Berry Corporation is considering installing a larger electric heater so sealant material would be closer to operating temperature in the morning.

* Hot oil boil over is evidenced by black streaks down side of tank. This is currently unresolved.

* There is excessive leakage of the material supply pump as evidenced by sealant accumulating in the bottom of the side panel. This indicates the seal packing nut is not sufficiently tightened or needs to be replaced. 
ROUTER

-Two routers are available on loan from the Division of Research. These were purchased so that an evaluation of their effectiveness could be made. Districts are encouraged to take advantage of this provided they keep track of use and maintenance. Please contact Gordon Hooker to make arrangements for borrowing the routers.

-All the routers purchased thus far are made by crafco. The routers come with an operational manual that covers basic procedure and maintenance. Crafco states: "No operator should be allowed to operate the router without training and reading the manual." subdistrict personnel seem to have made a good effort to train operators initially in the proper use of and hazards involved with the router. Several subs provided training in a controlled environment. This allowed operators to become more comfortable with the router before they ran it in field conditions. For the individuals who do not attend sessions like these, the supervisor should take time to go through the manual and explain basic safety and correct operating procedure before field implementation.

-Routers can "surprise" inexperienced operators by suddenly shoving the person out of control. For this reason new operators should begin their field work on roads free of deep ditches or obstacles close to the road (e.g. guard rail). Also, an experienced operator should accompany new operators until they can safely control the router. Some subdistricts have elected to forgo routing in areas where guardrail or ditches pose a hazard.

-OSHA has requested INDOT equip routers with a more passive shut off switch. Crafco has developed a prototype safety device at INDOT's request and will soon make it available.

-While observing the routing, it was noticed that some operators had the cutting level set excessively deep which made the router difficult to control. Some others were lowering the router abruptly when starting the cut. This will cause irregular wear and shorten cutter life significantly. The depth setting should produce a rout that is approximately $1 / 2$ inches deep and $1 / 2$ to $3 / 4$ inches wide. The depth and width of the rout depend upon sealant manufacturer recommendations, existing road conditions and severity of winter. In general, the rout should never be deeper than it is wide. A deep narrow rout causes higher stress at the sealant/crack interface and increases failures. The ideal shape for a rout produces a seal resembling thick tape. To change rout width, the washer spacing on the cutter pins should be adjusted. However, when the cutters are spread out, they wear faster. If rout width is doubled and the depth remains the same, cutters wear about twice as fast. Some areas of Canada feel they can justify the cost of a rout four times wider than it is deep. on roads which will experience frequent snow plowing, a routed seal will usually perform better than an overband. 
-One subdistrict with the Division of Research has mounted a flashing light on their routers for added visibility/safety. The magnetic flashers (normally for temporary use on vehicles) can be mounted easily on the router with simple wiring.

-One subdistrict purchased an inexpensive electric hoist (\$100) and welded it to the melter frame. They now transport the router on the melter and load and unload via the electric hoist. This convenient arrangement eliminates separate transport and reduces the physical effort of loading and unloading. We would suggest the hoist be adequately sized, securely mounted and checked periodically for cable wear/safety. The router needs to be secured to the melter frame during transport. The weight of the router (500 lb) when added to the allowable gross axle weight "appears" to be acceptable.

HOT LANCE

-Despite what the SHRP manual states, the neat lance probably will not dry crack faces. If the pavement is cold (40F), the lance may warm it up. This would enhance material bonding. However, bond strength would be compromised on scorched pavement.

\section{AIR COMPRESSOR}

-Compressed air seems to work very well in cleaning cracks. According to the SHRP manual, water/oil traps may need to be installed on the compressors. These impurities can inhibit surface bonding. The traps would need to be serviced regularly. If more information is needed on this, contact Gordon Hooker (317-4631521).

SQUEEGEE

-Presently three different squeegees are being tried. The first that LSC provides is a straight squeegee. Units often modify them by bending the sides forward. Some have three sides, while others have been bent into a "V". It has been found that the latter works best.

-The second kind of squeegee that LSC provides is a "U" shaped squeegee. With a little brute force, the "U" can be hammered into a "V" shape. A problem encountered with this model was that the angle the handle made with the ground was too high. This angle can be modified by lying the squeegee face down and stepping on the neck. Care should be taken when doing this to ensure that the welds do not break. This adjustment can be reversed by turning the squeegee over and repeating.

Several test sections on US 52 were recently evaluated. Almost 708 of the original sealant was in working condition after 51 months of service. It should also be noted that this area 


\section{marked the first time "better" sealants were applied in the state. Therefore, the crews were somewhat inexperienced on this application.}

One of the most important parts of this memorandum is for the district and subdistrict personnel to take advantage of information provided (manuals, videos, etc.). This is especially true when working with new projects and equipment. The SHRP manual "Asphalt Pavement Repair Manuals of Practice" (SHRP-H-348) contains the answers to many of the problems presently encountered.

CC: Mr. Marvin Motuliak, Operations Support

Mr. Michael Long, Operations Support

Mr. Bill Rinard, Operations Support

Mr. Rich Smutzer, Materials and Testing

Mr. Larry Goode, Operations Support

Mr. Dennis Belter, Operations Support

Mr. Don Lucas, Chief Engineer

Mr. Dave Pluckebaum, Deputy Chief Engineer

File No. R-92-8 


\title{
ATHACELEMT
}

\begin{abstract}
As You are avere the Departmant has begun ilmited implenentation of various not pour how D-3405 "type" sealants. These ocalants are placed vaing double bollar molters which highor). Because thealants to high temparatures (300 degrees $F$ or curtent as materiale, beslants ar bignificantly affierent Irom accoxdingly. the

whe vill intormation detalled below hould be pased along to those cadants. conduct crack sealing oparations with D-340s "eypen
\end{abstract}

IsDOF, (as do noet other DOro), prepared sealant bid opeciffeations which are lairly genacic and bucod andery on the asIM D-3405 test. Thit moans enveral vendors have been

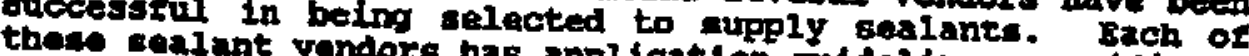
their 0-3405 pondore has applioation guldel ines opecifte to difterent. product. These guidolinos can bo ignifleantly difterences they caling crewe are not ade aware of these

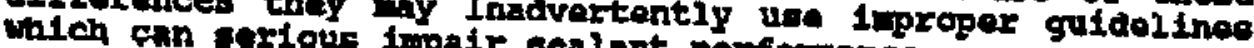
com sertous impair soalant performance.

involve tomparatur. speciflcation with sene vendors can meet the D-3405 mix of sealante. Beveral of their products and can rupply a apolication ter. kah of these cen have a different

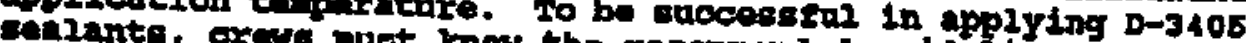
weolelc cealant they are uhe reoonnonded ouldelines for the diffor by lont thy are uning. Applioation terpartitures can coalant.

The elret rtop in merenting inproper apglcation is to Jnow the ese is to guldelines on hand. being upad and have ft's speoffio

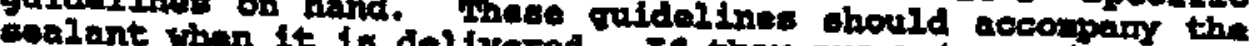
wanuent when it is dellverad. If thay axe not propided, the if not a should be contaoted and a copy abtained. If this is not a tinely alternative, the Divicion of posoaroh iny be Hooker). For the three types of ceazante IkDOr currently has on 
hand the recomended appliontion temporature ranges aro:

- Crafco Road Saver 201 380-410 aggrees $y$

- Crafco Asphalt Rubber Plas 380-\$10 degres.F

- Studabajear 325-350 degraes :

Some gemeric guidelines that shoula be considored in

raxing applicatione with hot porr mealants are:

* Do not apply sealants unless the pavemont and crack are thoroughly dry and have been in thts condition for at least 24 hours. Rosidual moicture will provent propor bond and cause the sealent to bubble up or come off the pavenont in a shoot

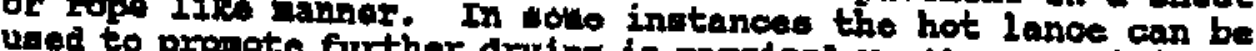
ued to promote further dxying in anginal veathor conditions. operated imodiate be offective only whon the hot lance is hot lance wiliately in tront of the caling oparacton. rho hot lance will not vork as an effective pavorent drying device or very high of continued wet wather. During vet periods

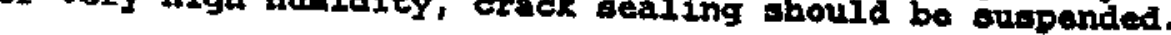

- Pavement tempexature shoula bo near to 40 degrees $F$. Some axceptions to this can be made whon the weather has been very dry and tho coalant can be heated to the upper range of the proper application temperature. The hot lance range of the be uand in thie instange to tacilitate proper boud by operating It 1mediately ahead of wealing operstans. Bowever, care wust be taken not to scoroh the exphalt as this prevents the calant from bonding to the pavement. Plecting D-3405 type probably won pavonent tomperatures are in the twenties wil probably result in signiflcunt fallures. If the westhor fs moderate temperature molter was doslgned to opernte in more to hoat the reratrie rangen, it may not have the btu capacity ouply enough bont to the proper temperature. Evap if it can be oxcosfive heat, the tire to reach proper remparature may For these, or tual conoumption way inorease signiflcently. opexatlons during axtrems Dors chooce to mapand cealing creather conditions.

- The tomperaturo gauges on Mall wlters can be in error. There has alreedy been an instance whers the gauge on a nas. palter vas off by 75 degreos $P$. The gauges need to be checked on a regulur busls to make aure they aro working. In gonoral, district meterials and teet locations should be able to provide a thexmometex to indopendently chook bealant tecuperatures to verisy gauge operation. These checks mut be 300 degrees in a safe munar as nort walants wi2l reach purchases inc or higher. It is recomended that nolter purchases include appropriate thermometers to encok gauge durina cract solis do requiro maintaining a temperature 109

- D-3405 soulante are regulred to pase laborutory bonding and elongation tests at reduoed touperatures. IyDot is equipped 
to conduot thow togte at c.o. Materinal and Toste. wealante, it in tor bldders are roquired to mupply D-3405 appooplite cortifieation ended the districte requent the independent teate to verify the mausectura. Addittonally, ade by taking occialonify the sealents quality whould bo

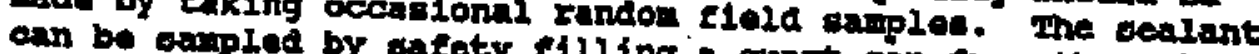
rand after the sacety flling a quart can frow the nelter application the raalant has been agitated at the proper andysis to c.o. In 530 form.

- Don't atx D-3405 mealents tron difternent vandors, as the base componants can be quite alferate. Ithe rodulting wix till likely not vock. In some cuese the renulting nixtiris nay pondors D-3405 the molter wand. Whan ohanging to another level bafore adding, run the melter to the lownt poxilble diesinilar soalante. new sealant. This reduces mixing of

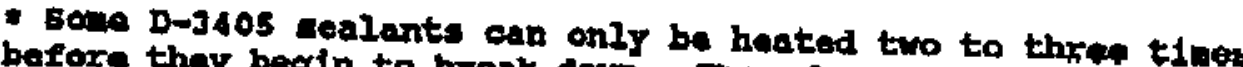
before thay begin to break down. Therefore, avoid loading us necessary to use wiert over anteriel.

In genaral, paveronts with vory wide ornolk $(+3 / 4)$ chould not be oodied with b-340s seelants. The reason is aluply ond

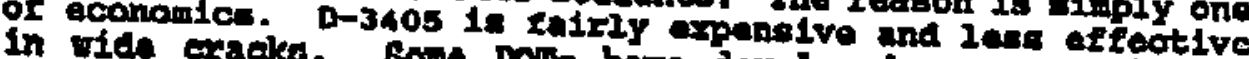
in vide cracks, some Dots heve developed a crack Ellilug a very tine ourface wide cracke, Instend of uning wallants, 3405 may not be aftectiv is used to 1112 the cracks. Nlso, D-

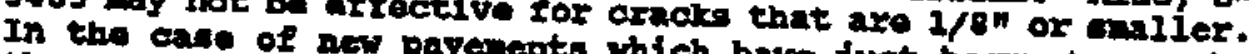
the une of a routor toents wich have fust begun to crack, varmanted. For porter to create a sealant resorvolx may be pattarn (alligatoring ots that have an extaraive cracking probably not cont offective. the use of D-3405 scalant lo

- It pavements are Ilkaly to be resurfucad within a tow yeare aftar crack caling with 2 D-3405 cenlant, the wowt of ninitul squecgeed orar the aurface should be kept to hoat of the renureato D-3405 cealante vill renelt under the rollex the ruureacing producing a sllda plane aftect as the undeolrable of over the crack. rule can reoult in an of two laye wteh a toen thic. If the resurfacing is composed the effective is probubly nogligibie

pi To bo affictent in applying D-340s sealante wone DoTs piocylack aguipimt on a lingle mat bed truek onen poosible, welter. equipaent in this not bo ble to initially conligure encourragad to aheck with adjoinlng Dore conoornting equipment 
Appendix I 


\section{Out-of-State Crack Sealing Survey}

Survey Conducted Dec. 15, 1997 to Jan. 30, 1998

\section{Questions:}

1. Do you seal all roads?
A. Illinois
B. lowa
No
C. Kentucky
No
D. Michigan
No
E. Minnesota
No
F. New Jersey
No
G. New York
Yes
H. Ohio
Yes
I. Pennsylvania
No
Yes

1A. Why not?
A. Illinois
B. lowa
C. Kentucky
D. Michigan
E. Minnesota
F. New Jersey
G. New York
H. Ohio
I. Pennsylvania

Present procedure doesn't call for it.

Left up to districts.

Lack of employees.

Only new roads.

Up to districts (different districts have different ideas about if and when sealing should be done).

Crack sealing is controlled by counties and is up to them.

1B. Frequency
A. Illinois
B. lowa
C. Kentucky
D. Michigan
E. Minnesota
Seal it $2-4$ yrs. After construction.
F. New Jersey
G. New York
Transverse at $8 \mathrm{yrs}$. and longitudinal at $16 \mathrm{yrs}$.
H. Ohio
I. Pennsylvania Every 5-7 yrs.

2. Do you use hot pour crack sealant?
A. Illinois
B. lowa
C. Kentucky
D. Michigan
E. Minnesota
F. New Jersey
G. New York

Use D-3405

Craftco 231 Roadsaver

Not sure.

Use D-3405

Use D-1190, D-3405 (with slight modification), and D-3720.

Use D-3405

Use D-3405 (only on hot asphalt mix pavements). 
H. Ohio

I. Pennsylvania
Use D-3405

Mostly pre-packaged asphalt and rubber. Some D-1190 and D-3405.

3. How do you decide when and where to seal?
A. Illinois
New concrete specified on plans. Rehab is judgement of maintenance
B. lowa
C. Kentucky operations.
D. Michigan
Visual inspection.
E. Minnesota
F. New Jersey
Only in conjunction with concrete repairs or rehab.
New roads, tight cracking, and no secondary cracking.
G. New York Up to districts (usually within first few years of overlay).
H. Ohio $33 \%$ of inventory each year.
Complex explanation (so he did not go into it).
Counties decide.
I. Pennsylvania
When the open crack is between $3 / 8$ " and 1" wide.

4. Percent of roads sealed with hot pour?
A. Illinois
$100 \%$
B. lowa
$35 \%-40 \%$
C. Kentucky
D. Michigan
$1 \%$
E. Minnesota
$50 \%$
F. New Jersey
$100 \%$
G. New York
$40 \%-45 \%$
H. Ohio
?
I. Pennsylvania
$>90 \%$
$100 \%$

5. How much of hot pour is under contract?
A. Illinois
$>50 \%$
B. lowa
$95 \%$
C. Kentucky
$100 \%$
D. Michigan
$100 \%$
E. Minnesota
$99 \%$
F. New Jersey
$50 \%$
G. New York
?
H. Ohio
$30 \%-40 \%$
I. Pennsylvania
$1 \%-2 \%$

6. What brand melter is used?
A. Illinois
B. lowa
Craftco 200 gal. diesel
C. Kentucky
D. Michigan
E. Minnesota
F. New Jersey
Low bid.
G. New York
H. Ohio
We do not specify a brand.
Contractor decides.
No preference.
Craftco preferred, but we don't specify.
Don't know.
I. Pennsylvania
Crack Pro $200 \& 400$ preferred, but use Craftco E2. 
6A. Why do you use/buy the above (\#6) melter?
A. Illinois
B. lowa
C. Kentucky
D. Michigan
E. Minnesota
F. New Jersey
G. New York
H. Ohio
I. Pennsylvania Low bid.

7. What melters you do not like or buy?
A. Illinois
None
B. lowa
None
C. Kentucky
D. Michigan
None
E. Minnesota
Contractor decides.
F. New Jersey
Low bid.
G. New York
None
H. Ohio
Don't know.
I. Pennsylvania All melters must pass stringent field testing. This eliminates marginal equipment.

7A. Why do you not use/buy the above (\#7) melter?
A. Illinois
B. lowa
C. Kentucky
D. Michigan
E. Minnesota
F. New Jersey
G. New York
H. Ohio
I. Pennsylvania

8. Cost per lineal foot to hot pour crack seal?
A. Illinois
B. lowa
C. Kentucky
D. Michigan
E. Minnesota
Bid by road bed kilometer. Under 2 yr. warranty.
F. New Jersey
G. New York
With routing (.40 per lineal ft.) without routing ( $\$ 4.70$ gal.)
H. Ohio
I. Pennsylvania
$\$ 1.00-\$ 1.25$ per lb. $(1 / 3 \mathrm{lb}$. per ft.)

8A. Cost for in-house crews?
A. Illinois
$\$ 19.00$ per mile
B. lowa
C. Kentucky
D. Michigan
Contracted 

E. Minnesota
F. New Jersey
G. New York
H. Ohio
Don't know.
I. Pennsylvania
$\$ 6.50$ per gal.

8B. Cost for contract work?
A. Illinois
Don't know.
B. lowa
AC (.63 - .75 per lineal foot)
C. Kentucky
$\$ 3.00$ per lineal foot
D. Michigan
$\$ 5,700$ per lane kilometer
E. Minnesota
.34 or .35 per lineal foot
F. New Jersey
.65 per lineal foot
G. New York
H. Ohio
I. Pennsylvania
$\$ 1.00-\$ 1.25$ per lb. (1/3 lb. per foot)
$\$ 5.50-\$ 6.00$ per gal.

9. Average size of crew.
A. Illinois
5
B. lowa
$5-6$
C. Kentucky
Don't know.
D. Michigan
N/A (Contracted out)
E. Minnesota
Contractor decides.
F. New Jersey
6
G. New York
without routing $(3-4)$
H. Ohio
$6-7$
I. Pennsylvania
7 which includes flagmen

10. Average production in lane miles per day.
A. Illinois
Don't know.
B. lowa
2.5 miles
C. Kentucky
Don't know.
D. Michigan
6,000 lineal ft. per day
E. Minnesota
Do not know.
F. New Jersey
1 lane mile per day
G. New York
H. Ohio
Don't know.
I. Pennsylvania
175 gal. per day

11. Do you always route?
A. Illinois
B. lowa
C. Kentucky
D. Michigan
E. Minnesota
F. New Jersey
G. New York
H. Ohio
I. Pennsylvania

No. Policy calls for them to route but they do not always do so.

Yes

Yes

Leave it up to the contractor since it is under warranty.

No. Only route on new roads in better condition.

No. Try to clean them out first.

No.

No. In-house work doesn't but contract work does some.

We do not route at this time. 
Appendix J 
Projected Cracks Per Lane Mile

A key element of the INDOT pavement management system is the assessment of condition by observing surface indicators. A rating system has been developed to categorize, prioritize and assign weights to this information. Subsequently this is used to rank various road sections to determine probable causes for loss of serviceability and recommend remediation in terms of cost effectiveness. The data bases developed to support these efforts can and are used for other functions. The basic types of pavements categorized in the databases include; (1) asphalt surfaces, (2)-jointed concrete and (3) continuously reinforced concrete. The type of distresses for each pavement varies and each is rated for severity and extent. For the purpose of this analysis only asphalt surfaces (full depth, or built-up layers, or composite-asphalt over a rigid pavement) in two geographical locations were considered (Crawfordsville district west central IN and Seymour district, south eastern IN).

A 500-foot section of road is the sample size assigned to represent one mile of pavement. Sections are chosen by using standard reference posts as the beginning point and then "marking off" 500 feet in the direction of traffic. On two lane roads only the northerly or easterly direction is rated, on four or more lane roads both directions are rated. Although the distresses for asphalt include a number of distresses, such as raveling, only transverse and/or block cracks were of interest for this analysis. The distresses are rated for severity on a scale of 0 to 3 ( 0 is good, 3 is bad.) The cracks of interest were those that maintenance forces would likely seal. The Roadway Management Division recommended that cracks with a rating of 1-3 were appropriate choices and that each crack be considered full width for the purpose of using the data to project the number of cracks for an "average mile." 
Disclaimer-Even though the latest and most extensive data available was used the following should be considered:

1. The age of the pavement was not taken into account. Older pavement becomes brittle and will have more hairline cracks that skew the data and are not likely to be routed and sealed.

2. The date the data was taken can skew the results. Some of the roads with the highest number of cracks may have been rehabilitated since this data was taken.

3. Person(s) who processed the videotaped 500 sections may have different inspection criteria or eye sight capability.

4. Quality of the videotapes may vary, due to wet pavement and/or other weather conditions.

5.

\begin{tabular}{|c|c|c|c|c|c|c|c|}
\hline $\begin{array}{l}\text { Cvi. } \\
\text { District } \\
\text { Route }\end{array}$ & $\begin{array}{c}\text { No. of } \\
500^{\prime} \\
\text { Sections }\end{array}$ & $\begin{array}{l}\text { Total no. } \\
\text { of cracks }\end{array}$ & $\begin{array}{c}\text { Projected no. } \\
\text { of cracks per } \\
\text { mile }\end{array}$ & $\begin{array}{l}\text { Cvi. } \\
\text { District } \\
\text { Route }\end{array}$ & $\begin{array}{l}\text { No. of } 500^{\prime} \\
\text { Sections }\end{array}$ & $\begin{array}{l}\text { Total no. } \\
\text { of cracks }\end{array}$ & $\begin{array}{c}\text { Projected no. } \\
\text { of cracks per } \\
\text { mile }\end{array}$ \\
\hline 165 & 108 & 2161 & 211 & SR157 & 13 & 216 & 176 \\
\hline 170 & 112 & 898 & 85 & SR159 & 17 & 554 & 344 \\
\hline 174 & 107 & 3172 & 313 & SR234 & 39 & 673 & 182 \\
\hline SR 18 & 32 & 1205 & 398 & SR236 & 35 & 1048 & 316 \\
\hline SR 25 & 33 & 1092 & 349 & SR240 & 8 & 151 & 199 \\
\hline SR 26 & 64 & 718 & 119 & SR243 & 7 & 57 & 86 \\
\hline SR 28 & 44 & 1615 & 388 & SR246 & 29 & 415 & 151 \\
\hline SR 32 & 66 & 1142 & 183 & SR263 & 9 & 160 & 188 \\
\hline SR 38 & 28 & 500 & 189 & SR267 & 20 & 206 & 109 \\
\hline SR 39 & 44 & 663 & 159 & SR340 & 5 & 215 & 454 \\
\hline SR 42 & 57 & 857 & 159 & SR341 & 22 & 726 & 349 \\
\hline SR 43 & 11 & 241 & 231 & SR352 & 20 & 868 & 458 \\
\hline SR 46 & 35 & 708 & 214 & SR443 & 1 & 23 & 243 \\
\hline SR 47 & 57 & 1341 & 248 & SR526 & 1 & 13 & 137 \\
\hline SR 55 & 35 & 742 & 224 & US 36 & 54 & 1463 & 286 \\
\hline SR 59 & 36 & 575 & 169 & US 40 & 127 & 2031 & 169 \\
\hline SR 63 & 105 & 2621 & 264 & US 41 & 126 & 1619 & 136 \\
\hline SR 71 & 27 & 478 & 187 & US 52 & 99 & 1985 & 212 \\
\hline SR 75 & 45 & 1049 & 246 & US136 & 72 & 2620 & 384 \\
\hline SR126 & 1 & 31 & 327 & US150 & 13 & 303 & 246 \\
\hline SR142 & 9 & 208 & 244 & US231 & 98 & 3383 & 365 \\
\hline & & & & US421 & 42 & 980 & 246 \\
\hline & & & & $\begin{array}{c}\text { Total } \\
\text { Minimum } \\
\text { Maximum }\end{array}$ & 1913 & 41726 & $\begin{array}{c}85 \\
458\end{array}$ \\
\hline & & & & \multicolumn{3}{|c|}{ No. of cracks per mi. all roads = } & 230 \\
\hline
\end{tabular}




\begin{tabular}{|c|c|c|c|c|c|c|c|}
\hline $\begin{array}{c}\text { Seymour } \\
\text { District } \\
\text { Route }\end{array}$ & $\begin{array}{l}\text { No. of } \\
500^{\prime} \\
\text { Sections }\end{array}$ & $\begin{array}{l}\text { Total no. } \\
\text { of cracks }\end{array}$ & $\begin{array}{c}\text { Projected no. } \\
\text { of cracks per } \\
\text { mile }\end{array}$ & $\begin{array}{l}\text { Seymour } \\
\text { District } \\
\text { Route }\end{array}$ & $\begin{array}{c}\text { No. of } 500^{\prime} \\
\text { Sections }\end{array}$ & $\begin{array}{l}\text { Total no. } \\
\text { of cracks }\end{array}$ & $\begin{array}{l}\text { Projected no. } \\
\text { of cracks per } \\
\text { mile }\end{array}$ \\
\hline 164 & 16 & 48 & 32 & SR135 & 111 & 1307 & 124 \\
\hline 165 & 131 & 848 & 68 & SR144 & 3 & 5 & 18 \\
\hline 174 & 20 & 197 & 104 & SR156 & 11 & $20^{\circ}$ & 19 \\
\hline 1275 & 3 & 1 & 4 & SR203 & 11 & 114 & 109 \\
\hline SR 1 & 20 & 62 & 33 & SR211 & 2 & 2 & 11 \\
\hline $\mathrm{SR} 3$ & 60 & 681 & 120 & SR229 & 24 & 183 & 81 \\
\hline SR 7 & 40 & 926 & 245 & SR235 & 7 & 111 & 168 \\
\hline SR 9 & 9 & 47 & 55 & SR250 & 48 & 451 & 99 \\
\hline SR 11 & 56 & 415 & 78 & SR252 & 28 & 385 & 145 \\
\hline SR 37 & 23 & 330 & 152 & SR256 & 12 & 197 & 173 \\
\hline SR039 & 18 & 144 & 85 & SR258 & 1 & 1 & 11 \\
\hline SR 43 & 10 & 173 & 183 & SR262 & 3 & 2 & 7 \\
\hline SR 44 & 12 & 85 & 75 & SR311 & 8 & 123 & 162 \\
\hline SR 45 & 26 & 325 & 132 & SR335 & 10 & 19 & 20 \\
\hline SR 46 & 104 & 1308 & 133 & SR337 & 12 & 41 & 36 \\
\hline SR 48 & 22 & 145 & 70 & SR350 & 12 & 189 & 166 \\
\hline SR 56 & 77 & 833 & 114 & SR356 & 12 & 29 & 26 \\
\hline SR 58 & 30 & 272 & 96 & SR362 & 6 & 54 & 95 \\
\hline SR 60 & 11 & 187 & 180 & SR446 & 21 & 75 & 38 \\
\hline SR 62 & 104 & 823 & 84 & SR462 & 2 & 7 & 37 \\
\hline SR 64 & 13 & 323 & 262 & US 31 & 95 & 1578 & 175 \\
\hline SR 67 & 34 & 584 & 181 & US 50 & 90 & 1780 & 209 \\
\hline SR101 & 17 & 31 & 19 & US 52 & 31 & 912 & 311 \\
\hline SR111 & 18 & 87 & 51 & US150 & 21 & 687 & 346 \\
\hline SR129 & 37 & 563 & 161 & US231 & 15 & 158 & 111 \\
\hline & & & & US421 & 35 & 331 & 100 \\
\hline & & & & $\begin{array}{c}\text { Total } \\
\text { Minimum } \\
\text { Maximum }\end{array}$ & 1542 & 18199 & $\begin{array}{c}4 \\
346\end{array}$ \\
\hline & & & & \multicolumn{3}{|c|}{ No. of cracks per mi. all roads = } & 125 \\
\hline
\end{tabular}


Appendix K 


\section{HOT POUR CRACK SEALING CHECK LIST}

(to be kept on a clip board on the melter)

\section{Startup Procedures}

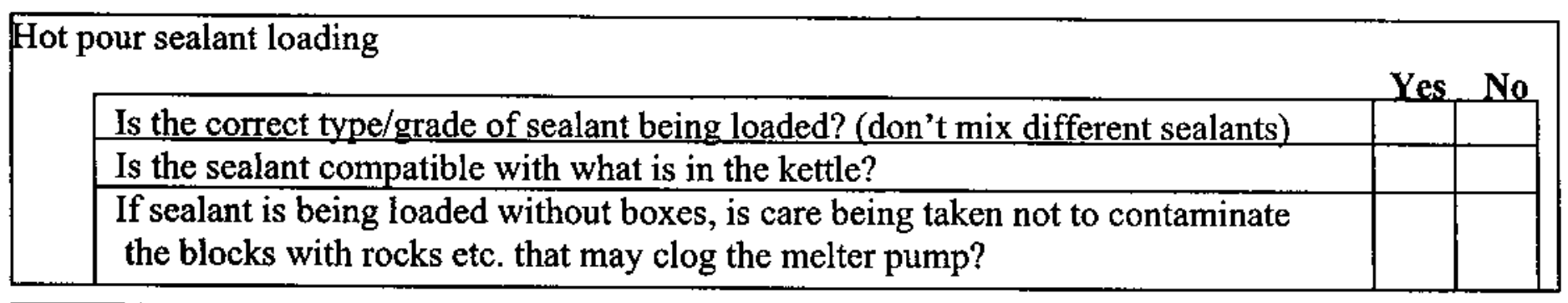

Pre-check of melter at unit garage

Are fluid levels OK?

Is the operators manual available for reference?

Has unit been fueled properly?

Are tires in good condition and at proper air pressure?

Are spare parts available (nozzles etc.) along with the necessary tools?

Has unit been preheated prior to job site arrival to reduce delays?

Are temperature gages working and been verified as accurate?

Is a handheld temperature gun available to check temperatures?

Is unit properly connected to the tow vehicle?

Is the transfer oil clean and been replaced per the manufacture's specifications?

Are sealant lines or fittings properly secured to prevent excessive sealant leakage?

Router

Are cutting blades and spindles OK?

Is air filter clean?

Are extra blades available for use? 


\section{Production Operations}

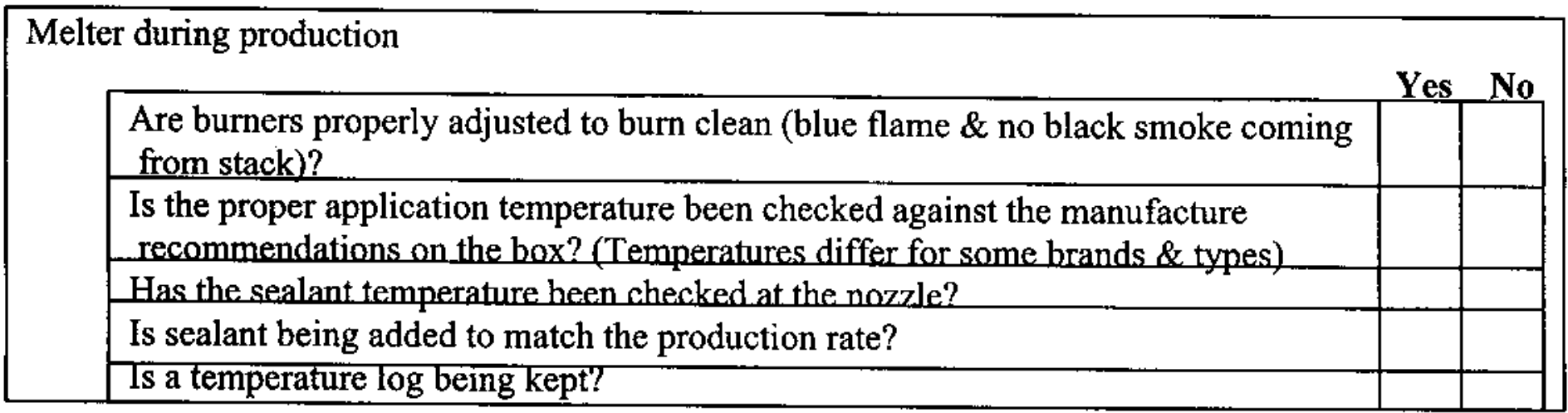

Production information

Is the lineal feet of crack sealed being recorded?

Is sealant use being monitored to reduce the volume of sealant left in the tank at the end of the day?

Is the depth/width of the rout being checked? (1/2 wide/deep-approximately)

Is the air compressor wand passing blow-by? (if yes, check or install traps)

\section{Shut Down}

\section{Melter Shut Down}

\begin{tabular}{|l|l|l|}
\hline Has sealant level been reduced to the lowest practical level? & & \\
\hline Has nozzle been removed and cleaned? & & \\
\hline Have sealant lines been evacuated? & & \\
\hline Do over-night heaters need to be used or melter stored indoors? & & \\
\hline
\end{tabular}

Signed By Date 